\title{
The Inhibition of Splicing of Glucose-6-phosphate Dehydrogenase mRNA During Starvation by Heterogeneous Nuclear Ribonucleoprotein K
}

Travis Cyphert

West Virginia University

Follow this and additional works at: https://researchrepository.wvu.edu/etd

\section{Recommended Citation}

Cyphert, Travis, "The Inhibition of Splicing of Glucose-6-phosphate Dehydrogenase mRNA During Starvation by Heterogeneous Nuclear Ribonucleoprotein K" (2013). Graduate Theses, Dissertations, and Problem Reports. 4959.

https://researchrepository.wvu.edu/etd/4959

This Dissertation is protected by copyright and/or related rights. It has been brought to you by the The Research Repository @ WVU with permission from the rights-holder(s). You are free to use this Dissertation in any way that is permitted by the copyright and related rights legislation that applies to your use. For other uses you must obtain permission from the rights-holder(s) directly, unless additional rights are indicated by a Creative Commons license in the record and/ or on the work itself. This Dissertation has been accepted for inclusion in WVU Graduate Theses, Dissertations, and Problem Reports collection by an authorized administrator of The Research Repository @ WVU.

For more information, please contact researchrepository@mail.wvu.edu. 


\title{
The Inhibition of Splicing of Glucose-6-phosphate Dehydrogenase mRNA During Starvation by Heterogeneous Nuclear Ribonucleoprotein $\mathbf{K}$
}

\author{
Travis Cyphert \\ Dissertation submitted to the \\ School of Medicine \\ at West Virginia University \\ in partial fulfillment of the requirements \\ for the degree of \\ Doctor of Philosophy \\ in \\ Biochemistry and Molecular Biology
}

Lisa Salati, Ph.D., Chair

Frank Hillgartner, Ph.D.

Alexey Ivanov, Ph.D.

Robert Brock, Ph.D.

Peter Mathers, Ph.D.

Department of Biochemistry

Morgantown, West Virginia 2013

Keywords: splicing, hnRNP, hnRNP K, glucose-6-phosphate dehydrogenase, alternative splicing, exonic splicing silencer, RNA immunoprecipitation 


\section{ABSTRACT \\ The Inhibition of Splicing of Glucose-6-phosphate Dehydrogenase mRNA During Starvation by Heterogeneous Nuclear Ribonucleoprotein K}

\section{Travis Cyphert}

Splicing of nascent RNA transcripts is an essential step in gene expression and a target of nutrient regulation. Glucose-6-phosphate dehydrogenase (G6PD) is a lipogenic gene whose expression is regulated exclusively at this posttranscriptional stage. Expression of G6PD mRNA increases 15- to 17-fold during refeeding and is inhibited $80-90 \%$ by starvation and the addition of polyunsaturated fat to the diet. The large changes in the accumulation of G6PD mRNA are due to changes the rate of pre-mRNA splicing and not changes in its transcription. In this regard, dietary carbohydrate enhances intron removal, which increases the accumulation of G6PD mRNA. Starvation alters pre-mRNA splicing by decreasing the rate of intron removal, leading to intron retention and a decrease in the accumulation of mature mRNA. A regulatory element within exon 12 of the G6PD pre-mRNA that contains both an ESS and an ESE mediates these changes in splicing efficiency. SR proteins, like SRp20, along with hnRNP K, L and A2/B1 bind to this regulatory region. Starvation caused an increase in the expression of heterogeneous nuclear ribonucleoprotein (hnRNP) K protein and this increase coincided with the increase in the binding of hnRNP $\mathrm{K}$ to the regulatory element and a decrease in the expression of G6PD mRNA in vivo. HnRNP K bound to two C-rich motifs forming an ESS within exon 12. Overexpression of hnRNP K decreased the splicing and expression of G6PD mRNA, while siRNA-mediated depletion of hnRNP K caused an increase in the splicing and expression of G6PD mRNA. HnRNP K binding to the Crich motifs blocked binding of serine-arginine rich, splicing factor 3 (SRSF3), a splicing enhancer. Thus hnRNP $\mathrm{K}$ is a nutrient regulated splicing factor responsible for the inhibition of the splicing of G6PD during starvation. 


\section{ACKNOWLEDGEMENTS}

I would like to thank the people who gave me encouragement and advice during my time in graduate school. I would like to thank my advisor Lisa Salati for giving me an opportunity to be a part of her laboratory and helping me develop into an independent scientist. I would like to thank Peter Stoilov, Ph.D for all his advice and help for developing my project. I would like to thank Alison Kohan and Callee Walsh for all their advice and support at the beginning of the Ph.D. process. I thank Amanda Suchanek for her scientific advice and discussion. Also, I would like to thank my committee for all their guidance and support that has made me a better scientist. Lastly, I couldn't have made it through graduate school without my wife Holly Cyphert. When times were tough, she was always there for me to help me and keep me positive. I could always talk to her about my problems or vent after a bad day. 


\section{Table of Contents}

\section{Chapter 1: Literature Review}

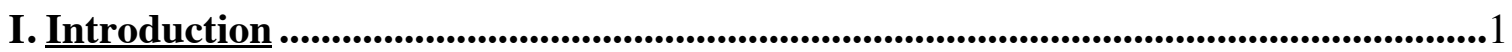

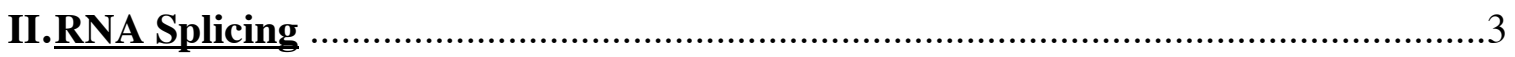

A. Types of Alternative Splicing ………………...............................................

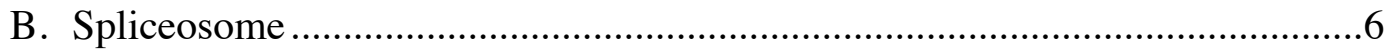

C. Cis-acting Elements Involved in RNA Splicing ....................................................9

D. SR Proteins ………………………………………………….................................11

E. Regulation of SR Proteins..................................................................................12

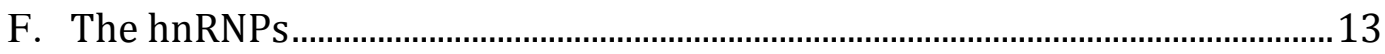

\section{HnRNP K}

A. Introduction and Protein Structure ................................................................16

B. Transcriptional Regulation by HnRNP K.........................................................18

C. Translational Regulation by HnRNP K ……………….................................20

D. RNA Splicing and HnRNP K ............................................................................21

\section{IV. $\underline{\text { HnRNP L }}$}

A. Introduction and Protein Structure ...................................................................23

B. Translation and HnRNP L .................................................................................2

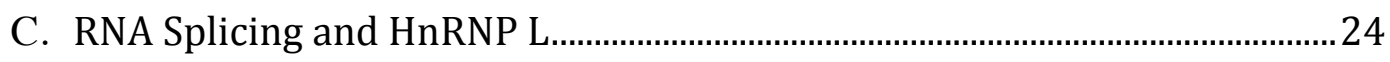

\section{V. $\underline{\text { HnRNP A2/B1 }}$}

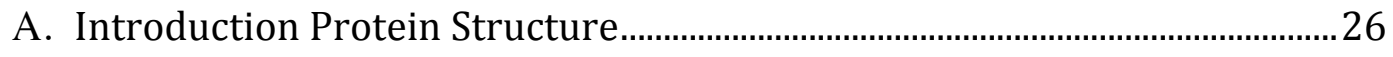

B. RNA Splicing and HnRNP A2/B1 ………………..........................................27

C. RNA Stability and HnRNP A2/B1 ...................................................................28

D. Regulation of Transcription and Translation by HnRNP A2/B1..................29 
VI. Glucose-6-Phosphate Dehydrogenase ............................................................. 30

VII. Hypothesis

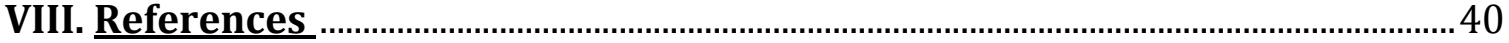

\section{Chapter 2: Paper Published in BBA-Gene Regulatory Mechanisms}

Starvation actively inhibits splicing of glucose-6-phosphate dehydrogenase mRNA via a bifunctional ESE/ESS element bound by hnRNP K 63

Appendix 108 


\section{List of Figures}

\section{Chapter 1}

Figure 1. Types of Alternative Splicing 5

Figure 2. The Assembly of the Spliceosome 8

Figure 3. The Structure of Some HnRNPs 15

Figure 4. Reactions Catalyzed by Fatty Acid Synthase 33

\section{Chapter 2}

Figure1. Starvation causes an increase in the amount of hnRNP K protein in mice $\begin{array}{ll}\text { livers. } & 102\end{array}$

Figure 2. Depletion of hnRNP K by siRNA causes an increase in the splicing of G6PD mRNA.

Figure 3. Ectopic expression of hnRNP K decreases the splicing of G6PD mRNA.

Figure 4. HnRNP K binds to exon 12 of the G6PD mRNA and in mouse liver; the binding is enhanced by starvation.

Figure 5. HnRNP K binds to C-rich sequences with in the regulatory element of G6PD mRNA.

Figure 6. Binding of hnRNP K and SRSF3 to the regulatory element is mutually exclusive.

\section{Appendix}

Figure1. Phosphorylation of hnRNP K is not altered by nutrient signals after 2 hours of treatment.

Figure 2. Depletion of hnRNP M by siRNA causes a slight but not significant decrease in the splicing of G6PD mRNA. 


\section{List of Abbreviations}

ACP

Clk/Sty

ESE

ESS

G6PD

HnRNP

ISE

ISS

LDLR

NADPH

NLS

PKC

RIP

RRM

RS Domain

SnRNP

SRPK
Acyl Carrier Protein

Cdc2-like kinase/serine/threonine/tyrosine

Exonic Splicing Enhancer

Exonic Splicing Scilencer

Glucose-6-phosphate Dehydrogenase

Heterogeneous nuclear ribonucleoprotein

Intronic Splicing Enhancer

Intronic Splicing Scilencer

Low Density Lipoprotein Receptor

Nicotinamide adenine dinucleotide

Nuclear Localization Signal

Protein Kinase C

RNA Immunoprecipitation

RNA Recognition Motif

Serine-arginine Rich Domain

Small nuclear ribonucleoprotein

SR Protein Kinase 


\section{Chapter 1}

\section{Introduction}

Carbohydrate and lipid metabolism encompass a complex network of pathways that maintain proper energy homeostasis. In regards to the consumption of carbohydrates, the process of lipogenesis is involved in converting excess glucose molecules into energy-storing molecules known as triacylglycerides. In response to nutrient and hormone signals, the expression of the enzymes involved in lipogenesis is highly regulated to allow for increases or decreases in lipogenesis. The lipogenic enzymes include malic enzyme, fatty acid synthase, ATP-citrate lysase, acetyl-CoA carboxylase and glucose-6-phosphate dehydrogenase (G6PD). The expression of these enzymes increases following the consumption of a high carbohydrate meal and decreases in response to starvation (1). Our laboratory is interested in how hormones like insulin and glucagon, as well as dietary nutrients, like fatty acids, regulate the expression of these enzymes. To approach the cellular mechanisms involved in nutrient regulation of gene expression, we have used G6PD as our model gene.

In order to study the effects of nutrients on the expression of G6PD, we use refeeding after a period of starvation and starvation alone as the dietary paradigms. Starvation causes a decrease in the G6PD activity and the expression of G6PD mRNA, while starvation that is followed by a period of refeeding results in a large increase in G6PD activity and expression of G6PD mRNA. Starvation followed by a 
period of refeeding causes a larger increase in G6PD activity and the expression of G6PD mRNA than animals fed ad libitum. This effect on G6PD activity by starvation followed by a period of refeeding is called enzyme overshoot $(2,3)$ and the large changes in the expression of G6PD mRNA explain the changes in G6PD activity (3-9).

Unlike the regulation of most lipogenic enzymes, which occurs through changes in the rate of transcription for their genes, our laboratory discovered that the change in the expression of G6PD is due to changes in the splicing of its mRNA $(3,10-13)$. Current research in our laboratory has focused on how the different dietary conditions cause changes in the splicing of G6PD mRNA. Starvation inhibits the expression of G6PD mRNA by causing a decrease in the splicing of the G6PD mRNA (3,10-13). In addition, the heterogeneous nuclear ribonucleoproteins (hnRNPs) that include hnRNP K, hnRNP L, and hnRNP A2/B1 may be necessary for the inhibition of the splicing of G6PD mRNA by starvation. In in vitro assays, these hnRNPs bind more to the G6PD mRNA during starvation then during refeeding (14). The nutrient signals during starvation may cause changes in the activity of these splicing factors that allows them to bind to the mRNA and inhibit splicing.

All mRNAs are spliced before they can be transcribed. Nutrient regulation of splicing is most likely not unique to G6PD. Reports indicate that greater than $90 \%$ of our genes are alternatively spliced $(15,16)$ and that the human genome contains around 23,000 genes but they encode for over 90,000 proteins $(17,18)$. The increase in protein diversity occurs at least partly due to the ability of alternative splicing to include or exclude various exons within a transcript, which changes the final 
message that is to be translated. Thus, understanding how nutrients control this step in gene expression is important for elucidating all aspects by which nutritional status can regulate cellular function.

In regards to the inhibition of the expression of G6PD mRNA by starvation, we hypothesize that splicing factors hnRNP K, hnRNP L, and/or hnRNP A2/B1 are necessary for the inhibition of the splicing of G6PD mRNA during starvation. One function of the hnRNPs is the inhibition of RNA splicing. The enhanced binding of these hnRNPs to the G6PD mRNA occurs concurrently with the decrease in the splicing and expression of G6PD mRNA.

\section{RNA Splicing}

The process of RNA splicing starts with the pre-mRNA that has been transcribed by RNA polymerase II and occurs exclusively in eukaryotic organisms. The pre-mRNA contains sequences that are either exons or introns. The exons are the coding sequences within the pre-mRNA and contain the information that is translated into an amino acid sequence for a protein. The introns are sequences within the pre-mRNA that are found between exons and do not contain the coding sequence used for translation. In order for the pre-mRNA to be made into the final mRNA that is translated into protein, the intervening introns must be removed during RNA splicing and the exons are spliced together. 


\section{A. Types of Alternative splicing}

A pre-mRNA that contains multiple exons has the potential to produce multiple mRNAs from one pre-mRNA. The exons that are always included in the final transcript are called constitutive exons. The splicing of certain exons that are not always included in the final transcript is typically regulated and are known as alternatively spliced exons. Depending on the removal or inclusion of an exon in the final transcript, the final mRNA can have an exon structure that varies greatly (Fig 1). Intron retention occurs when RNA splicing is inhibited and an intron remains in the final mRNA. The retention of an intron can lead to the production of a protein with altered function or the retention of an intron can lead to degradation of the RNA due to the introduction of a premature stop codon. The RNA that contains a premature stop codon is degraded via the nonsense-mediated decay pathway $(19,20)$. Nonsense-mediated decay surveys RNA for a premature stop codon to prevent the translation of these incorrect mRNAs into protein. The exonic inclusion/exclusion type of alternative splicing involves the inclusion or exclusion of a specific exon. The mutually exclusive type of alternative splicing also involves the inclusion or exclusion of certain exons in the final transcript; however, this type of alternative splicing occurs when the inclusion of one exon excludes another exon. The inclusion or exclusion of certain exons will ultimately alter the protein coding sequence. By including or excluding certain exons, the protein produced from that mRNA could differ greatly in protein structure and function. Certain alternatively spliced exons can code for whole domains of proteins. Lastly, the alternative 5' or 3' splice site selection will produce an exon of varying length depending on the site 
selection (21). The alternative 5' or 3' splice site selection will also alter the coding sequence and can produce a protein that differs in structure and function. The $5^{\prime}$ and 3' splice site will be covered in greater detail in the next section.

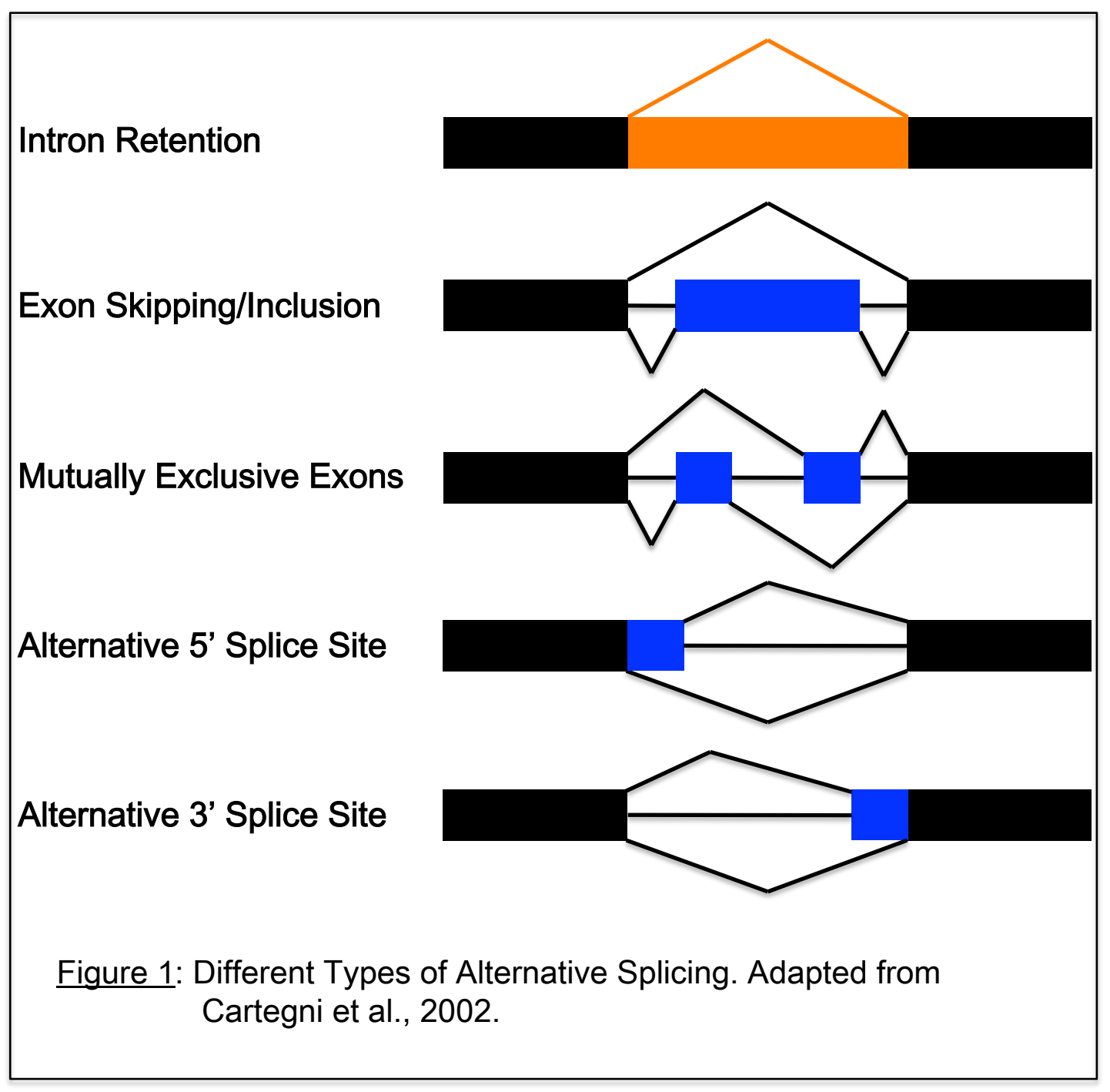




\section{B. The Spliceosome}

RNA splicing is mediated by a large macromolecular structure that is called the spliceosome. The spliceosome consists of small nuclear ribonucleoprotein complexes (snRNPs) and potentially over 300 other proteins that are involved in the splicing process (22). The main snRNPs are U1, U2, U4/U6, U5 and they consist of protein and RNA. The RNA part of the snRNP is a small nuclear RNA (snRNA) and it is responsible for recognizing specific sequences within the introns of pre-mRNA that are needed to define the exon/intron boundary. Also, the snRNPs contain proteins known as Sm and Lsm ring proteins that bind to the snRNA. The Sm and Lsm proteins are essential for proper spliceosome assembly and function. These proteins provide the protein-protein interactions that occur throughout the RNA splicing process. In addition to the snRNPs, RNA splicing involves proteins that enhance or inhibit splicing by binding to specific sequences found in the pre-mRNA. The proteins that enhance splicing are the serine-arginine rich (SR) proteins and the hnRNPs inhibit splicing. These proteins will be discussed in more detail in later sections. The proteins SF1 and U2 auxiliary factor (U2AF) are also necessary for proper spliceosome assembly. SF1 and U2AF are involved in the initial recognition of specific sequences within introns early in spliceosomal assemble. The sequences that SF1 and U2AF bind to will be discussed later. Other factors, like helicases and kinases, are necessary for progression of the different reactions of RNA splicing (23). Helicases are necessary for unwinding the RNA during RNA splicing and promoting the release of the final spliced mRNA from the spliceosome. The main helicases involved are Prp16, Sub2, Prp5, Prp28, Prp22, Brr2, Prp2, and Prp43 (24). 
Many of the other known proteins thought to be part of the spliceosome have not been extensively studied and their function is unknown.

The spliceosome is necessary for defining what sequences are exons and what sequences are introns. Exon definition is the process by which exonic sequences in the RNA are differentiated from the introns. Several sequences that participate in exon definition are the 5'-splice site GU, polypyrimidine tract (PY), branch point A, and the 3 '-splice site AG $(25,26)$. The U1 snRNP binds to the 5 'splice site, SF1 and U2 snRNP bind to the branch point, U2AF 65kDa subunit binds to the polypyrimidine tract, and the U2AF 35kDa subunit binds to the 3' splice site. The snRNPs bind to the intronic sequences in a stepwise fashion though the assembly of different complexes (Fig 2). The first complexes that form are called either the $\mathrm{E}$ complex or $\mathrm{H}$ complex. The $\mathrm{H}$ complex is not part of the canonical splicing pathway. The $\mathrm{H}$ complex is named after the hnRNPs, which can bind initially to the pre-mRNA. The hnRNPs can bind to sequences in the pre-mRNA and prevent the formation of $\mathrm{E}$ complex. The competition between these complexes is a target for regulation of RNA splicing $(23,27)$. For splicing to occur, E complex must form instead of $\mathrm{H}$ complex. The U1 snRNP binds to the 5' splice site and initiates the assembly of E complex. Also, $\mathrm{E}$ complex formation requires the binding of the $65 \mathrm{kDa}$ subunit of $\mathrm{U} 2 \mathrm{AF}$ to the polypyrimidine tract and the $35 \mathrm{kDa}$ subunit of U2AF to the 3' splice site. SF1 binding to the branch point completes the formation of the E complex. Next, A complex forms when U2 snRNP is recruited to the branchpoint and replaces the SF1 protein. The binding of $\mathrm{U} 2 \mathrm{snRNP}$ is facilitated by the $65 \mathrm{kDa}$ subunit of U2AF in an ATP-dependent manner. 


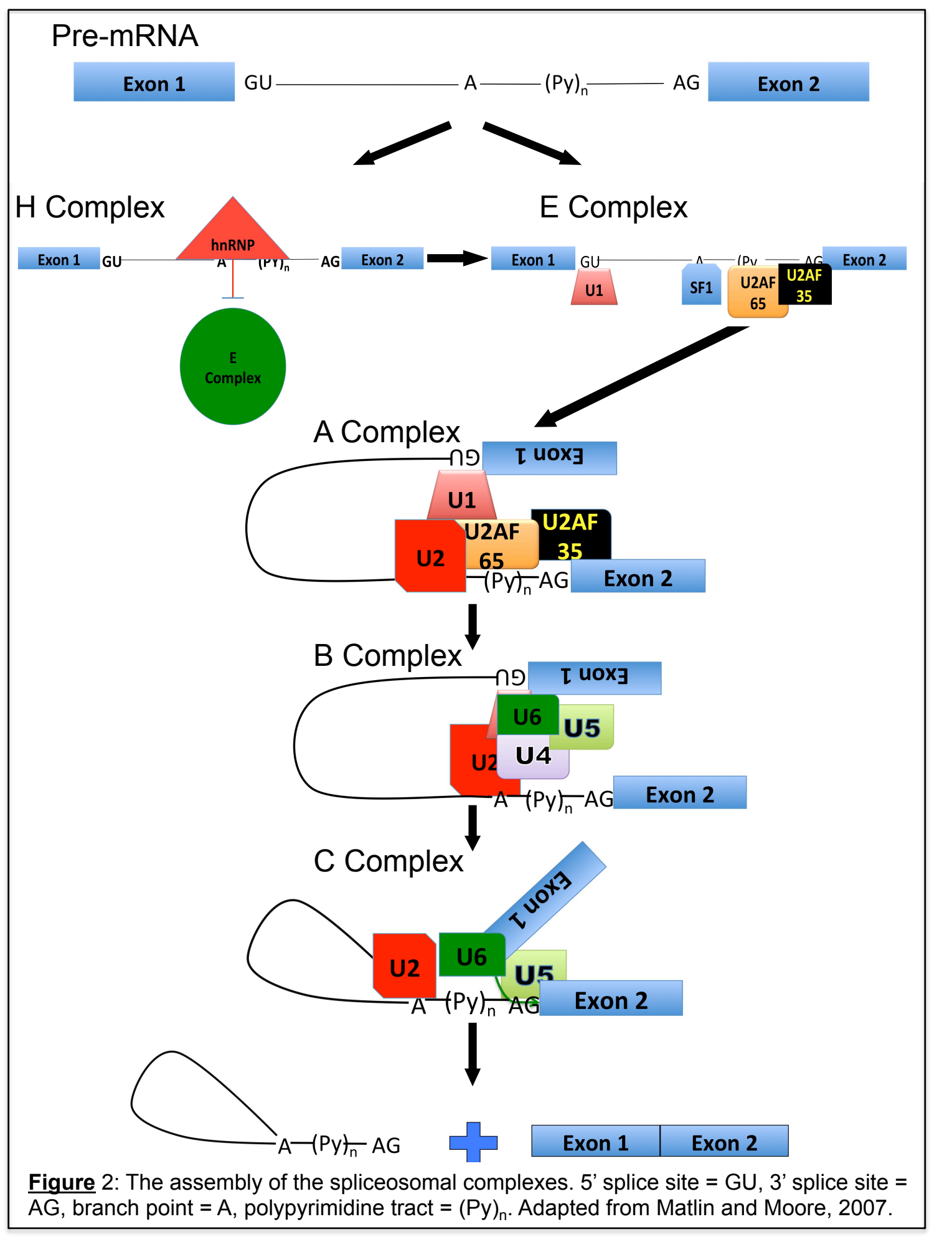

The B complex is the next complex to form when the snRNPs U4, U5, and U6 are added to the spliceosome complex. The U4/U5/U6 snRNPs form a tri-snRNP 
particle that forms stabile interactions with the rest of the spliceosomal components. The B complex undergoes significant rearrangement and during this rearrangement the U1 snRNP and the U4 snRNP are lost from the complex. The completion of the rearrangement of the $\mathrm{B}$ complex produces the $\mathrm{C}$ complex. The $\mathrm{C}$ complex is the "catalysis complex" and this complex facilitates the transesterification reactions that ultimately remove the intron and join the exons together $(26,28)$. The first transesterification reaction produces a free $5^{\prime}$ exon and an intron lariat still connected to the 3' exon. Further rearrangement occurs and the second transesterification reaction joins the 2 exons together and removes the intron lariat. With the removal of the intron lariat, the spliceosome has completed the splicing of the 2 exons and the final mRNA has been produced.

\section{Cis-acting Elements Involved in RNA Splicing}

In addition to the sequences within the intron that are recognized by the components of the spliceosome, there are also sequences within exons that enhance or inhibit exon definition. The sequences are termed exonic splicing enhancers (ESE) or exonic splicing silencers (ESS). ESEs are sequences within exons that enhance splicing of that exon by recruiting SR proteins that are a family of proteins known to enhance splicing. Together, the ESE and SR proteins promote exon definition by aiding in the recruitment of spliceosomal components like U1 snRNP and both subunits of U2AF. The family of SR proteins includes SRSF 1-12 (29,30). SR protein are able to recognize the ESE sequences due to their RNA recognition motif (RRM) domain. In many cases the ESE sequences are highly degenerative, but the SR 
proteins are able to recognize and bind to the sequences that are specific for a particular SR protein (31).

Exonic splicing silencers are also important for the proper regulation of RNA splicing. Like the ESEs, the ESSs are also highly degenerative sequences found within the exons of mRNA. The ESS is the cis-acting element found within the RNA and one of the main trans-acting factors that binds to the ESS sequence are the hnRNPs. By binding to the ESSs within the exons, hnRNPs will lead to skipping of that exon (32). The combination of the ESS and hnRNPs prevent exon definition

Interestingly, some exons can contain both an ESE and an ESS. One example of a juxtaposed ESS/ESE occurs in the bovine papillomavirus type 1 (BVP-1) transcript. Exon 2 of the BVP-1 transcript contains both an ESE and an ESS. The ESE is required for the splicing of exon 2 and the ESS that is immediately downstream of the ESS will repress the splicing of exon 2 (33). The exact trans-acting factors that are involved in the function of the ESS and ESE of BVP-1 are not known. Other examples of juxtaposed ESE and ESS will be discussed in later sections.

In addition to ESSs and ESEs, there are sequences in introns that enhance or inhibit splicing. These sequences are intronic splicing enhancers (ISE) and intronic splicing silencers (ISS). Like the ESE and ESS sequences, the ISEs and ISSs are bound by trans-acting factors. The factors that bind to ISEs enhance the inclusion of exons in the final transcript. For example, the ISE defined by the sequence UGCAUG is found within some transcripts in neural tissue. FOX-1 and FOX-2 bind the ISE in neural tissue and in the case of the N30 exon in myosin heavy chain B, binding of 
these proteins to the ISE is necessary for exon inclusion, while in non-neural tissues in the absence of these proteins the N30 exon is skipped $(34,35)$. ISS sequences are bound by trans-acting factors that inhibit the splicing of exons. One such factor is polypyrimidine tract-binding protein (PTB), which binds to the ISS found within the c-src mRNA. PTB prevents the binding of the 65kDa subunit of U2AF to the polypyrimidine tract and thereby recruitment of U2 snRNP. As a result, the downstream $\mathrm{N} 1$ exon is excluded from the mature mRNA $(36,37)$. The ISE and ISS provide another layer of regulation to the complicated process of RNA splicing.

\section{SR Proteins}

The SR proteins are a family of RNA binding proteins that primarily enhance splicing. The name is derived from a domain in the C-terminus that is rich in serines and arginines (RS domain). In addition to the RS domain, SR proteins contain one or two RNA recognition motifs (RRM). In regard to function, the RRM is used for binding to sequences within RNA, while the RS domain can promote RNA splicing and spliceosome assembly by interacting via protein-protein interactions between SR proteins and spliceosomal components $(38,39)$. The SR proteins are typically described as proteins that bind to an ESE and promote splicing. This may involve the recruitment of spliceosomal machinery and/or may also prevent the binding of inhibitory proteins to a nearby or overlapping ESS $(21,40,41)$. A juxtaposed ESS and ESE regulate the splicing of HIV-1 tat gene. The SR protein SRSF2 binds to an ESE that overlaps with the ESS that is a binding site for the splicing inhibitor, hnRNP A1 (42). Similarly, juxtaposed regulatory elements occur with the regulation of the mutually exclusive exons, exon 2 and exon 3, of the $\alpha$-tropomyosin pre-mRNA. Exon 
2 is included in smooth muscle cells and exon 3 is included in most other cell types.

The inclusion of exon 2 requires the activity of the SR protein, SRSF7. SRSF7 binds to an ESE in exon 2 and prevents the binding of the splicing of inhibitors hnRNP H and hnRNP F to a juxtaposed ESS (43). Competition between these splicing enhancers and silencers plays an essential role in the proper regulation of RNA splicing.

\section{E. The Regulation of SR Proteins}

Phosphorylation of SR proteins is the major posttranslational modification that enhances their function. When SR proteins are inactive and not participating in splicing, they are localized to nuclear speckles. Nuclear speckles are located in interchromatin regions and are regions within the nucleus containing high concentrations of splicing factors (44-46). Increased phosphoylation can cause the SR proteins to leave the speckle and move to sites of transcription, where they can bind to pre-mRNA and cause changes in RNA splicing (44). Phosphorylation status of the SR proteins also enhances the movement of SR proteins from the nucleus to the cytoplasm. When the SR proteins are partially dephosphorylated, it promotes their exit from the nucleus bound to the spliced mRNA through interaction between the SR protein and TAP export protein (47-49). To re-enter the nucleus, the SR protein must be re-phosphorylated. The specific residues on SR proteins that are phosphorylated and activate shuttling remain to be identified.

Phosphorylation of SR proteins involves specific kinases. The SR protein kinases (SRPK) are made up of SRPK1 and SRPK2. SRPK1 is required for SR protein re-entry into the nucleus (50). SRPK2 has similar enzymatic activity when compared 
to SRPK1 but little is known about SRPK2 (51). Cdc2-like kinase/serine/threonine/tyrosine kinase (Clk/Sty) is another kinase that can phosphorylate SR proteins. Clk/Sty has an RS domain like the SR proteins and it is found within nuclear speckles, where the phosphorylation of SR protein by Clk/Sty regulates SR protein movement within the nucleus $(52,53)$. In this regard, increasing the activity of Clk/Sty by overexpression increased phosphorylation of SRSF1 and causes SRSF1 to leave the nuclear speckle and move to transcription site (53). Clk/Sty can also phosphorylate and activate most other SR proteins in addition to SRSF1 $(53,54)$. In addition to SRPK and Clk/Sty, Akt2 is another kinase that can phosphorylate SR proteins. Akt2 is activated by insulin signaling and phosphorylates SRp40. The phosphorylation of SRp40 promotes the binding of SRp40 and subsequent splicing of PKC mRNA, which produces the PKC $\beta I I$ protein. The production of PKC $\beta I$ II important for insulin's action toward increasing glucose uptake $(55,56)$. Furthermore, Akt 2 can phosphorylate Clk/Sty increasing its activity (57). Thus, Akt 2 has both cytoplasmic and nuclear activity.

\section{F. The hnRNPs}

The hnRNPs were originally described as proteins that associated with premRNA. They were discovered in rapidly dividing cells, where they are almost as highly expressed as histones (32). The hnRNPs can function in many areas of gene expression, like transcription, RNA splicing, translation, RNA export from the nucleus, mRNA stability, and chromatin remodeling $(32,58)$. Interestingly, overlapping functions of the hnRNPs in the different areas of gene expression 
demonstrates that they play a major role in proper gene expression and cell function.

The structures of the hnRNPs contain similar domains but are not as structurally conserved as the SR proteins (Fig 3) (32). HnRNPs have either a RNA recognition motif (RRM) or a K homology domain (KH), which are responsible for recognizing specific sequences within a nucleotide sequence $(58,59)$. The RRM only binds to RNA sequences, while the KH domain can bind to both RNA and DNA sequences. Additional domains that are found in many of the hnRNPs are the RGG box domains that are Arg-Gly-Gly repeats (RGG), glycine-rich domains, proline-rich domains, and/or serine, arginine, glycine, and tyrosine domain (SRGY). The RGG domain within some hnRNPs, like hnRNP A2, can be methylated and affects cellular localization (60). The glycine-rich domain can also act as a RNA binding domain for some of the hnRNPs, like hnRNP U (32). Lastly, many of the hnRNPs shuttle between the nucleus and cytoplasm due to the presence of a nuclear localization signal (NLS), or M9 signal $(32,58,61)$. Many hnRNPs, like hnRNP H, F, M, and possibly others are distributed in a speckled pattern within the cell $(62,63)$ and this is likely due to the different localization signals. As mentioned in the introduction, the hnRNPs, hnRNP $\mathrm{K}$, hnRNP L, and hnRNP A2/B1, may be involved in the regulation of G6PD during starvation and will be highlighted in detail in upcoming sections. 


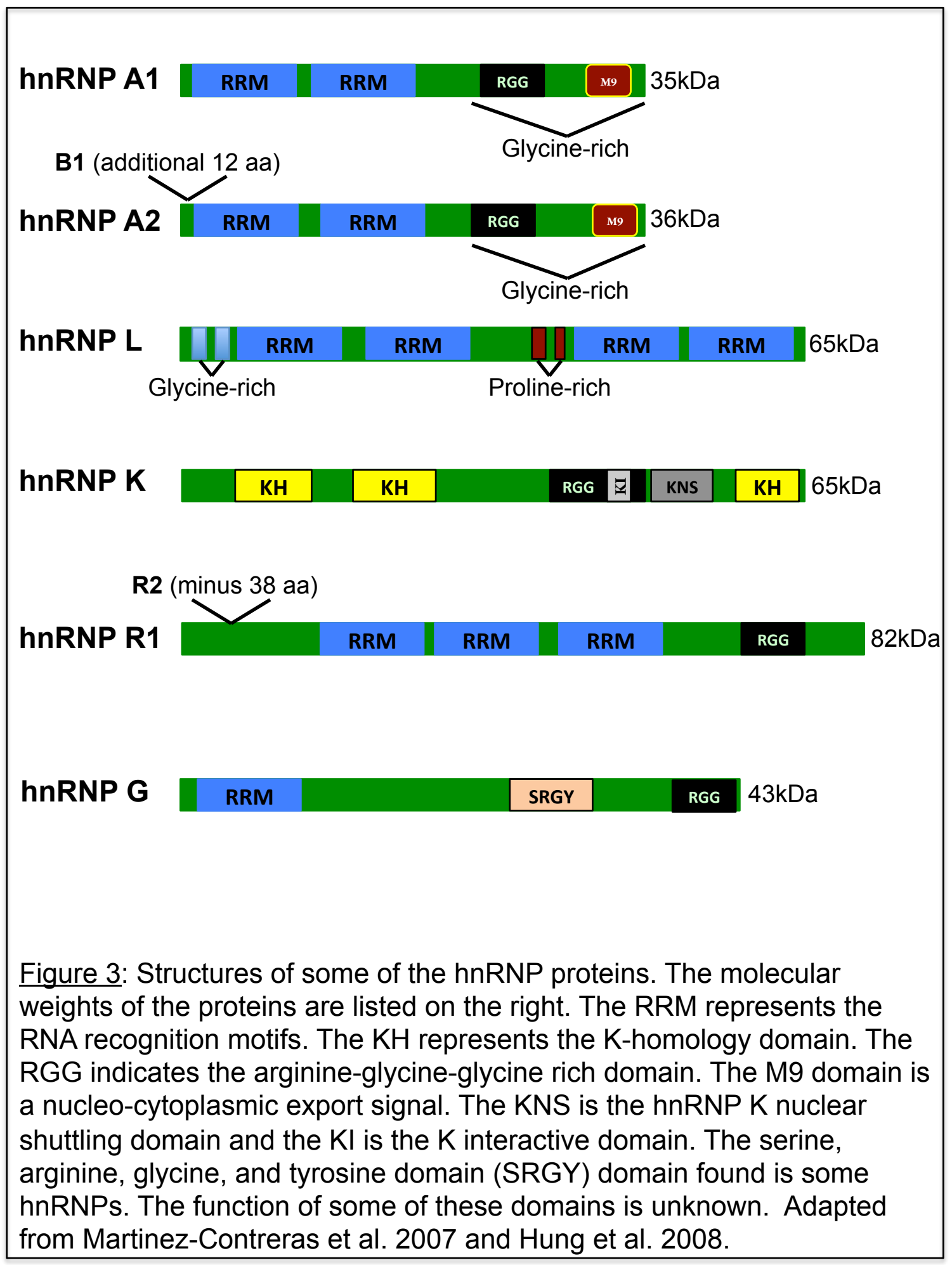




\section{HnRNP K}

\section{A. Introduction and Protein Structure}

HnRNP K is one of the more widely studied hnRNPs. HnRNP K regulates many areas of gene expression from transcription to translation. HnRNP K is a 65 kDa protein and has three $\mathrm{K}$ homology domains $(\mathrm{KH})$ that are required for binding to cytidine-rich sequences found within both DNA and RNA. HnRNP K is most similar to hnRNP E1 and hnRNP E2, which both have KH domains and bind to cytidine-rich sequences (64-66). The structure of hnRNP K can vary as four hnRNP $\mathrm{K}$ transcripts can be produced by alternative splicing, but the function of these different spliced transcripts remains to be determined $(67,68)$. The KH domains in hnRNP K bind to cytidine-rich sequences and these sequences can be a single stretch of cytidines to as many as a group of three cytidine-rich elements within the nucleotide sequences $(65,69)$. The three $\mathrm{KH}$ domains are required for optimal binding as one KH domain alone weakly binds cytidine-rich nucleotides (70). HnRNP K not only recognizes these sequences in RNA but also recognizes them within DNA $(71,72)$. The ability of hnRNP K to bind to both DNA and RNA contributes to the ability of hnRNP K to regulate multiple levels of gene expression.

HnRNP K also contains other important domains that contribute to its function and interactions with other proteins/pathways. These are involved in protein/protein interactions and affect the cellular localization of hnRNP K. The Kprotein interactive (KI) domain is responsible for some of the known proteinprotein interactions and is not present in the other hnRNPs that bind to cytidine- 
rich sequences, like hnRNPs E1 and E2 (73). The KI domain is known to promote interaction with $\mathrm{SH} 3$ domains in other proteins. One known group of proteins containing SH3 domains that interact with hnRNP K is the Src kinase family (74). It is not clear whether the KI domain is responsible for all the protein-protein interactions between hnRNP K and its partners. HnRNP K does interact with an extensive array of different proteins that are involved in signal transduction, chromatin remodeling, transcription, translation, and RNA splicing (73). HnRNP K also contains a nuclear localization signal (NLS) and nuclear shuttling domain (KNS) that presumably affect the localization of hnRNP K; however, the exact function of the KNS and NLS within hnRNP K has not been determined (73,75). Phosphorylation of hnRNP K does regulate its intracellular location and causes the cytoplasmic accumulation of hnRNP K (76). Lastly, hnRNP K contains a RGG domain, which can be methylated and the mutation of this domain decreases the nuclear localization of hnRNP K $(73,77)$.

HnRNP K can be extensively post-translationally modified by phosphorylation, methylation, sumoylation, and ubiqitination $(73,78)$. HnRNP K is phosphorylated by JNK, ERK, Protein kinase C (PKC), and the Src-family of kinases (76,79-81). Additionally, the RGG domain within hnRNP K is methylated at seven sites; Arg256, Arg258, Arg268, Arg287, Arg296, Arg299, and Arg303 (82-84). Protein arginine methyltransferase 1 (PRMT1) has so far been the only arginine methyltransferase identified to methylate hnRNP K at these sites (82). Whether or not other methyltransferases can methylate hnRNP K has yet to be determined. Lastly, hnRNP K is sumoylated by the E3 ligase, Pc2, at lysine 422 (85) and can also 
be ubiquinated (86). The sumolyation of hnRNP K enhances its transcriptional activity (85). The ubiquitination of hnRNP $\mathrm{K}$ is required for proteasomal degradation of the protein $(85,86)$. The roles of the many of these post-translational modifications of hnRNP K will be discussed in the next few sections. The posttranslational modifications of hnRNP K have major implications in regulating the function of hnRNP $\mathrm{K}$ and these modifications link hnRNP K with many signaling pathways and a wide array of gene expression processes.

\section{B. Transcriptional Regulation by HnRNP K}

The transcriptional activity of hnRNP K has been extensively studied with respect to $\mathrm{p} 53$. The protein $\mathrm{p} 53$ is a tumor suppressor that is responsible for promoting and maintaining genomic stability following DNA damage. DNA damage increases p53 transcriptional activity that leads to cell cycle arrest or apoptosis $(87,88)$. HnRNP K is a transcriptional cofactor for $\mathrm{p} 53$ and promotes the transcription of p53 target genes by interacting with p53 on the promoters of genes. With a depletion of hnRNP K, p53 was unable to bind as effectively to the promoters of gene for which it activates (86). More recent evidence has established a role for the posttranslational modifications of hnRNP K, such as methylation and sumoylation, as they relate to the transcriptional activity of p53. Arginine methylation of hnRNP $\mathrm{K}$ is induced due to UV damage and is required for p53 transcriptional activity. Inhibition of the methylation caused a decrease in the binding of p53 to the promoter of its target genes and decreased transcription of those targets (89). Additionally, research has identified that DNA damage induced 
stabilization of hnRNP K. The stabilization of hnRNP K is caused by a decrease in the human double minute 2 (HDM2)-mediated ubiquitin-dependent degradation of hnRNP K (86). The decease in ubiquitination was due to the increase in sumoylation of hnRNP K. Small ubiquitin-related modifier (SUMO) is covalently attached at lysine 422 of hnRNP K. DNA damage caused by UV radiation increased the sumoylation of hnRNP K either by Pc2 (85) or PIAS3 (90), which are both E3 SUMO-protein ligases. In addition to the stabilization, sumoylation of hnRNP $\mathrm{K}$ is required for hnRNP $\mathrm{K}$ to co-activate p53 transcription when DNA is damaged $(85,90)$. The data suggests that the sumoylation of hnRNP not only protects against its degradation, but also is necessary for the interaction between p53 and hnRNP K that is necessary for the transcriptional activity of $\mathrm{p} 53$.

HnRNP K has also been identified as a transcriptional regulator of genes other than p53. One such gene is c-myc, which is an oncogenic transcription factor (91). HnRNP K binds to the promoter of c-myc at a cytidine/thymidine-rich (CT) element (92). By overexpressing hnRNP K protein in cells, c-myc promoter activity increases, as long as TFIID TATA box-binding protein is co-expressed (71). Also, hnRNP K enhances transcription of the low-density lipoprotein receptor (LDLR). HnRNP K binds to a CT-rich element in the promoter of LDLR and causes an increase in the expression of LDLR (93). In contrast to c-myc and LDLR, hnRNP K binds to another CT-rich element in the promoter of the thymidine kinase gene and causes a repression of transcription (94). Lastly, hnRNP K inhibits the transcription of the angiotensinogen gene in the kidney. HnRNP K binds to the promoter of angiotensinogen and along with hnRNP F, hnRNP K inhibits its transcription in 
kidney cells (95). This suggests that activation versus inhibition of transcription involves differing sets of binding partners.

\section{Translational Regulation by HnRNP K}

The idea that hnRNP K could potentially be involved in regulating translation came from the observation that hnRNP K can bind to the translation elongation factor, EF-1 $\alpha$ (75). EF- $1 \alpha$ is responsible for regulating the rate of translation by transferring aminoacyl-transfer RNAs to the ribosome (96). However, whether or not this interaction has any role in regulating translation is unknown. HnRNP K can indirectly regulate translation through increasing the cellular content of the eukaryotic translation initiation factor 4E (eIF4E). EIF4E is a translation initiation factor that aids the interaction of the ribosome with the cap of mRNAs. This interaction is the rate-limiting step of protein synthesis (97). HnRNP K binds to a cytidine-rich element in the eIF4E promoter and increases the expression eIF4E (98). The increase in eIF4E expression by the over-expression of hnRNP K causes an

overall increase in the rate of translation in cells and this increase in global translation caused by the increase in eIF4E can trigger an increase in cell transformation (98).

HnRNP K can also inhibit translation by binding to an element found in the 3' UTR of some RNAs. HnRNP K binds to a CU-rich element called the differentiation control element (DICE) that is found in the 3' UTR of the 15-lipoxygenase gene (LOX) (99). The binding of hnRNP K and also hnRNP E1/E2 to this element inhibits translation by preventing the recruitment and assembly of the ribosome (100). 
Some reports have indicated that phosphorylation has a role in regulating the translational activity of hnRNP K. HnRNP K will bind to c-Src, which causes c-Src to phosphorylate hnRNP K at tyrosine residues Y72, Y225, Y230, Y234, Y236, and Y380. The phosphorylation of hnRNP K by c-Src inhibits hnRNP K binding to DICE within the LOX mRNA. The ability of c-Src to phosphorylate hnRNP K prevents the translational silencing of LOX mRNA in cells by hnRNP K (79). Phosphorylation of hnRNP K by ERK also causes an increase in the translational repression by hnRNP K. When ERK is activated, it phosphorylates hnRNP K at the serine resides, S284, and S353. The phosphorylation at these serine residues is required for the translational inhibition by hnRNP K on RNAs that contain a 3' UTR DICE element in cells.

However, the ability of hnRNP K to bind to RNA that contains a DICE in vitro was not dependent on phosphorylation by ERK. The phosphorylation of hnRNP K by ERK causes it to translocate from the nucleus to the cytoplasm. The accumulation of hnRNP K in the cytoplasm coincides with the increase in translational repression (76). Whether hnRNP K can inhibit the translation of other RNAs besides the LOX gene and if this repression requires a DICE remains to be determined.

\section{RNA Splicing and HnRNP K}

The involvement of hnRNP K in RNA splicing has not been studied as extensively as the other areas of gene expression regulated by hnRNP K. One of the first clues that hnRNP K could be involved in splicing is that hnRNP K can interact with a number of known splicing factors. HnRNP K can interact with splicing factors like hnRNP L, hnRNP A1, SFRS7, and SFRS3 $(101,102)$. The first evidence that 
hnRNP K is involved in directly regulating RNA splicing was discovered for the chicken $\beta$-tropomyosin gene. HnRNP K binds to an intronic enhancer element downstream of exon $6 \mathrm{~A}$ and promotes the inclusion of the alternative exon $6 \mathrm{~A}$ in the final transcript (103). More recently hnRNP K was discovered as a splicing regulator of the Bcl-x pre-mRNA (104). Bcl-x is a regulator of apoptosis and its pre-mRNA can produce two isoforms of opposing function. The isoforms of Bcl-x are Bcl- $\mathrm{x}_{\mathrm{L}}$, which is anti-apoptotic, and Bcl-xs, which is a smaller protein and is pro-apoptotic (105). HnRNP K binds to a silencer element in the Bcl-x pre-mRNA and represses the production of the Bcl- $\mathrm{x}_{\mathrm{s}}$ isoform (104). The involvement of hnRNP $\mathrm{K}$ in the regulation of RNA splicing also includes the regulation of the splicing of the synaptosomal-associated protein 25 (Snap25) mRNA during neuronal differentiation. Exon $5 b$ is included in the mRNA during differentiation and development, but in adult animals and developed tissues, the mutually exclusive exon 5 a is included in the final transcript $(106,107)$. HnRNP K promotes the inclusion of exon $5 \mathrm{~b}$ and the exclusion of exon $5 \mathrm{a}$ by binding to a protein kinase $\mathrm{A}$ (PKA)-responsive RNA element (KARRE) that is within the intron upstream of exon 5a. When hnRNP K binds to the KARRE, it prevents the binding of U2AF65 and spliceosomal assembly. This causes exon 5a of Snap25 to be skipped (108). While the known regulation of RNA splicing by hnRNP K is limited, future research will likely define other RNA splicing events that are regulated by hnRNP K. Additionally, the interaction between hnRNP $\mathrm{K}$ and other splicing factors likely plays an important role in the function of hnRNP K as a splicing regulator. Further research is required to understand the importance of these interactions. 


\section{HnRNP L}

\section{A. Introduction and Protein Structure}

The areas of gene expression that are regulated by hnRNP L are RNA splicing and translation. HnRNP L is a $65 \mathrm{kDa}$ protein that has 4 RNA recognition motifs (RRM) (32). The RRM domains of hnRNP L recognize a cytidine-adenosine rich element within RNA (109). Unlike hnRNP K, hnRNP L binds to RNA, not DNA. The only known posttranslational modification of hnRNP L is phosphorylation (110112).

\section{B. Translation and HnRNP L}

HnRNP L can enhance the translation of hepatitis C virus RNA. HnRNP L binds to an internal ribosomal entry site that is required for efficient translation of the hepatitis C virus RNA $(113,114)$. In addition to hepatitis C virus RNA, hnRNP L, along with PTB, also binds to the internal ribosomal entry site within the Cat-1 arginine/lysine transporter mRNA (115). This binding is required for efficient translation of Cat-1 arginine/lysine transporter mRNA during amino-acid starvation. Without PTB or hnRNP L there is no increase in translational efficiency of Cat-1 during amino-acid starvation (115). These data provide evidence that hnRNP L can regulated a translational events where an internal ribosomal entry site is present. More research is needed to better define a role for hnRNP L in translation and if there are additional translational events that are regulated by hnRNP L. 


\section{RNA Splicing and HnRNP L}

The regulation of RNA splicing has been the main focus of the research surrounding hnRNP L and its effects on gene expression. The regulation of RNA splicing by hnRNP L was first identified for the endothelial nitric oxide synthase (eNOS) mRNA. HnRNP L binds to a set of CA-repeats in the (eNOS) RNA sequence within intron 13 and activates the upstream 5' splice site (109). Since the discovery that hnRNP L can regulate splicing, a number of studies have been conducted that provide more evidence for the role of hnRNP L in RNA splicing.

The splicing of CD45 mRNA has been extensively studied. CD45 is a transmembrane protein tyrosine phosphatase that has several isoforms. Within the CD45 mRNA there are 3 alternatively spliced exons, exons 4, 5, and 6 that encode for the extracellular domain of the protein $(116,117)$. The RNA splicing of exon 4 of the CD45 mRNA is inhibited by an ESS. HnRNP $\mathrm{L}$ is the trans-acting factor that binds to the ESS in exon 4 and causes the exclusion of exon 4 from the final mature mRNA (118). In addition to binding to the ESS, hnRNP L also recruits another hnRNP, hnRNP A1, to a sequence that is upstream of the 5 'splice site of exon 4 . The binding of both hnRNP L and A1 inhibit splicing of exon 4 by preventing U6 snRNA association, thereby blocking catalysis of the splicing reaction (119). HnRNP L not only acts to inhibit splicing by binding directly to an ESS element, but can recruit proteins that are also necessary for the proper regulation of RNA splicing.

In addition to regulation of CD45 by hnRNP L, a protein closely related to hnRNP L known as hnRNP L-Like (hnRNP LL) also regulates the splicing of CD45 mRNA. These two proteins share 58\% amino acid similarity and are similar in size. 
HnRNP LL lacks the proline-rich domain that is found in hnRNP L (Fig 3) (120). The skipping of all the exons, exons 4, 5, and 6 that were previously discussed requires not only hnRNP L but also hnRNP LL. HnRNP LL binds to two silencer elements within exon 6. The binding of hnRNP L to exon 4 and the binding of hnRNP LL and/or hnRNP L to exon 6 cause the skipping of the exons 4, 5, and 6 (121). This suggests a possible compensatory mechanism between hnRNP L and hnRNP LL, as they are able to bind to similar silencing elements. However, it is unknown whether hnRNP LL regulates the splicing of other mRNAs.

HnRNP L also plays an important role in regulating the alternative splicing of the potassium channel gene, Slo. Slo contains an exon that is called stress axisregulated exon (STREX) and this exon is found between exon 18 and exon 19. Within the STREX exon there are CA-repeats to which hnRNP L binds and inhibits the inclusion of the STREX exon in the final transcript of Slo. Interestingly, there is a serine residue, Ser-513, within hnRNP L that is phosphorylated by $\mathrm{Ca}^{2+} /$ calmodulindependent protein kinase IV (CaMKIV) when it is activated by membrane depolarization. The phosphorylation of hnRNP L enhances the binding of hnRNP L to the CA-repeats within STREX and is required for the inhibition of STREX in the final transcript. When the STREX exon is excluded from the final transcript it causes the production of potassium channels with slightly altered properties. One of those properties includes a decrease in the $\mathrm{Ca}^{2+}$ and voltage sensitivity $(112,122)$. The alteration of the splicing of Slo mRNA by hnRNP L is necessary for the normal function of the potassium channel after membrane depolarization. 
A final example that has been well studied in relation to the affect of hnRNP L on its splicing is caspase- 9 mRNA. Caspase- 9 is an important protein in the apoptotic pathway and is a tumor suppressor (123). Transcription of the caspase-9 gene produces two splice variants called caspase-9a and caspase-9b. Caspase-9a includes the exon 4 cassette that consists of exons $3,4,5$, and 6 and is pro-apoptotic. Caspase-9b excludes the exon 4 cassette and is anti-apoptotic $(124,125)$. Exon 3 of this cassette contains a purine-rich ESS to which hnRNP L binds. HnRNP L was recently identified as a target of AKT phosphorylation and the phosphorylation of hnRNP L at serine-52 by AKT causes a decrease in splicing of the exon 4 cassette and lowers the ratio of caspase-9a to caspase-9b. The lowering of the capsase-9a/9b ratio is necessary for the tumorigenic ability of non-small lung cancer cells (110). Phosphorylated hnRNP L competes against the splicing enhancer, hnRNP U for binding to the element (111).

In addition to the well studied genes affected by hnRNP L, hnRNP L was also determined to affect a wide variety of RNAs that were identified by microarray analysis after hnRNP L depletion (120). While the function of these splicing events has yet to be studied, this suggests that hnRNP L may be involved in the regulation of a large number of splicing events beyond the examples presented above.

\section{HnRNP A2/B1}

\section{A. Introduction Protein Structure}

HnRNP A2/B1 is part of a family of hnRNPs that include hnRNP A0-A3 and hnRNP B0-B2. This subset of hnRNPs is known to regulate many different RNAs 
$(32,126)$. HnRNP A2/B1 are known to regulate gene expression by regulating RNA splicing, mRNA stability, transcription, and translation.

HnRNP A2/B1 are actually two proteins. HnRNP B1 contains 12 amino acids in its $\mathrm{N}$-terminus that are not found in hnRNP A2. The inclusion of these amino acids is due to an alternative splicing event $(32,127)$. Commercial antibodies are not available that distinguish between these isoforms thus the literature likewise does not distinguish between them when characterizing their function. These proteins are 36kDa and their structure includes two RRMs in their N-terminus. The RRM domains of hnRNP A2/B1 recognize and bind to the sequences UAG(purine)GA/U and UAGG which are similar to sequences to those bound by hnRNP A1 $(128,129)$. The C-terminal ends of hnRNP A2/B1 have a glycine rich region and a nucleocytoplasmic export signal (M9). In addition, there is an RGG (arginine, glycine, glycine) motif (32) that is necessary for shuttling between the cytoplasm and the nucleus. The RGG motif is methylated and blocking this methylation prevents the nuclear localization of hnRNP A2/B1 (60). The only other posttranslational modification of hnRNP A2/B1 that has been identified is phosphorylation by AKT1 $(130)$.

\section{B. RNA Splicing and HnRNP A2/B1}

RNA splicing is one step in gene expression that hnRNP A2/B1 are known to regulate. HnRNP A2/B1 will repress the splicing of exon 2 of HIV by binding to an ESS the exon. Other members of the hnRNP A/B family also bind to this element and 
repress the splicing. HnRNP A2/B1 compete against the SR protein, SRSF2 for binding to the juxtaposed ESE/ESS in HIV RNA and inhibits splicing $(42,131)$. The splicing of the BRCA1 pre-mRNA is also regulated by hnRNP A2/B1, as well as hnRNP A1. The BRCA1 gene encodes a protein that is necessary for DNA repair $(132,133)$. A mutation that causes a switch from $\mathrm{G}$ to $\mathrm{T}$ in exon 18 of BRCA1 causes skipping of this exon (134). The mutation creates an ESS element that was previously not there and the ESS is bound by the trans-acting factors, hnRNP A2/B1 and hnRNP A1. This binding causes the exclusion of exon 18 in the final transcript (135). Another example of the regulation of alternative splicing by hnRNP A2/B1 is the regulation of the production of the different isoforms of pyruvate kinase (PK). Pyruvate kinase has 2 isoforms that are called PK-M1 and PK-M2. The PK-M1 isoform arises from the inclusion of exon 9 and the exclusion of exon 10. The PK-M2 isoform is a result of exon 9 skipping and the inclusion of exon 10. PK-M2 is expressed at higher levels in cancer and is important for promoting tumorigenesis. PK-M1 is mainly expressed in tissues that are terminally differentiated (136-139).

\section{RNA Stability and HnRNP A2/B1}

HnRNP A2/B1 enhances RNA stability by binding to a U rich segment in the 3' untranslated region (UTR) of collagen prolyl 4 hydroxykase alpha-subunit mRNA (140). The stability of collagen prolyl 4-hydroxylase mRNA is also regulated by hnRNP A2/B1. It binds within a uridine rich element in the 3'UTR of the collagen prolyl 4-hydroxylase mRNA and increases the expression of this mRNA by stabilizing it (140). HnRNP A2/B1 can also inhibit RNA stability of the Glut-I 
transporter mRNA. It binds to the 3'UTR and causes a decrease in the mRNA stability and a decrease in the expression of the mRNA (141). It is unknown whether or not hnRNP A2/B1 can regulate RNA stability outside of its binding to the 3' UTR of mRNAs.

\section{Regulation of Transcription and Translation by HnRNP A2/B1}

The evidence for a role for hnRNP A2/B1 in translation is very limited. One groups showed that hnRNP A2/B1 binds to an A2 response element (A2RE) within A2RE containing RNA. The binding of hnRNP A2/B1 to the A2RE recruits hnRNP E1 and this is associated with an inhibition of translation for that RNA (142). The only other evidence for the translational regulation by hnRNP A2/B1 occurs when hnRNP A2/B1 binds to CGG repeats in RNA and enhances the translation of RNAs that contain those repeats (143).

The only example of hnRNP A2/B1 as a transcriptional regulator occurs during mitochondrial respiratory stress. The response of hnRNP A2 to this stress involves the phosphorylation of A2/B1 by AKT1. Phosphorylation of hnRNP A2/B1 is necessary for the recruitment of hnRNP A2/B1 to the promoters of the stress response genes $(130,144,145)$. This example only associates hnRNP A2/B1 with transcription. Further research is needed to define a direct role for the regulation of transcription by hnRNP A2/B1. 


\section{VI.Glucose-6-Phosphate Dehydrogenase}

G6PD is part of the lipogenic enzyme family. The lipogenic enzymes include fatty acid synthase (FAS), malic enzyme, ATP-citrate lyase, and G6PD. G6PD is the rate-limiting enzyme of the pentose phosphate pathway that is sometimes referred to as the phosphogluconate pathway or the hexose monophosphate shunt. G6PD converts glucose-6-phosphate to 6-phosphogluconolacetone and this conversion takes $\mathrm{NADP}^{+}$and converts it to $\mathrm{NADPH}+\mathrm{H}^{+}$. The $\mathrm{NADPH}+\mathrm{H}^{+}$that is produced is used for reductive biochemical reactions during fatty acid synthesis, amino acid synthesis, cholesterol synthesis, and the reduction of glutathione $(3,146)$. Ultimately, G6PD and the pentose phosphate pathway lead to the production of ribose-5-phosphate, which is a precursor for nucleotides and erythrose-4phosphate, which is a precursor to many amino acids. The $\mathrm{NADPH}+\mathrm{H}^{+}$that is produced by the reaction catalyzed by G6PD is required in all cells to help protect against oxidative stress and the knock out of G6PD is embryonic lethal $(147,148)$. Mice that are partially deficient in G6PD have an increase in apoptosis in the renal cortex and high levels of albumin in their urine, which are signs of increased oxidative stress (149). G6PD deficiency affects nearly 400 million people worldwide. Acute hemolysis due to oxidative stress is the most common problem seen in people with G6PD deficiency (150) and can be precipitated by common infections. Highlighting the essentiality of G6PD activity, G6PD deficiency is triggered by point mutations that cause a decrease in its activity and not by frame shifts or large deletions that would ablate the enzyme. 
The first step of glycolysis provides the glucose-6-phosphate that is a necessary substrate for G6PD. Glucose enters the cell and is phosphorylated by glucokinase in a reaction that uses 1 ATP to convert glucose into glucose-6phosphate. The glucose-6-phosphate can be metabolized by either the glycolytic pathway or through the pentose phosphate pathway. Flux through glycolysis is regulated by the activity of 6-phosphofructo-1-kinase and involves multiple allosteric effectors. Flux through the pentose phosphate pathway is regulated by G6PD, which changes in its activity are predominantly regulated by changes in its amount.

The pentose phosphate pathway provides a critical role in fatty acid synthesis in lipogenic tissues such as the liver. The $\mathrm{NADPH}+\mathrm{H}^{+}$that is produced by the enzymes G6PD and 6-phosphogluconate dehydrogenase of the pentose phosphate pathway provide approximately half of the $\mathrm{NADPH}+\mathrm{H}^{+}$needed for fatty acid synthesis, while the malic enzyme reaction provides the other half (146). Carbon substrates for fatty acid synthesis are derived from excess dietary carbohydrate that is converted from glucose to citrate via glycolysis and the TCA cycle. Citrate exits the mitochondria via the citrate shuttle and is converted into oxaloacetate and acetyl-CoA in the cytoplasm. In order to synthesize fatty acids the acetyl-CoA must be converted to malonyl-CoA via acetyl-CoA carboxylase. The remaining reactions of fatty acid synthesis are carried out by fatty acid synthase. Fatty acid synthase is a large dimer that has 7 different catalytic activities. The reduction reactions of fatty acid synthase (Fig 4$)$ require $\mathrm{NADPH}+\mathrm{H}^{+}$and 14 molecules of $\mathrm{NADPH}+\mathrm{H}^{+}$are used in the production of 1 molecule of palmitate. 
These reactions are essential for the productions of fatty acids. After one round of the reactions 1-4 (Fig 4), the acyl-ACP re-enters at reaction 1 where it takes the place of acetyl- CoA and receives carbons from malonyl-ACP, which extends the carbon chain of the acyl-ACP by 2 carbons as the reactions 1-4 repeat. This cycle of reactions where 2 carbons are added per cycle of reactions 1-4 repeats until palmitate is produced. 


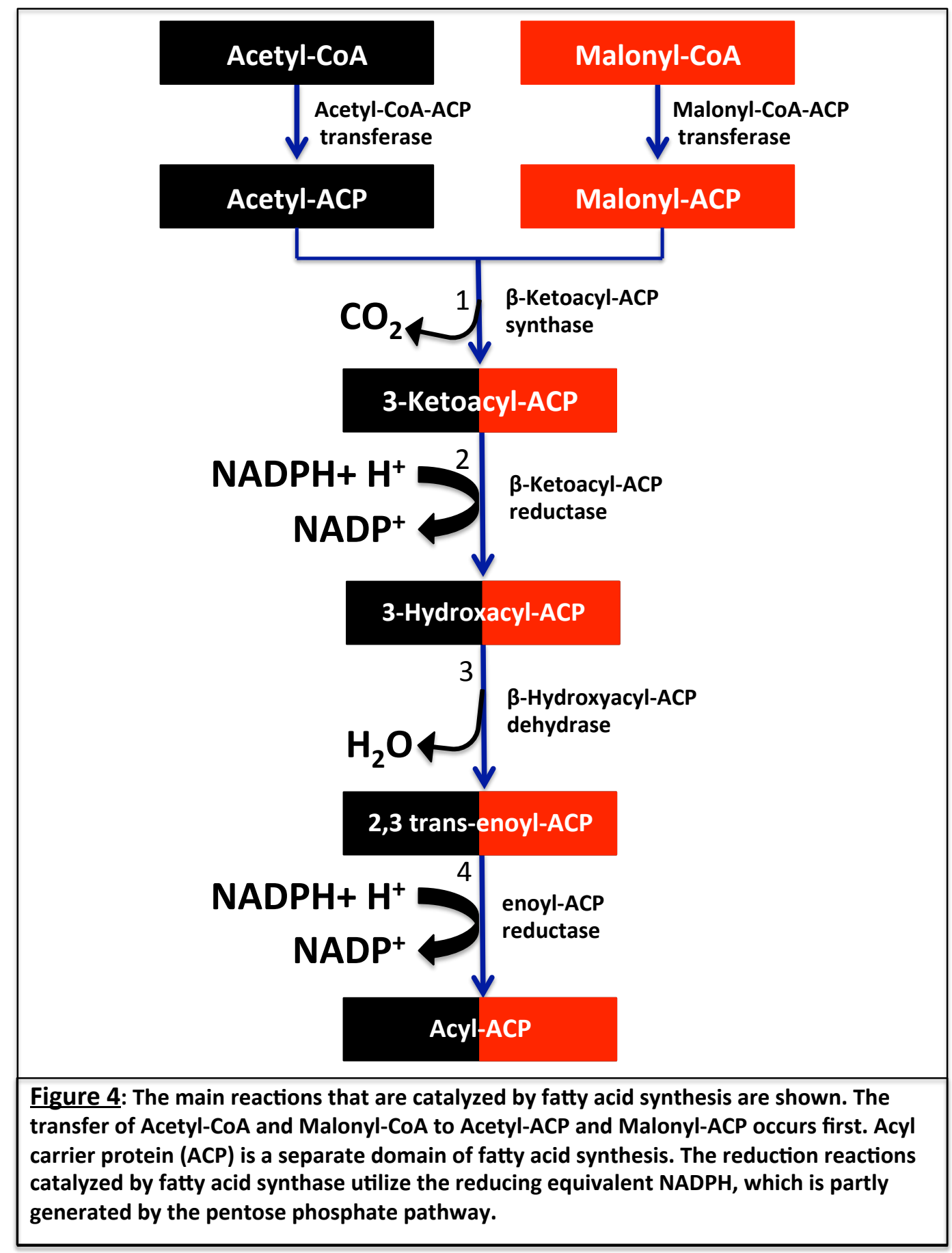

The lipogenic enzymes are coordinately regulated by nutritional status in liver and adipose tissue, which are the primary sites of lipogenesis. During times of decreased food intake, like starvation, the rate of lipogenesis decreases due to a lack of substrates. Conversely, refeeding enhances substrate supply and induces the 
synthesis of lipogenic enzymes and this regulation occurs at pre-translational level. G6PD follows this same pattern of regulation of the enzymes in this pathway. Refeeding after starvation causes at least a 12-fold increase in the accumulation of G6PD mRNA $(11,13)$. In addition to starvation and refeeding, mice fed a diet that contains $6 \%$ polyunsaturated fat had a $80 \%$ decrease in the expression of G6PD mRNA, compared to mice fed a diet containing only $1 \%$ polyunsaturated fat (11). Primary rat hepatocytes have been used to identify dietary signaling hormones or metabolites that can regulate G6PD expression. Primary rat hepatocytes that were treated with insulin to mimic the fed state also had an increase in the expression of G6PD mRNA. Glucagon, a hormone secreted during the starved state does not regulate G6PD expression $(151,152)$. Primary rat hepatocytes treated with polyunsaturated fatty acids to mimic starvation-induced lipolysis or to reflect the increase in circulating fatty acid due to a diet enriched in polyunsaturated fat had a 40-60\% decrease in the insulin-induced increase in the expression of G6PD mRNA $(153,154)$. The inhibition of insulin-induced expression of G6PD mRNA by polyunsaturated fatty acids occurs due to the activation of p38 MAP. The activation of p38 MAP kinase coincides with the phosphorylation of IRS-1 at the ser-307 and the inhibition of the insulin-induced increase in G6PD mRNA (155).

Most of the lipogenic enzymes are regulated by changes the rate of transcription of their genes in response to dietary signals. Dietary signals include hormones, like insulin and glucagon, and dietary molecules like glucose and fatty acids. Unlike the other lipogenic enzymes whose expression is regulated by 
transcriptional changes, transcriptional activity of the G6PD gene is unchanged following dietary manipulation. In addition to transcription, polyadenylation is not altered by dietary manipulation $(10,13,153)$. The expression of G6PD mRNA is regulated at a posttranscriptional step due to changes in the rate of pre-mRNA splicing $(3,11,13)$. Starvation, a diet rich in polyunsaturated fatty acids, and treatment of rat hepatocytes with arachidonic acid inhibit pre-mRNA splicing and cause an increase in intron retention around exon 12. The increase in intron retention leads to degradation of the incompletely spliced transcript and prevents the accumulation of mature mRNA that can be translated into protein (153).

We hypothesized that nutrients regulated the splicing of G6PD mRNA, via a cis-acting element in the primary transcript. To identify this element, various reporter constructs were constructed that contained the CMV promoter to drive the transcription and progressive deletions of the G6PD gene. These reporters were transfected into primary rat hepatocytes and the affects insulin or insulin plus arachidonic acid on the expression of the reporter mRNA was measured. Expression of the mRNA from these reporters was regulated by insulin and polyunsaturated fatty acid until exon 12 was deleted $(153,156)$. In order to characterize the location of the regulatory element in exon 12 , separate G6PD reporters were made that contain block mutations within exon 12 . The block mutations were 10 nucleotides (AAGCATGCAA) in length. A total of 9 reporters were constructed to span the 93nucleotide exon. Again, these reporters were transfected into primary rat hepatocytes and the effects of insulin or insulin plus arachidonic acid on the accumulation of the reporter mRNA were measured. When nucleotides 43-72 of 
exon 12 were mutated by the block mutations, arachidonic acid treatment of rat hepatocytes no longer inhibited the expression of these reporters. Furthermore, addition of exon 12 onto a heterologous gene, $\beta$-galactosidase, resulted in inhibition of the expression of this construct by arachidonic acid $(153,156)$. Thus, a regulatory element within nucleotides $43-72$ of exon 12 is involved in nutritional regulation of G6PD expression.

An in vitro splicing assay was used to further characterize the functional consequence of the regulatory element. RNA substrates that contain exon 12 or lack exon 12 were transcribed in vitro with ${ }^{32} \mathrm{P}$-labeled CTP. The labeled RNA substrates were incubated with HeLa nuclear extracts that contain all the proteins needed for the splicing reaction. Constructs that lack exon 12, which includes RNA substrates containing exon8-intron8-exon 9 or exon 10-intron 10-exon 11 undergo splicing in the HeLa nuclear extracts. In contrast to the constructs that could be spliced, any of the RNA substrates that contain exon 12 were unable to be spliced in HeLa nuclear extracts (156). The RNA substrates that contain exon 12 either in its native context (exon 11-intron 11-exon 12) or in a heterologous context (exon 10-intron 10- exon 12) would not splice. In addition to the in vitro splicing assays, spliceosome assembly assays were used to determine how the regulatory element affects the steps in splicing catalysis. The different complexes that form during spliceosomal assembly can be visualized following polyacrylamide gel separation due to their different sizes (see Fig 2). The early complexes that form are $\mathrm{H}$ and E, which are smaller, less complex, and migrate faster in the gel. The later complexes that form, like A, B and C, are larger and more complex, which causes them to migrate slower 
in the gel. The regulatory element in exon 12 decreases the formation of the $\mathrm{A}$ complex and completely inhibits the formation of the B and C complexes. This indicates that the regulatory element represses the binding of U2 snRNP to the intron, as the A complex requires the binding of this protein (156). Taken together, the in vitro splicing assays and spliceosomal assembly assays have identified an ESS within nucleotides 43-72 of exon 12 that inhibits the splicing of exon 12.

The identification of a cis-acting ESS lead to the search for potential transacting factors that bind to the ESS and inhibit RNA splicing. UV crosslinking was one technique used to determine what possible factors may bind to the ESS and are potentially necessary for the splicing inhibition of G6PD. The oligonucleotides that span nucleotides 65-79 and 50-79 of exon 12 were incubated with liver nuclear extracts from starved and refed mice. UV crosslinking revealed bands at 60kDa and $37 \mathrm{kDa}$ that bound to the regulatory element. In addition to UV crosslinking, RNA affinity experiments were used to purify the proteins in these complexes. The $60 \mathrm{kDa}$ band was determined to be hnRNP $\mathrm{K}$ and hnRNP $\mathrm{L}$ and the $37 \mathrm{kDA}$ band was determined to be hnRNP A2/B1 by liquid chromatography-tandem mass spectrometry. Interestingly, binding of hnRNPs K, L and A2/B1 to the probe that spans nucleotides 50-79 was increased 60-70\% when nuclear extracts were made from the livers of starved mice as compared to the livers of mice that were refed $(14,156)$. Based on this data, the hnRNPs $\mathrm{K}, \mathrm{L}$, and A2/B1 may be the trans-acting factors that bind to the ESS to inhibit splicing of G6PD, as they bound more to the ESS during starvation. 
In addition to the ESS, the regulatory element contains a second cis-acting element that is required for the nutrient regulation of the splicing of G6PD mRNA. The first piece of data to support that exon 12 contains another cis-acting element that is found within the regulatory element was the in vitro splicing assay. When the regulatory element was removed from the exon 11-intron-11-exon-12 substrate used in the in vitro splicing assay, splicing was still inhibited and if this region only contained an ESS then the substrate should be able to be splice (156). This data suggests that the regulatory element also contains an ESE. More recent evidence shows that exon 12 does in fact contain an ESE and that a trans-acting factor that enhances the splicing of G6PD binds to the ESE. We identified that a SR protein, SRSF3 binds to the exon 12 regulator element by using RNA affinity assays. Mouse liver nuclear extracts from mice that were either starved or refed were incubated with an oligonucleotide that spans the regulatory element in exon 12. Interestingly, the binding of SRSF3 was enhanced in the extracts from the refed mice. Treating primary rat hepatocytes with insulin to mimic refeeding also showed that there was an increase the expression of phosphorylated SR proteins, which included SRSF3. Depletion of SRSF3 by siRNA in HepG2 cells that stably express a G6PD reporter identified that SRSF3 acts to enhance the expression of this reporter and the endogenous G6PD gene. Additionally, using RNA immunoprecipitation (RIP), the binding of to SRSF3 the regulatory element was detected in mouse liver. SRSF3 does bind to the regulatory element in whole mouse liver and refeeding enhances the binding of SRSF3. The increase in the binding of SRSF3 corresponds with an increase in the expression of G6PD mRNA (157). 


\section{Hypothesis}

Our laboratory has shown that exon 12 of G6PD mRNA contains an ESE and ESS. The recent identification of a trans-acting factor that not only binds, but also regulates the splicing of G6PD provides further insight on how external signals can regulate splicing. During starvation we hypothesize that hnRNP K, hnRNP L and/or hnRNP A2/B1 bind to the RNA and inhibit the splicing of G6PD. The juxtaposed nature of the ESE and ESS would suggest that when one of the factors, either the hnRNPs or SRSF3, bind to the regulatory element that it excludes the other from binding.

Crucial to the test of this hypothesis is determining the relative contributions of hnRNP K, hnRNP L, and hnRNP A2/B1 to the inhibition of the splicing of G6PD mRNA. The goal of this dissertation was to identify the relevant splicing silencer and to determine its mechanism of action. 


\section{References}

1. Hillgartner, F.B., Salati, L.M. and Goodridge, A.G. (1995) Physiological and molecular mechanisms involved in nutritional regulation of fatty acid synthesis. Physiol Rev. 75, 47-76.

2. Berdanier, C.D. and Shubeck, D. (1979) Interaction of glucocorticoid and insulin in the responses of rats to starvation-refeeding. J Nutr. 109, 17661771.

3. Salati, L.M. and Amir-Ahmady, B. (2001) Dietary regulation of expression of glucose-6-phosphate dehydrogenase. Annu Rev Nutr. 21, 121-140.

4. Geisler, R.W., Roggeveen, A.E. and Hansen, R.J. (1978) The effects of insulin on the turnover of glucose-6-phosphate dehydrogenase in epididymal adipose tissue of the rat. Biochim Biophys Acta. 544, 284-293.

5. Garcia, D.R. and Holten, D. (1975) Inhibition of rat liver glucose-6-phosphate dehydrogenase synthesis by glucagon. J Biol Chem. 250, 3960-3965.

6. Gozukara, E.M., Frolich, M. and Holten, D. (1972) The effect of unsaturated fatty acids on the rate of synthesis of rat liver glucose-6-phosphate dehydrogenase. Biochim Biophys Acta. 286, 155-163.

7. Miksicek, R.J. and Towle, H.C. (1982) Changes in the rates of synthesis and messenger RNA levels of hepatic glucose-6-phosphate and 6phosphogluconate dehydrogenases following induction by diet or thyroid hormone. J Biol Chem. 257, 11829-11835. 
8. Morikawa, N., Nakayama, R. and Holten, D. (1984) Dietary induction of glucose-6-phosphate dehydrogenase synthesis. Biochem Biophys Res Commun. 120, 1022-1029.

9. Tomlinson, J.E., Nakayama, R. and Holten, D. (1988) Repression of pentose phosphate pathway dehydrogenase synthesis and mRNA by dietary fat in rats. J Nutr. 118, 408-415.

10. Amir-Ahmady, B. and Salati, L.M. (2001) Regulation of the processing of glucose-6-phosphate dehydrogenase mRNA by nutritional status. J Biol Chem. 276, 10514-10523.

11. Hodge, D.L. and Salati, L.M. (1997) Nutritional regulation of the glucose-6phosphate dehydrogenase gene is mediated by a nuclear posttranscriptional mechanism. Arch Biochem Biophys. 348, 303-312.

12. Salati, L.M., Szeszel-Fedorowicz, W., Tao, H., Gibson, M.A., Amir-Ahmady, B., Stabile, L.P. and Hodge, D.L. (2004) Nutritional regulation of mRNA processing. J Nutr. 134, 2437S-2443S.

13. Stabile, L.P., Hodge, D.L., Klautky, S.A. and Salati, L.M. (1996) Posttranscriptional regulation of glucose-6-phosphate dehydrogenase by dietary polyunsaturated fat. Arch Biochem Biophys. 332, 269-279.

14. Griffith, B.N., Walsh, C.M., Szeszel-Fedorowicz, W., Timperman, A.T. and Salati, L.M. (2006) Identification of hnRNPs K, L and A2/B1 as candidate proteins involved in the nutritional regulation of mRNA splicing. Biochim Biophys Acta. 1759, 552-561. 
15. Pan, Q., Shai, O., Lee, L.J., Frey, B.J. and Blencowe, B.J. (2008) Deep surveying of alternative splicing complexity in the human transcriptome by highthroughput sequencing. Nat Genet. 40, 1413-1415.

16. Wang, E.T., Sandberg, R., Luo, S., Khrebtukova, I., Zhang, L., Mayr, C., Kingsmore, S.F., Schroth, G.P. and Burge, C.B. (2008) Alternative isoform regulation in human tissue transcriptomes. Nature. 456, 470-476.

17. Black, D.L. (2000) Protein diversity from alternative splicing: a challenge for bioinformatics and post-genome biology. Cell. 103, 367-370.

18. Harrison, P.M., Kumar, A., Lang, N., Snyder, M. and Gerstein, M. (2002) A question of size: the eukaryotic proteome and the problems in defining it. Nucleic Acids Res. 30, 1083-1090.

19. Hansen, K.D., Lareau, L.F., Blanchette, M., Green, R.E., Meng, Q., Rehwinkel, J., Gallusser, F.L., Izaurralde, E., Rio, D.C., Dudoit, S. et al. (2009) Genome-wide identification of alternative splice forms down-regulated by nonsensemediated mRNA decay in Drosophila. PLoS Genet. 5, e1000525.

20. Sayani, S., Janis, M., Lee, C.Y., Toesca, I. and Chanfreau, G.F. (2008) Widespread impact of nonsense-mediated mRNA decay on the yeast intronome. Mol Cell. 31, 360-370.

21. Cartegni, L., Chew, S.L. and Krainer, A.R. (2002) Listening to silence and understanding nonsense: exonic mutations that affect splicing. Nat Rev Genet. 3, 285-298.

22. Jurica, M.S. and Moore, M.J. (2002) Capturing splicing complexes to study structure and mechanism. Methods. 28, 336-345. 
23. Matlin, A.J. and Moore, M.J. (2007) Spliceosome assembly and composition. Adv Exp Med Biol. 623, 14-35.

24. Bleichert, F. and Baserga, S.J. (2007) The long unwinding road of RNA helicases. Mol Cell. 27, 339-352.

25. Mount, S.M. (1982) A catalogue of splice junction sequences. Nucleic Acids Res. 10, 459-472.

26. Brow, D.A. (2002) Allosteric cascade of spliceosome activation. Annu Rev Genet. 36, 333-360.

27. Reed, R. (1996) Initial splice-site recognition and pairing during pre-mRNA splicing. Curr Opin Genet Dev. 6, 215-220.

28. Black, D.L. (2003) Mechanisms of alternative pre-messenger RNA splicing. Annu Rev Biochem. 72, 291-336.

29. Long, J.C. and Caceres, J.F. (2009) The SR protein family of splicing factors: master regulators of gene expression. Biochem J. 417, 15-27.

30. Manley, J.L. and Krainer, A.R. (2010) A rational nomenclature for serine/arginine-rich protein splicing factors (SR proteins). Genes Dev. 24, 1073-1074.

31. Tacke, R. and Manley, J.L. (1999) Determinants of SR protein specificity. Curr Opin Cell Biol. 11, 358-362.

32. Martinez-Contreras, R., Cloutier, P., Shkreta, L., Fisette, J.F., Revil, T. and Chabot, B. (2007) hnRNP proteins and splicing control. Adv Exp Med Biol. 623, 123-147. 
33. Zheng, Z.M., Huynen, M. and Baker, C.C. (1998) A pyrimidine-rich exonic splicing suppressor binds multiple RNA splicing factors and inhibits spliceosome assembly. Proc Natl Acad Sci U S A. 95, 14088-14093.

34. Venables, J.P. (2007) Downstream intronic splicing enhancers. FEBS Lett. $\mathbf{5 8 1}, 4127-4131$.

35. Guo, N. and Kawamoto, S. (2000) An intronic downstream enhancer promotes 3' splice site usage of a neural cell-specific exon. J Biol Chem. 275, 33641-33649.

36. Chan, R.C. and Black, D.L. (1997) The polypyrimidine tract binding protein binds upstream of neural cell-specific c-src exon N1 to repress the splicing of the intron downstream. Mol Cell Biol. 17, 4667-4676.

37. Chou, M.Y., Underwood, J.G., Nikolic, J., Luu, M.H. and Black, D.L. (2000) Multisite RNA binding and release of polypyrimidine tract binding protein during the regulation of c-src neural-specific splicing. Mol Cell. 5, 949-957.

38. Wu, J.Y. and Maniatis, T. (1993) Specific interactions between proteins implicated in splice site selection and regulated alternative splicing. Cell. 75, 1061-1070.

39. Kohtz, J.D., Jamison, S.F., Will, C.L., Zuo, P., Luhrmann, R., Garcia-Blanco, M.A. and Manley, J.L. (1994) Protein-protein interactions and 5'-splice-site recognition in mammalian mRNA precursors. Nature. 368, 119-124.

40. Kan, J.L. and Green, M.R. (1999) Pre-mRNA splicing of IgM exons M1 and M2 is directed by a juxtaposed splicing enhancer and inhibitor. Genes Dev. 13, $462-471$. 
41. Zhu, J., Mayeda, A. and Krainer, A.R. (2001) Exon identity established through differential antagonism between exonic splicing silencer-bound hnRNP A1 and enhancer-bound SR proteins. Mol Cell. 8, 1351-1361.

42. Zahler, A.M., Damgaard, C.K., Kjems, J. and Caputi, M. (2004) SC35 and heterogeneous nuclear ribonucleoprotein A/B proteins bind to a juxtaposed exonic splicing enhancer/exonic splicing silencer element to regulate HIV-1 tat exon 2 splicing. J Biol Chem. 279, 10077-10084.

43. Crawford, J.B. and Patton, J.G. (2006) Activation of alpha-tropomyosin exon 2 is regulated by the SR protein 9G8 and heterogeneous nuclear ribonucleoproteins H and F. Mol Cell Biol. 26, 8791-8802.

44. Misteli, T., Caceres, J.F. and Spector, D.L. (1997) The dynamics of a pre-mRNA splicing factor in living cells. Nature. 387, 523-527.

45. Huang, S. and Spector, D.L. (1992) U1 and U2 small nuclear RNAs are present in nuclear speckles. Proc Natl Acad Sci U S A. 89, 305-308.

46. Spector, D.L. and Lamond, A.I. (2011) Nuclear speckles. Cold Spring Harb Perspect Biol. 3.

47. Caceres, J.F., Screaton, G.R. and Krainer, A.R. (1998) A specific subset of SR proteins shuttles continuously between the nucleus and the cytoplasm. Genes Dev. 12, 55-66.

48. Huang, Y., Gattoni, R., Stevenin, J. and Steitz, J.A. (2003) SR splicing factors serve as adapter proteins for TAP-dependent mRNA export. Mol Cell. 11, 837-843. 
49. Lai, M.C. and Tarn, W.Y. (2004) Hypophosphorylated ASF/SF2 binds TAP and is present in messenger ribonucleoproteins. J Biol Chem. 279, 31745-31749.

50. Lai, M.C., Lin, R.I., Huang, S.Y., Tsai, C.W. and Tarn, W.Y. (2000) A human importin-beta family protein, transportin-SR2, interacts with the phosphorylated RS domain of SR proteins. J Biol Chem. 275, 7950-7957.

51. Wang, H.Y., Lin, W., Dyck, J.A., Yeakley, J.M., Songyang, Z., Cantley, L.C. and Fu, X.D. (1998) SRPK2: a differentially expressed SR protein-specific kinase involved in mediating the interaction and localization of pre-mRNA splicing factors in mammalian cells. J Cell Biol. 140, 737-750.

52. Colwill, K., Feng, L.L., Yeakley, J.M., Gish, G.D., Caceres, J.F., Pawson, T. and Fu, X.D. (1996) SRPK1 and Clk/Sty protein kinases show distinct substrate specificities for serine/arginine-rich splicing factors. J Biol Chem. 271, $24569-24575$.

53. Colwill, K., Pawson, T., Andrews, B., Prasad, J., Manley, J.L., Bell, J.C. and Duncan, P.I. (1996) The Clk/Sty protein kinase phosphorylates SR splicing factors and regulates their intranuclear distribution. EMBO J. 15, 265-275.

54. Prasad, J., Colwill, K., Pawson, T. and Manley, J.L. (1999) The protein kinase Clk/Sty directly modulates SR protein activity: both hyper- and hypophosphorylation inhibit splicing. Mol Cell Biol. 19, 6991-7000.

55. Patel, N.A., Apostolatos, H.S., Mebert, K., Chalfant, C.E., Watson, J.E., Pillay, T.S., Sparks, J. and Cooper, D.R. (2004) Insulin regulates protein kinase CbetaII alternative splicing in multiple target tissues: development of a hormonally responsive heterologous minigene. Mol Endocrinol. 18, 899-911. 
56. Patel, N.A., Kaneko, S., Apostolatos, H.S., Bae, S.S., Watson, J.E., Davidowitz, K., Chappell, D.S., Birnbaum, M.J., Cheng, J.Q. and Cooper, D.R. (2005) Molecular and genetic studies imply Akt-mediated signaling promotes protein kinase CbetaII alternative splicing via phosphorylation of serine/arginine-rich splicing factor SRp40. J Biol Chem. 280, 14302-14309.

57. Jiang, K., Patel, N.A., Watson, J.E., Apostolatos, H., Kleiman, E., Hanson, O., Hagiwara, M. and Cooper, D.R. (2009) Akt2 regulation of Cdc2-like kinases (Clk/Sty), serine/arginine-rich (SR) protein phosphorylation, and insulininduced alternative splicing of PKCbetaII messenger ribonucleic acid. Endocrinology. 150, 2087-2097.

58. Han, S.P., Tang, Y.H. and Smith, R. (2010) Functional diversity of the hnRNPs: past, present and perspectives. Biochem J. 430, 379-392.

59. Hoffman, D.W., Query, C.C., Golden, B.L., White, S.W. and Keene, J.D. (1991) RNA-binding domain of the A protein component of the $\mathrm{U} 1$ small nuclear ribonucleoprotein analyzed by NMR spectroscopy is structurally similar to ribosomal proteins. Proc Natl Acad Sci U S A. 88, 2495-2499.

60. Nichols, R.C., Wang, X.W., Tang, J., Hamilton, B.J., High, F.A., Herschman, H.R. and Rigby, W.F. (2000) The RGG domain in hnRNP A2 affects subcellular localization. Exp Cell Res. 256, 522-532.

61. Pinol-Roma, S. and Dreyfuss, G. (1992) Shuttling of pre-mRNA binding proteins between nucleus and cytoplasm. Nature. 355, 730-732. 
62. Matunis, M.J., Xing, J. and Dreyfuss, G. (1994) The hnRNP F protein: unique primary structure, nucleic acid-binding properties, and subcellular localization. Nucleic Acids Res. 22, 1059-1067.

63. Gattoni, R., Mahe, D., Mahl, P., Fischer, N., Mattei, M.G., Stevenin, J. and Fuchs, J.P. (1996) The human hnRNP-M proteins: structure and relation with early heat shock-induced splicing arrest and chromosome mapping. Nucleic Acids Res. 24, 2535-2542.

64. Makeyev, A.V. and Liebhaber, S.A. (2002) The poly(C)-binding proteins: a multiplicity of functions and a search for mechanisms. RNA. 8, 265-278.

65. Thisted, T., Lyakhov, D.L. and Liebhaber, S.A. (2001) Optimized RNA targets of two closely related triple $\mathrm{KH}$ domain proteins, heterogeneous nuclear ribonucleoprotein $\mathrm{K}$ and alphaCP-2KL, suggest Distinct modes of RNA recognition. J Biol Chem. 276, 17484-17496.

66. Siomi, H., Matunis, M.J., Michael, W.M. and Dreyfuss, G. (1993) The pre-mRNA binding K protein contains a novel evolutionarily conserved motif. Nucleic Acids Res. 21, 1193-1198.

67. Dejgaard, K., Leffers, H., Rasmussen, H.H., Madsen, P., Kruse, T.A., Gesser, B., Nielsen, H. and Celis, J.E. (1994) Identification, molecular cloning, expression and chromosome mapping of a family of transformation upregulated hnRNPK proteins derived by alternative splicing. J Mol Biol. 236, 33-48.

68. Kimura, Y., Nagata, K., Suzuki, N., Yokoyama, R., Yamanaka, Y., Kitamura, H., Hirano, H. and Ohara, O. (2010) Characterization of multiple alternative 
forms of heterogeneous nuclear ribonucleoprotein $\mathrm{K}$ by phosphate-affinity electrophoresis. Proteomics. 10, 3884-3895.

69. Ostrowski, J., Wyrwicz, L., Rychlewski, L. and Bomsztyk, K. (2002) Heterogeneous nuclear ribonucleoprotein K protein associates with multiple mitochondrial transcripts within the organelle. J Biol Chem. 277, 6303-6310.

70. Paziewska, A., Wyrwicz, L.S., Bujnicki, J.M., Bomsztyk, K. and Ostrowski, J. (2004) Cooperative binding of the hnRNP K three KH domains to mRNA targets. FEBS Lett. 577, 134-140.

71. Michelotti, E.F., Michelotti, G.A., Aronsohn, A.I. and Levens, D. (1996) Heterogeneous nuclear ribonucleoprotein K is a transcription factor. Mol Cell Biol. 16, 2350-2360.

72. Ostrowski, J., Van Seuningen, I., Seger, R., Rauch, C.T., Sleath, P.R., McMullen, B.A. and Bomsztyk, K. (1994) Purification, cloning, and expression of a murine phosphoprotein that binds the kappa B motif in vitro identifies it as the homolog of the human heterogeneous nuclear ribonucleoprotein $\mathrm{K}$ protein. Description of a novel DNA-dependent phosphorylation process. J Biol Chem. 269, 17626-17634.

73. Bomsztyk, K., Denisenko, O. and Ostrowski, J. (2004) hnRNP K: one protein multiple processes. Bioessays. 26, 629-638.

74. Van Seuningen, I., Ostrowski, J., Bustelo, X.R., Sleath, P.R. and Bomsztyk, K. (1995) The K protein domain that recruits the interleukin 1-responsive K protein kinase lies adjacent to a cluster of c-Src and Vav SH3-binding sites. 
Implications that K protein acts as a docking platform. J Biol Chem. 270, 26976-26985.

75. Bomsztyk, K., Van Seuningen, I., Suzuki, H., Denisenko, O. and Ostrowski, J. (1997) Diverse molecular interactions of the hnRNP K protein. FEBS Lett. 403, 113-115.

76. Habelhah, H., Shah, K., Huang, L., Ostareck-Lederer, A., Burlingame, A.L., Shokat, K.M., Hentze, M.W. and Ronai, Z. (2001) ERK phosphorylation drives cytoplasmic accumulation of hnRNP-K and inhibition of mRNA translation. Nat Cell Biol. 3, 325-330.

77. Chang, Y.I., Hsu, S.C., Chau, G.Y., Huang, C.Y., Sung, J.S., Hua, W.K. and Lin, W.J. (2011) Identification of the methylation preference region in heterogeneous nuclear ribonucleoprotein $\mathrm{K}$ by protein arginine methyltransferase 1 and its implication in regulating nuclear/cytoplasmic distribution. Biochem Biophys Res Commun. 404, 865-869.

78. Li, T., Evdokimov, E., Shen, R.F., Chao, C.C., Tekle, E., Wang, T., Stadtman, E.R., Yang, D.C. and Chock, P.B. (2004) Sumoylation of heterogeneous nuclear ribonucleoproteins, zinc finger proteins, and nuclear pore complex proteins: a proteomic analysis. Proc Natl Acad Sci U S A. 101, 8551-8556.

79. Ostareck-Lederer, A., Ostareck, D.H., Cans, C., Neubauer, G., Bomsztyk, K., Superti-Furga, G. and Hentze, M.W. (2002) c-Src-mediated phosphorylation of hnRNP K drives translational activation of specifically silenced mRNAs. Mol Cell Biol. 22, 4535-4543. 
80. Ostrowski, J., Schullery, D.S., Denisenko, O.N., Higaki, Y., Watts, J., Aebersold, R., Stempka, L., Gschwendt, M. and Bomsztyk, K. (2000) Role of tyrosine phosphorylation in the regulation of the interaction of heterogenous nuclear ribonucleoprotein K protein with its protein and RNA partners. J Biol Chem. 275, 3619-3628.

81. Schullery, D.S., Ostrowski, J., Denisenko, O.N., Stempka, L., Shnyreva, M., Suzuki, H., Gschwendt, M. and Bomsztyk, K. (1999) Regulated interaction of protein kinase Cdelta with the heterogeneous nuclear ribonucleoprotein $\mathrm{K}$ protein. J Biol Chem. 274, 15101-15109.

82. Ostareck-Lederer, A., Ostareck, D.H., Rucknagel, K.P., Schierhorn, A., Moritz, B., Huttelmaier, S., Flach, N., Handoko, L. and Wahle, E. (2006) Asymmetric arginine dimethylation of heterogeneous nuclear ribonucleoprotein $\mathrm{K}$ by protein-arginine methyltransferase 1 inhibits its interaction with c-Src. J Biol Chem. 281, 11115-11125.

83. Ong, S.E., Mittler, G. and Mann, M. (2004) Identifying and quantifying in vivo methylation sites by heavy methyl SILAC. Nat Methods. 1, 119-126.

84. Chiou, Y.Y., Lin, W.J., Fu, S.L. and Lin, C.H. (2007) Direct mass-spectrometric identification of Arg296 and Arg299 as the methylation sites of hnRNP K protein for methyltransferase PRMT1. Protein J. 26, 87-93.

85. Pelisch, F., Pozzi, B., Risso, G., Munoz, M.J. and Srebrow, A. (2012) DNA damage-induced heterogeneous nuclear ribonucleoprotein K sumoylation regulates p53 transcriptional activation. J Biol Chem. 287, 30789-30799. 
86. Moumen, A., Masterson, P., O'Connor, M.J. and Jackson, S.P. (2005) hnRNP K: an HDM2 target and transcriptional coactivator of p53 in response to DNA damage. Cell. 123, 1065-1078.

87. Vazquez, A., Bond, E.E., Levine, A.J. and Bond, G.L. (2008) The genetics of the p53 pathway, apoptosis and cancer therapy. Nat Rev Drug Discov. 7, 979987.

88. Riley, T., Sontag, E., Chen, P. and Levine, A. (2008) Transcriptional control of human p53-regulated genes. Nat Rev Mol Cell Biol. 9, 402-412.

89. Chen, Y., Zhou, X., Liu, N., Wang, C., Zhang, L., Mo, W. and Hu, G. (2008) Arginine methylation of hnRNP K enhances p53 transcriptional activity. FEBS Lett. 582, 1761-1765.

90. Lee, S.W., Lee, M.H., Park, J.H., Kang, S.H., Yoo, H.M., Ka, S.H., Oh, Y.M., Jeon, Y.J. and Chung, C.H. (2012) SUMOylation of hnRNP-K is required for p53mediated cell-cycle arrest in response to DNA damage. EMBO J. 31, 44414452.

91. Dang, C.V. (2012) MYC on the path to cancer. Cell. 149, 22-35.

92. Takimoto, M., Tomonaga, T., Matunis, M., Avigan, M., Krutzsch, H., Dreyfuss, G. and Levens, D. (1993) Specific binding of heterogeneous ribonucleoprotein particle protein K to the human c-myc promoter, in vitro. J Biol Chem. 268, 18249-18258.

93. Li, H. and Liu, J. (2010) Identification of heterogeneous nuclear ribonucleoprotein $\mathrm{K}$ as a transactivator for human low density lipoprotein receptor gene transcription. J Biol Chem. 285, 17789-17797. 
94. Hsieh, T.Y., Matsumoto, M., Chou, H.C., Schneider, R., Hwang, S.B., Lee, A.S. and Lai, M.M. (1998) Hepatitis C virus core protein interacts with heterogeneous nuclear ribonucleoprotein K. J Biol Chem. 273, 17651-17659.

95. Wei, C.C., Zhang, S.L., Chen, Y.W., Guo, D.F., Ingelfinger, J.R., Bomsztyk, K. and Chan, J.S. (2006) Heterogeneous nuclear ribonucleoprotein K modulates angiotensinogen gene expression in kidney cells. J Biol Chem. 281, 2534425355.

96. Condeelis, J. (1995) Elongation factor 1 alpha, translation and the cytoskeleton. Trends Biochem Sci. 20, 169-170.

97. Raught, B. and Gingras, A.C. (1999) eIF4E activity is regulated at multiple levels. Int J Biochem Cell Biol. 31, 43-57.

98. Lynch, M., Chen, L., Ravitz, M.J., Mehtani, S., Korenblat, K., Pazin, M.J. and Schmidt, E.V. (2005) hnRNP K binds a core polypyrimidine element in the eukaryotic translation initiation factor 4E (eIF4E) promoter, and its regulation of eIF4E contributes to neoplastic transformation. Mol Cell Biol. 25, 6436-6453.

99. Ostareck, D.H., Ostareck-Lederer, A., Wilm, M., Thiele, B.J., Mann, M. and Hentze, M.W. (1997) mRNA silencing in erythroid differentiation: hnRNP K and hnRNP E1 regulate 15-lipoxygenase translation from the 3' end. Cell. 89, 597-606.

100. Ostareck, D.H., Ostareck-Lederer, A., Shatsky, I.N. and Hentze, M.W. (2001) Lipoxygenase mRNA silencing in erythroid differentiation: The 3'UTR 
regulatory complex controls 60S ribosomal subunit joining. Cell. 104, 281290.

101. Shnyreva, M., Schullery, D.S., Suzuki, H., Higaki, Y. and Bomsztyk, K. (2000) Interaction of two multifunctional proteins. Heterogeneous nuclear ribonucleoprotein K and Y-box-binding protein. J Biol Chem. 275, 1549815503.

102. Mikula, M., Dzwonek, A., Karczmarski, J., Rubel, T., Dadlez, M., Wyrwicz, L.S., Bomsztyk, K. and Ostrowski, J. (2006) Landscape of the hnRNP K proteinprotein interactome. Proteomics. 6, 2395-2406.

103. Expert-Bezancon, A., Le Caer, J.P. and Marie, J. (2002) Heterogeneous nuclear ribonucleoprotein (hnRNP) K is a component of an intronic splicing enhancer complex that activates the splicing of the alternative exon $6 \mathrm{~A}$ from chicken beta-tropomyosin pre-mRNA. J Biol Chem. 277, 16614-16623.

104. Revil, T., Pelletier, J., Toutant, J., Cloutier, A. and Chabot, B. (2009) Heterogeneous nuclear ribonucleoprotein $\mathrm{K}$ represses the production of proapoptotic Bcl-xS splice isoform. J Biol Chem. 284, 21458-21467.

105. Boise, L.H., Gonzalez-Garcia, M., Postema, C.E., Ding, L., Lindsten, T., Turka, L.A., Mao, X., Nunez, G. and Thompson, C.B. (1993) bcl-x, a bcl-2-related gene that functions as a dominant regulator of apoptotic cell death. Cell. 74, 597608.

106. Johansson, J.U., Ericsson, J., Janson, J., Beraki, S., Stanic, D., Mandic, S.A., Wikstrom, M.A., Hokfelt, T., Ogren, S.O., Rozell, B. et al. (2008) An ancient 
duplication of exon 5 in the Snap25 gene is required for complex neuronal development/function. PLoS Genet. 4, e1000278.

107. Bark, C., Bellinger, F.P., Kaushal, A., Mathews, J.R., Partridge, L.D. and Wilson, M.C. (2004) Developmentally regulated switch in alternatively spliced SNAP25 isoforms alters facilitation of synaptic transmission. J Neurosci. 24, 87968805.

108. Cao, W., Razanau, A., Feng, D., Lobo, V.G. and Xie, J. (2012) Control of alternative splicing by forskolin through hnRNP K during neuronal differentiation. Nucleic Acids Res. 40, 8059-8071.

109. Hui, J., Stangl, K., Lane, W.S. and Bindereif, A. (2003) HnRNP L stimulates splicing of the eNOS gene by binding to variable-length CA repeats. Nat Struct Biol. 10, 33-37.

110. Goehe, R.W., Shultz, J.C., Murudkar, C., Usanovic, S., Lamour, N.F., Massey, D.H., Zhang, L., Camidge, D.R., Shay, J.W., Minna, J.D. et al. (2010) hnRNP L regulates the tumorigenic capacity of lung cancer xenografts in mice via caspase-9 pre-mRNA processing. J Clin Invest. 120, 3923-3939.

111. Vu, N.T., Park, M.A., Shultz, J.C., Goehe, R.W., Hoeferlin, L.A., Shultz, M.D., Smith, S.A., Lynch, K.W. and Chalfant, C.E. (2013) hnRNP U enhances caspase9 splicing and is modulated by AKT-dependent phosphorylation of hnRNP L. J Biol Chem.

112. Liu, G., Razanau, A., Hai, Y., Yu, J., Sohail, M., Lobo, V.G., Chu, J., Kung, S.K. and Xie, J. (2012) A conserved serine of heterogeneous nuclear ribonucleoprotein 
L (hnRNP L) mediates depolarization-regulated alternative splicing of potassium channels. J Biol Chem. 287, 22709-22716.

113. Hahm, B., Kim, Y.K., Kim, J.H., Kim, T.Y. and Jang, S.K. (1998) Heterogeneous nuclear ribonucleoprotein $\mathrm{L}$ interacts with the 3 ' border of the internal ribosomal entry site of hepatitis C virus. J Virol. 72, 8782-8788.

114. Hwang, B., Lim, J.H., Hahm, B., Jang, S.K. and Lee, S.W. (2009) hnRNP L is required for the translation mediated by HCV IRES. Biochem Biophys Res Commun. 378, 584-588.

115. Majumder, M., Yaman, I., Gaccioli, F., Zeenko, V.V., Wang, C., Caprara, M.G., Venema, R.C., Komar, A.A., Snider, M.D. and Hatzoglou, M. (2009) The hnRNAbinding proteins hnRNP L and PTB are required for efficient translation of the Cat-1 arginine/lysine transporter mRNA during amino acid starvation. Mol Cell Biol. 29, 2899-2912.

116. Lynch, K.W. and Weiss, A. (2000) A model system for activation-induced alternative splicing of CD45 pre-mRNA in T cells implicates protein kinase $\mathrm{C}$ and Ras. Mol Cell Biol. 20, 70-80.

117. Trowbridge, I.S. and Thomas, M.L. (1994) CD45: an emerging role as a protein tyrosine phosphatase required for lymphocyte activation and development. Annu Rev Immunol. 12, 85-116.

118. Rothrock, C.R., House, A.E. and Lynch, K.W. (2005) HnRNP L represses exon splicing via a regulated exonic splicing silencer. EMBO J. 24, 2792-2802. 
119. Chiou, N.T., Shankarling, G. and Lynch, K.W. (2013) HnRNP L and HnRNP A1 Induce Extended U1 snRNA Interactions with an Exon to Repress Spliceosome Assembly. Mol Cell.

120. Hung, L.H., Heiner, M., Hui, J., Schreiner, S., Benes, V. and Bindereif, A. (2008) Diverse roles of hnRNP L in mammalian mRNA processing: a combined microarray and RNAi analysis. RNA. 14, 284-296.

121. Preussner, M., Schreiner, S., Hung, L.H., Porstner, M., Jack, H.M., Benes, V., Ratsch, G. and Bindereif, A. (2012) HnRNP L and L-like cooperate in multipleexon regulation of CD45 alternative splicing. Nucleic Acids Res. 40, 56665678.

122. Yu, J., Hai, Y., Liu, G., Fang, T., Kung, S.K. and Xie, J. (2009) The heterogeneous nuclear ribonucleoprotein $\mathrm{L}$ is an essential component in the $\mathrm{Ca} 2+/$ calmodulin-dependent protein kinase IV-regulated alternative splicing through cytidine-adenosine repeats. J Biol Chem. 284, 1505-1513.

123. Soengas, M.S., Alarcon, R.M., Yoshida, H., Giaccia, A.J., Hakem, R., Mak, T.W. and Lowe, S.W. (1999) Apaf-1 and caspase-9 in p53-dependent apoptosis and tumor inhibition. Science. 284, 156-159.

124. Seol, D.W. and Billiar, T.R. (1999) A caspase-9 variant missing the catalytic site is an endogenous inhibitor of apoptosis. J Biol Chem. 274, 2072-2076.

125. Srinivasula, S.M., Ahmad, M., Guo, Y., Zhan, Y., Lazebnik, Y., FernandesAlnemri, T. and Alnemri, E.S. (1999) Identification of an endogenous dominant-negative short isoform of caspase- 9 that can regulate apoptosis. Cancer Res. 59, 999-1002. 
126. Landsberg, M.J., Moran-Jones, K. and Smith, R. (2006) Molecular recognition of an RNA trafficking element by heterogeneous nuclear ribonucleoprotein A2. Biochemistry. 45, 3943-3951.

127. Burd, C.G., Swanson, M.S., Gorlach, M. and Dreyfuss, G. (1989) Primary structures of the heterogeneous nuclear ribonucleoprotein A2, B1, and C2 proteins: a diversity of RNA binding proteins is generated by small peptide inserts. Proc Natl Acad Sci U S A. 86, 9788-9792.

128. Hutchison, S., LeBel, C., Blanchette, M. and Chabot, B. (2002) Distinct sets of adjacent heterogeneous nuclear ribonucleoprotein (hnRNP) A1/A2 binding sites control 5' splice site selection in the hnRNP A1 mRNA precursor. J Biol Chem. 277, 29745-29752.

129. Burd, C.G. and Dreyfuss, G. (1994) RNA binding specificity of hnRNP A1: significance of hnRNP A1 high-affinity binding sites in pre-mRNA splicing. EMBO J. 13, 1197-1204.

130. Guha, M., Tang, W., Sondheimer, N. and Avadhani, N.G. (2010) Role of calcineurin, hnRNPA2 and Akt in mitochondrial respiratory stress-mediated transcription activation of nuclear gene targets. Biochim Biophys Acta. 1797, 1055-1065.

131. Caputi, M., Mayeda, A., Krainer, A.R. and Zahler, A.M. (1999) hnRNP A/B proteins are required for inhibition of HIV-1 pre-mRNA splicing. EMBO J. 18, 4060-4067. 
132. Starita, L.M. and Parvin, J.D. (2003) The multiple nuclear functions of BRCA1: transcription, ubiquitination and DNA repair. Curr Opin Cell Biol. 15, 345350.

133. Friedenson, B. (2007) The BRCA1/2 pathway prevents hematologic cancers in addition to breast and ovarian cancers. BMC Cancer. 7, 152.

134. Mazoyer, S., Puget, N., Perrin-Vidoz, L., Lynch, H.T., Serova-Sinilnikova, O.M. and Lenoir, G.M. (1998) A BRCA1 nonsense mutation causes exon skipping. Am J Hum Genet. 62, 713-715.

135. Goina, E., Skoko, N. and Pagani, F. (2008) Binding of DAZAP1 and hnRNPA1/A2 to an exonic splicing silencer in a natural BRCA1 exon 18 mutant. Mol Cell Biol. 28, 3850-3860.

136. Christofk, H.R., Vander Heiden, M.G., Harris, M.H., Ramanathan, A., Gerszten, R.E., Wei, R., Fleming, M.D., Schreiber, S.L. and Cantley, L.C. (2008) The M2 splice isoform of pyruvate kinase is important for cancer metabolism and tumour growth. Nature. 452, 230-233.

137. Christofk, H.R., Vander Heiden, M.G., Wu, N., Asara, J.M. and Cantley, L.C. (2008) Pyruvate kinase M2 is a phosphotyrosine-binding protein. Nature. 452, 181-186.

138. Jurica, M.S., Mesecar, A., Heath, P.J., Shi, W., Nowak, T. and Stoddard, B.L. (1998) The allosteric regulation of pyruvate kinase by fructose-1,6bisphosphate. Structure. 6, 195-210.

139. Clower, C.V., Chatterjee, D., Wang, Z., Cantley, L.C., Vander Heiden, M.G. and Krainer, A.R. (2010) The alternative splicing repressors hnRNP A1/A2 and 
PTB influence pyruvate kinase isoform expression and cell metabolism. Proc Natl Acad Sci U S A. 107, 1894-1899.

140. Fahling, M., Mrowka, R., Steege, A., Martinka, P., Persson, P.B. and Thiele, B.J. (2006) Heterogeneous nuclear ribonucleoprotein-A2/B1 modulate collagen prolyl 4-hydroxylase, alpha (I) mRNA stability. J Biol Chem. 281, 9279-9286.

141. Griffin, M.E., Hamilton, B.J., Roy, K.M., Du, M., Willson, A.M., Keenan, B.J., Wang, X.W. and Nichols, R.C. (2004) Post-transcriptional regulation of glucose transporter-1 by an AU-rich element in the 3'UTR and by hnRNP A2. Biochem Biophys Res Commun. 318, 977-982.

142. Kosturko, L.D., Maggipinto, M.J., Korza, G., Lee, J.W., Carson, J.H. and Barbarese, E. (2006) Heterogeneous nuclear ribonucleoprotein (hnRNP) E1 binds to hnRNP A2 and inhibits translation of A2 response element mRNAs. Mol Biol Cell. 17, 3521-3533.

143. Khateb, S., Weisman-Shomer, P., Hershco-Shani, I., Ludwig, A.L. and Fry, M. (2007) The tetraplex (CGG)n destabilizing proteins hnRNP A2 and CBF-A enhance the in vivo translation of fragile X premutation mRNA. Nucleic Acids Res. 35, 5775-5788.

144. Guha, M., Fang, J.K., Monks, R., Birnbaum, M.J. and Avadhani, N.G. (2010) Activation of Akt is essential for the propagation of mitochondrial respiratory stress signaling and activation of the transcriptional coactivator heterogeneous ribonucleoprotein A2. Mol Biol Cell. 21, 3578-3589.

145. Guha, M., Pan, H., Fang, J.K. and Avadhani, N.G. (2009) Heterogeneous nuclear ribonucleoprotein $\mathrm{A} 2$ is a common transcriptional coactivator in the nuclear 
transcription response to mitochondrial respiratory stress. Mol Biol Cell. 20, 4107-4119.

146. Rognstad, R. and Katz, J. (1979) Effects of 2,4-dihydroxybutyrate on lipogenesis in rat hepatocytes. J Biol Chem. 254, 11969-11972.

147. Longo, L., Vanegas, O.C., Patel, M., Rosti, V., Li, H., Waka, J., Merghoub, T., Pandolfi, P.P., Notaro, R., Manova, K. et al. (2002) Maternally transmitted severe glucose 6-phosphate dehydrogenase deficiency is an embryonic lethal. EMBO J. 21, 4229-4239.

148. Pandolfi, P.P., Sonati, F., Rivi, R., Mason, P., Grosveld, F. and Luzzatto, L. (1995) Targeted disruption of the housekeeping gene encoding glucose 6phosphate dehydrogenase (G6PD): G6PD is dispensable for pentose synthesis but essential for defense against oxidative stress. EMBO J. 14, 5209-5215.

149. Xu, Y., Zhang, Z., Hu, J., Stillman, I.E., Leopold, J.A., Handy, D.E., Loscalzo, J. and Stanton, R.C. (2010) Glucose-6-phosphate dehydrogenase-deficient mice have increased renal oxidative stress and increased albuminuria. FASEB J. 24, 609-616.

150. Cappellini, M.D. and Fiorelli, G. (2008) Glucose-6-phosphate dehydrogenase deficiency. Lancet. 371, 64-74.

151. Yoshimoto, K., Nakamura, T., Niimi, S. and Ichihara, A. (1983) Hormonal regulation of translatable mRNA of glucose-6-phosphate dehydrogenase in primary cultures of adult rat hepatocytes. Biochim Biophys Acta. 741, 143149. 
152. Nakamura, T., Yoshimoto, K., Aoyama, K. and Ichihara, A. (1982) Hormonal regulations of glucose-6-phosphate dehydrogenase and lipogenesis in primary cultures of rat hepatocytes. J Biochem. 91, 681-693.

153. Tao, H., Szeszel-Fedorowicz, W., Amir-Ahmady, B., Gibson, M.A., Stabile, L.P. and Salati, L.M. (2002) Inhibition of the splicing of glucose-6-phosphate dehydrogenase precursor mRNA by polyunsaturated fatty acids. J Biol Chem. 277, 31270-31278.

154. Stabile, L.P., Klautky, S.A., Minor, S.M. and Salati, L.M. (1998) Polyunsaturated fatty acids inhibit the expression of the glucose-6-phosphate dehydrogenase gene in primary rat hepatocytes by a nuclear posttranscriptional mechanism. J Lipid Res. 39, 1951-1963.

155. Talukdar, I., Szeszel-Fedorowicz, W. and Salati, L.M. (2005) Arachidonic acid inhibits the insulin induction of glucose-6-phosphate dehydrogenase via p38 MAP kinase. J Biol Chem. 280, 40660-40667.

156. Szeszel-Fedorowicz, W., Talukdar, I., Griffith, B.N., Walsh, C.M. and Salati, L.M. (2006) An exonic splicing silencer is involved in the regulated splicing of glucose 6-phosphate dehydrogenase mRNA. J Biol Chem. 281, 34146-34158.

157. Walsh, C.M., Suchanek, A.L., Cyphert, T.J., Kohan, A.B., Szeszel-Fedorowicz, W. and Salati, L.M. (2013) Serine Arginine Splicing Factor 3 (SRSF3) is involved in enhanced splicing of glucose-6-phosphate dehydrogenase (G6PD) RNA in response to nutrients and hormones in liver. J Biol Chem. 288, 2816-2828. 


\section{Chapter 2}

\section{Starvation actively inhibits splicing of glucose-6-phosphate dehydrogenase mRNA via a bifunctional ESE/ESS element bound by hnRNP K}

Cyphert, T.J. ${ }^{a}$, Suchanek, A.L. ${ }^{\mathrm{a}}$, Griffith, B.N. ${ }^{\mathrm{a} 1}$ and Salati, L.M. ${ }^{\mathrm{a}^{*}}$

aDepartment of Biochemistry, West Virginia University, Morgantown, West Virginia, 26506, USA

* To whom correspondence should be addressed. Tel: 1-304-293-7759; Fax: 1-304293-6846; Email: Imsalati@hsc.wvu.edu

1Present address: Department of Biomedical Sciences, West Virginia School of Osteopathic Medicine, Lewisburg, WV 24901 


\section{ABSTRACT}

Regulated expression of glucose-6-phosphate dehydrogenase (G6PD) is due to changes in the rate of pre-mRNA splicing and not changes in its transcription. Starvation alters pre-mRNA splicing by decreasing the rate of intron removal, leading to intron retention and a decrease in the accumulation of mature mRNA. A regulatory element within exon 12 of G6PD pre-mRNA controls splicing efficiency. Starvation caused an increase in the expression of heterogeneous nuclear ribonucleoprotein (hnRNP) K protein and this increase coincided with the increase in the binding of hnRNP $\mathrm{K}$ to the regulatory element and a decrease in the expression of G6PD mRNA. HnRNP K bound to two C-rich motifs forming an ESS within exon 12. Overexpression of hnRNP K decreased the splicing and expression of G6PD mRNA, while siRNA-mediated depletion of hnRNP K caused an increase in the splicing and expression of G6PD mRNA. Binding of hnRNP K to the regulatory element was enhanced in vivo by starvation coinciding with a decrease in G6PD mRNA. HnRNP K binding to the C-rich motifs blocked binding of serine-arginine rich, splicing factor 3 (SRSF3), a splicing enhancer. Thus hnRNP K is a nutrient regulated splicing factor responsible for the inhibition of the splicing of G6PD during starvation.

\section{KEYWORDS}

mRNA splicing, hnRNP K, SRSF3, nutrient regulation, liver 


\section{INTRODUCTION}

Maintenance of energy homeostasis throughout the body is achieved by balancing the use of dietary energy to meet immediate needs and the storage of excess energy for use in the absence of dietary intake. A key pathway involved in this process is lipogenesis, by which excess energy in the form of carbohydrate is converted to triacylglycerol for storage in adipose tissue and as such this pathway is highly active and regulated in adipose tissue and liver. The enzymes involved in lipogenesis, ATP-citrate lyase, malic enzyme, fatty acid synthase, glucose-6phosphate dehydrogenase (G6PD) ${ }^{2}$, and acetyl-CoA carboxylase increase in amount during consumption of high-carbohydrate diets in order to increase a cell's capacity for lipogenesis; however, in response to starvation the amount of these proteins is decreased [1]. Dietary regulation of these proteins is controlled by both dietary nutrients and by changes in the amounts of key regulatory hormones such as insulin and glucagon. Regulation of most of the lipogenic enzymes is primarily through changes the transcriptional activity of their genes [1]. G6PD is an exception in this family. Nutrient and hormonal regulation of G6PD expression is exclusively by changes in the degree of splicing of its mRNA [2, 3].

\footnotetext{
${ }^{2} \mathrm{CMV}$, cytomegalovirus; EMSA, electrophoretic mobility shift assay; ESE, exonic splicing enhancer; ESS, exonic splicing silencer; G6PD, glucose-6-phosphate dehydrogenase; GAPDH, glyceraldehyde-3-phosphate dehydrogenase; GST, glutathione S-transferase; $\mathrm{HEX}^{\mathrm{TM}}$, hexachlorofluorescein; hnRNP, heterogeneous nuclear ribonucleoprotein; RFP, red fluorescent protein; RIP, RNA immunoprecipitation; SRSF3, serine-arginine rich, splicing factor 3
} 
RNA splicing is an essential step in gene expression that joins together the exons in the nascent transcript [4]. Splicing is a highly regulated process such that a single transcript can generate multiple mature mRNA via a process called alternative splicing. Evidence from global RNA sequencing indicates that alternative splicing is widespread and crucial for the proper function and fate of a cell [5-8]. In addition to alternative exon inclusion, the recognition and splicing of constitutive exons that are always present in the mature mRNA is regulated. Regulation of constitutive exon splicing can result in retained introns, which can trigger degradation of the mRNA presumably through nonsense-mediated decay [9]. This latter category is the type of alternative splicing that regulates expression of G6PD [3]. Alternative splicing and intron retention share regulatory mechanisms that involve the binding of splicing regulatory proteins to cis-acting elements within the mRNA. Within exons, these sequences are called exonic splicing enhancers (ESE) or exonic splicing silencers (ESS). Two protein families that include serine-arginine rich (SR) proteins and heterogeneous nuclear ribonucleoproteins (hnRNPs) are known to function as trans-acting factors, which regulate splicing through binding to the ESE and ESS elements, respectively [10-15]. As such, these proteins contain RNA recognition motifs by which they can bind to the pre-mRNA.

The mechanisms by which SR proteins and hnRNPs respond to environmental and cellular cues are only now emerging. Serine phosphorylation of 
SR proteins is a primary mechanism regulating their activity, and phosphorylation is associated with enhanced splicing of the SR protein targets [16]. In contrast, hnRNPs act both as enhancers or inhibitors of mRNA splicing as well as regulate other steps in gene expression [17-19]. Many hnRNPs can be phosphorylated, methylated on arginines and modified by sumoylation [20,21]. Thus, hnRNPs could be candidates for nutritional regulation of splicing.

The observation that nutritional status can regulate RNA splicing has widespread implications for regulation of cellular function. G6PD provides a useful model to study splicing changes that occur in response to nutritional status because this is the sole mechanism regulating the accumulation of its mRNA. In mouse liver, accumulation of spliced G6PD mRNA occurs following consumption of a high carbohydrate, low-fat diet. Conversely, the amount of mature mRNA is decreased significantly by starvation or consumption of a diet high in polyunsaturated fatty acids $[3,22,23]$. The decrease in splicing of the nascent transcript is associated with a decrease in the removal of introns surrounding exon 12 of the G6PD mRNA and G6PD pre-mRNA containing these retained introns accumulates prior to its degradation [23]. Exon 12 contains the regulatory elements that are necessary for the nutrient regulation of splicing, which include both an ESS and an ESE [3, 24]. The SR protein, SR splicing factor 3 (SRSF3) binds to the ESE within exon 12, thus increasing splicing of G6PD pre-mRNA during refeeding [24]. The increase in splicing of G6PD pre-mRNA results in accumulation of mature mRNA and ultimately 
more G6PD enzyme activity. The question remains, is inefficient splicing of exon 12 the default state to which liver reverts during starvation? In addition to SRSF3, we identified 3 members of the hnRNP family of proteins, K, L and A2/B1 that bind to this element in vitro [25]. In the present report, we test the hypothesis that hnRNP $\mathrm{K}, \mathrm{L}$ and/or A2/B1 inhibit splicing of the G6PD mRNA and are involved in the inhibition of G6PD expression during starvation. We found that expression of hnRNP K increased during starvation, which resulted in an increase in its binding to the ESS with exon 12. HnRNP K inhibited splicing of the G6PD nascent transcript as well as a splicing reporter that contains the exon 12 regulatory element. Conversely, siRNA-mediated depletion of hnRNP K resulted in increased splicing of the G6PD pre-mRNA. Finally, hnRNP K and SRSF3 bind to the same sequences within the regulatory element and do so in a mutually exclusive manner. We propose that hnRNP K is a nutrient-regulated silencer of RNA splicing.

\section{MATERIAL AND METHODS}

All animal experiments were conducted in conformity with the Public Health Service policy on Human Care and Use of Laboratory Animals, additionally the Institutional Animal Care and Use Committee of the Division of Laboratory Animal Resources at West Virginia University approved all experimental procedures.

2.1. RNA Electrophoretic Mobility Shift Assay (EMSA) 
The RNA EMSA protocol is a modification of existing methods [26, 27]. Briefly, $100 \mathrm{fmol}$ of a 5'-hexachlorofluorescein (HEX ${ }^{\mathrm{TM}}$ ) labelled-RNA probe (IDT) corresponding to nucleotides (nt) 50-84 of Exon 12 was mixed with $92 \mathrm{ng}$ of purified recombinant FLAG-tagged hnRNP K (Origene) in 1X binding buffer (10 mM Tris pH 7.3, $1 \mathrm{mM} \mathrm{MgCl}$, $20 \mathrm{mM} \mathrm{KCl}, 1 \mathrm{mM}$ DTT, $1 \mathrm{U}$ of SuperRNasin (Ambion)) plus/minus unlabeled competitor oligonucleotides (0,1 pmol, $2.5 \mathrm{pmol}, 5 \mathrm{pmol}$, $7.5 \mathrm{pmol}, 10 \mathrm{pmol}$; IDT) in a total reaction volume of $20 \mu \mathrm{L}$. The reactions were incubated for $30 \mathrm{~min}$ at room temperature. Supershift reactions received $1 \mu \mathrm{g}$ of anti-hnRNP K (3C2, Abcam) 20 min into the initial binding reaction and the reaction proceeded another $10 \mathrm{~min}$. The samples were loaded onto a pre-running 5\% native polyacrylamide gel. The gel was imaged directly on a Typhoon 9410 Imager and signals were quantified using ImageQuant TL software. RNA EMSAs involving competition between hnRNP K and SRSF3 were incubated in the conditions as previously described [24]. Purified recombinant FLAG-tagged hnRNP K (Origene) and purified recombinant glutathione S-transferase (GST) conjugated- SRSF3 (Abnova) were incubated in $1 \mathrm{X}$ binding buffer (10 mM Tris pH 7.5, $1 \mathrm{mM} \mathrm{MgCl2,100}$ $\mathrm{mM} \mathrm{KCl}, 0.1 \mathrm{mM}$ DTT, 5\% glycerol; ref. 25) in a total reaction volume of $20 \mu \mathrm{L}$ with $100 \mathrm{fmol}$ of a $5^{\prime}$-hexachlorofluorescein (HEX ${ }^{\mathrm{TM}}$ ) labelled-RNA probe (IDT) corresponding to nt 50-84 of Exon 12. Reactions were incubated and analyzed as previously described [24].

\subsection{Western analysis}


Whole cell lysates [24] and nuclear extracts [25] were prepared as described. After gel electrophoresis, the proteins were transferred to PDVF membrane (BioRad), and probed with the antibodies as indicated in the figure legends. HnRNP A2/B1, hnRNP L and hnRNP K specific antibodies (Santa Cruz Biotechnology) and btubulin antibody (Cell Signalling) were obtained from the indicated sources. Secondary antibodies were conjugated to horseradish peroxidase and the antibody interactions were detected using ECL plus (GE Healthcare) followed by visualization on film and a Typhoon 9410 Imager (GE Healthcare). Signals were quantified with ImageJ (NIH) and ImageQuant TL (Molecular Dynamics), respectively. To verify the accuracy of the protein quantitation in the nuclear extracts, the extracts were run on a polyacrylamide gel and silver stained. The overall intensity of the visualized bands was similar betweens starved and refed samples (data not shown).

\subsection{RNA isolation and measurement}

Total cellular RNA was isolated using TRI Reagent® (Molecular Research Center). The total RNA was then digested with DNase I (Turbo DNA-free, Invitrogen) according to the manufacture's protocol. Specific RNA amounts were quantified by RT-qPCR (ICYCLER, Bio-Rad) using the QuantiTect SYBR Green kit (Qiagen) and primers listed in supplemental Table 1. All reactions were carried out in duplicate and annealing temperatures for each set of primers were determined by using melting curves. The amount of each mRNA was calculated using a relative standard curve. All RNA samples were also amplified in the absence of reverse transcriptase 
to test for DNA contamination. Samples with DNA contamination were digested with DNase I a second time.

\subsection{HnRNP K overexpression and RNA reporters}

HepG2 (human hepatoma) cells were generated that stably express the RNA splicing reporters: Exon 12(+) or Exon 12(-) (Fig. 2) and were used for experiments testing the effect of overexpressing hnRNP K. The Exon 12(+) reporter contains mouse genomic DNA comprising nt 38-93 of exon 12 through the end of the G6PD gene as departed by a repetitive element, ligated to b-galactosidase and expression was driven by the CMV promoter. The cells were co-transfected with a plasmid expressing the neomycin resistance gene. Stable transformants were selected with G418 and then clonally isolated so that all cells reflect a single site of insertion of the RNA reporter. The Exon 12(-) reporter was constructed as the Exon 12(+) reporter but contains only the last $8 \mathrm{nt}$ of exon 12 to preserve the 5 ' splice site of the intron. One day after plating $2 \times 10^{5}$ cells in a 6 well plate, HepG2 cells were transfected with $3 \mu \mathrm{g}$ of an expression vector for hnRNP K (Origene) or a control plasmid that expressed red fluorescent protein (RFP; pEGFP-N1, Clontech with RFP substituted for GFP; gift of Peter Stoilov) using the Express-in transfection reagent (Thermo Scientific) in DMEM containing 10\% FBS. Total RNA and whole-cell protein extracts were collected after $48 \mathrm{~h}$. Cell lysates were prepared using RIPA buffer plus phosphatase and protease inhibitors (Thermo Scientific). The quantitation of spliced versus unspliced reporter RNA used RT-qPCR and primers that produced $218 \mathrm{bp}$ 
and 119 bp products, respectively.

To test for effects of hnRNP K on mRNA stability apart from splicing, HepG2 cells stably expressing a doxycycline inducible hnRNP K (section 2.5) were treated with doxycycline for $72 \mathrm{~h}$. During the last $24 \mathrm{~h}$ of doxycycline treatment, the cells were transiently transfected with $2 \mu \mathrm{g}$ of reporter plasmid that contains the CMV promoter, the mouse G6PD cDNA, and the entire 3'-end of the G6PD gene [23]. Transfection was performed as described above and RNA and protein extracts were prepared $24 \mathrm{~h}$ after transfection. The accumulation of mouse G6PD mRNA produced by the reporter was measured with RT-qPCR and primers to exon 13 of the mouse RNA (supplemental Table 1) that differs significantly from the endogenous human G6PD mRNA.

\subsection{Isolation of chromatin-associated RNA}

The isolation of the chromatin fraction of nuclei and of the RNA in this fraction was by an existing protocol [28]. HepG2 cells were derived that stably express hnRNP K under a doxycycline inducible promoter. Cells $\left(6.5 \mathrm{X} 10^{6}\right)$ were plated in a $150 \mathrm{~mm}$ plate with DMEM containing $10 \%$ FBS. Doxycycline $(5 \mu \mathrm{g} / \mathrm{ml})$ was added to the cells one day after plating. Wild type HepG2 cells were treated in the identical manner and were a control for non-specific effects of doxycycline. After $72 \mathrm{~h}$ with doxycycline, chromatin-associated RNA was collected. The quantitation of spliced versus unspliced RNA used RT-qPCR with primers to the 
endogenous G6PD mRNA (Fig. 3E). Primers detecting pre-mRNA retaining intron 11 produced a $156 \mathrm{bp}$ product and primers that detected pre-mRNA retaining intron 12 produced a 168 bp product (supplemental Table 1).

\subsection{SiRNA transfection}

HepG2 cells stably expressing the RNA splicing reporter Exon 12(+) or Exon 12(-) were used for siRNA depletion of hnRNPs. One day after plating, the HepG2 cells $\left(3.5 \times 10^{5}\right)$ were transfected with a mixture of 2 siRNAs (Thermo Scientific) against hnRNP K or hnRNP L (50 nM each siRNA; supplemental Table 1). Transfections were performed with TransIT-siQUEST $®$ transfection reagent (Mirus) in DMEM medium containing 10\% FBS. SiGENOME SMART non-targeting siRNA pool \#1 was used as a negative control (Thermo Scientific). Total RNA and whole-cell lysates were collected after $48 \mathrm{~h}$.

\subsection{RNA Immunoprecipitation (RIP)}

The RIP protocol is a modification of existing methods [29, 30]. For HepG2 cells, the formaldehyde crosslinking and cell lysis were performed as previously described [24]. Crosslinking was stopped by the addition of glycine to $125 \mathrm{mM}$. Following the cell lysis, lysate containing $500 \mu \mathrm{g}$ of protein was suspended in buffer (1x PBS, 2X Halt ${ }^{\mathrm{TM}}$ Protease and Phosphatase Inhibitor Cocktail and 2U/uL SUPERaseIn ${ }^{\mathrm{TM}}$ RNAse Inhibitor) and pre-cleared with protein G Dynabeads at $4^{\circ} \mathrm{C}$ for 
$2 \mathrm{~h}$ with rotation. A portion of the lysate was saved for the "input" sample. In a separate tube, protein G Dynabeads (Invitrogen) were washed twice with 1x PBS + 0.02\% Tween 20 (PBS/T). Antibodies (10 $\mu \mathrm{g}$, hnRNP K (3C2), Abcam and normal mouse IgG, Millipore) were added to the beads and incubated at room temperature for $2 \mathrm{~h}$ with rotation. The antibody-bound beads were washed three times with PBS/T and then mixed with the pre-cleared lysates. The bead/lysate mixtures were incubated overnight at $4^{\circ} \mathrm{C}$ with rotation and then washed six times with PBS/T. RNA bound to the immunoprecipitated proteins was released by treatment with proteinase K as previously described [24] and amplified by RT-qPCR using the primers in supplemental Table 1. Amplification without RT was used as a control for chromatin contamination.

For detection of hnRNP K binding to the regulatory element in whole liver, 810 week old male C57BL/6J (The Jackson Laboratory) were fasted for $18 \mathrm{~h}$ or were fasted for 18h, and then refed a low-fat, high-carbohydrate diet (Basal Mix TD.00235, Harlan Laboratories; supplemented with 1\% safflower oil) for $12 \mathrm{~h}$. The livers were removed and processed as previously described [24]. All subsequent immunoprecipitations and amplifications of bound RNA were done as described for HepG2 cells.

\subsection{Statistical Analysis}


All statistical comparisons were made using the student's t-test. Significance is defined as $\mathrm{p}<0.05$.

\section{RESULTS}

\subsection{Starvation increases hnRNP K protein levels in vivo}

To address the hypothesis that hnRNPs are starvation-induced splicing silencers, we measured the change in their expression in the livers of mice subjected to mild starvation. Starvation caused a 3-fold increase in the expression of hnRNP K protein as compared mice that were refed a high carbohydrate diet after a period of starvation (Fig. 1A). Antibodies to hnRNP L and hnRNP A2/B1 each detect 2 bands for the respective proteins. The reason for the doublet is not known. Regardless, expression of hnRNP L and A2/B1 did not change between starved and refed livers (Fig. 1B). Because hnRNP A2/B1 shuttles from the nucleus to the cytoplasm [31], we specifically measured its abundance in nuclear extracts to reflect the cellular pool in which the amount of this protein would be expected to change. Again, there was no change in the expression of hnRNP A2/B1 in the nucleus comparing the expression in 10 different mice (Fig. 1C). To control for protein quantitation, polyacrylamide gels of the nuclear extracts were silver-stained; overall protein abundance was similar between the dietary treatments. Thus abundance of hnRNP $\mathrm{K}$ is increased by a dietary paradigm that results in decreased splicing of the G6PD mRNA and decreased expression of the G6PD enzyme $[3,22,23]$. The fact that hnRNP A2/B1 does not change in abundance during starvation coupled with our 
previous data that hnRNP A2/B1 binds to multiple exons in the G6PD gene (Griffith and Salati, data not shown) argue that it does not play a major role in starvation induced silencing of G6PD expression. Thus, we have not pursued further experiments with this protein.

\subsection{SiRNA depletion of $h n R N P K$ but not $h n R N P L$ increases the splicing of G6PD}

SiRNA-mediated depletions of hnRNP K and hnRNP L were used to test their functional significance on the expression of G6PD mRNA. Two HepG2 cell lines were developed that stably expressed splicing reporters either with (+) or without (-) exon 12 ligated to the heterologous gene, $\beta$-galactosidase. The Exon $12(+)$ reporter permits the evaluation of changes in the splicing and the overall expression of the reporter mRNA driven solely by the splicing regulatory element within exon 12 and not affected by regulatory elements in other exons of the G6PD mRNA (Fig. 2A). While it only contains one of the introns surrounding exon 12, the splicing and expression of the Exon $12(+)$ reporter was regulated by insulin and fatty acids in an identical fashion to the endogenous gene following transfection into primary rat hepatocytes $[3,23]$. Knockdown of hnRNP K with siRNA resulted in a $69 \pm 1 \%$ depletion of hnRNP K protein (Fig. 2B). The depletion of hnRNP K was accompanied by a 7-fold or more increase in the amount of RNA produced by the Exon $12(+)$ reporter (Fig. 2C). This measurement does not discriminate between spliced and unspliced RNA and, thus this increase reflects primarily RNA that has been spliced, as the unspliced RNA is ultimately degraded. The overall increase in the accumulation of the reporter mRNA 
correlated with a significant increase in the amount of splicing of mRNA from the Exon $12(+)$ reporter, indicating that RNA splicing was no longer being silenced (Fig 2D). The increase in reporter RNA accumulation over and above what can be attributed to a change in splicing ratio may reflect that the less efficiently spliced RNA was being degraded in the cell without hnRNP K knockdown. HepG2 cells that stably express the Exon 12(-) reporter were used as a negative control to show that the regulatory element in exon 12 is required for this regulation. As expected, the depletion of hnRNP K did not alter the accumulation of mRNA expressed from the Exon 12(-) reporter (Fig 2E). SiRNA against hnRNP L caused a $55 \pm 6 \%$ depletion of hnRNP L but no change in the expression or splicing of the reporter RNA (Fig. 2 F-H). Depletion of hnRNP L to amounts greater than this compromised cellular viability. The absence of a change in hnRNP L amount by nutritional status and the lack of an effect of hnRNP L depletion on G6PD splicing suggest that hnRNP L per se is not a required splicing regulator albeit it may play a regulatory role in combination of that provided by hnRNP K. These data support a hypothesis whereby hnRNP K inhibits splicing of G6PD mRNA and that the exon 12 regulatory element is involved in this response.

\subsection{Overexpression of $h n R N P K$ decreases the splicing of G6PD $m R N A$}

A gain-of-function approach was used to test if hnRNP K inhibits splicing of G6PD mRNA in cells. Overexpression of hnRNP $\mathrm{K}$ was performed in the HepG2 cells that stably express the G6PD reporters, Exon 12(+) and Exon 12(-) (Fig. 2A). Transfection of HepG2 cells with a vector that results in expression of FLAG-hnRNP 
$\mathrm{K}$ caused a $53 \pm 4 \%$ increase in hnRNP K protein over endogenous levels (Fig. 3A).

The increase in hnRNP K protein levels caused a $60 \%$ decrease in the expression of mRNA from the Exon 12(+) reporter as compared to control cells that were transfected with a vector expressing an unrelated protein, RFP (Fig. 3B). To test for changes in splicing that could explain the decrease in expression of mRNA from the Exon $12(+)$ reporter, primers were designed that would amplify exon 12 , intron 12 , and exon 13 (Fig. 2A, black arrows). Amplification of the mRNA by RT-PCR with these primers results in 2 products representing pre-mRNA and spliced mRNA. After ectopic expression of hnRNP K, the extent of splicing of mRNA from the Exon $12(+)$ reporter decreased $80 \%$ when compared to control cells transfected with the vector expressing RFP (Fig. 3C). Overexpression of hnRNP K in HepG2 cells that express the Exon 12(-) reporter did not alter the expression of Exon 12(-) reporter mRNA (Fig. 3D). Thus, even small increases in hnRNP K can inhibit splicing and the regulatory element within exon 12 is involved in the inhibition of splicing by hnRNP K.

We next asked if overexpression of hnRNP K could decrease splicing of the endogenous G6PD gene. A clonal derivative of HepG2 cells was developed that ectopically expresses hnRNP K under the control of a doxycycline inducible promoter. Incubation of the HepG2 cells with doxycycline caused a $40 \pm 4 \%$ increase in the expression of hnRNP K (Fig. 3E). Splicing of the endogenous mRNA could not be measured in total RNA isolates. Thus, chromatin associated RNA was isolated to enrich the samples in newly transcribed RNA. RT-PCR and primers that 
resulted in amplification across the exon-intron boundaries surrounding exon 12 was used to measure the amount of endogenous G6PD pre-mRNA. Following the induction of hnRNP K expression, G6PD mRNA retaining intron 11 and intron 12 increased by 2-fold or more compared to the clonal HepG2 cells without doxycycline treatment or wild type HepG2 cells treated with doxycycline (Fig. 3F). The presence of these retained introns indicates a decrease in splicing efficiency.

A final possibility is that hnRNP $\mathrm{K}$ action involves stabilization of the mRNA and this could confound the interpretation of splicing data. To test for mRNA stabilization apart from splicing, the HepG2 cells were induced to express hnRNP K by doxycycline treatment. The cells were transfected with an RNA reporter that contained the G6PD cDNA as well as the G6PD 3'-UTR through the end of the gene. As stability elements can be within 3'-UTR, this plasmid would contain any such potential elements; however, the plasmid does not have introns from the G6PD gene and thus would not undergo exon 12-directed splicing. Following doxycycline treatment, FLAG-hnRNP K expression was increased $136 \pm 4$ - fold ( $n=5$; blot not shown), but expression of mRNA from the cDNA reporter was not changed (Fig. 3G). Thus, hnRNP K does not regulate stability of mRNA containing exon 12 . Together, these data demonstrate that hnRNP K is involved in the inhibition of splicing of G6PD mRNA.

3.4. HnRNP $K$ binds to the exon 12 regulatory element in cells 
Our previously reported RNA affinity assays demonstrated that hnRNP K can bind to the splicing regulatory element in vitro [25]. To determine if hnRNP K binds to the regulatory element in intact cells, we subjected the cells to chemical crosslinking and immunoprecipitated hnRNP K. RNA crosslinked to hnRNP K was detected by RT-qPCR using primers that amplify exon 12 RNA produced by the Exon $12(+)$ reporter. Because the reporter contains mouse sequences, reporter RNA can be amplified without interference of the endogenous gene. In HepG2 cells expressing the Exon $12(+)$ reporter, hnRNP $\mathrm{K}$ binding to the regulatory element was enriched 14-fold or more as compared to the IgG control (Fig. 4A). This result was not due to incompletely fragmented RNA, as primers to the $\beta$-galactosidase portion of the mRNA did not amplify RNA in the immunoprecipitate. Thus hnRNP K is binding to the exon 12 regulatory element in intact cells.

3.5. Starvation enhances the binding of $h n R N P K$ to the splicing regulatory element in vivo

In intact animals, starvation inhibits G6PD splicing and causes retention of introns surrounding exon 12 [23]. To test if hnRNP K interaction with the regulatory element is regulated by nutritional status in intact liver, we performed RIP using mice that had been starved or starved and then refed a high-carbohydrate diet. The livers were subjected to chemical crosslinking and the amount of hnRNP K bound to the exon 12 regulatory element was measured by RT-qPCR. Exon 12 RNA was enriched in the hnRNP K immunoprecipitates by 23 -fold or more compared to the 
IgG control (Fig. 4B). Furthermore, starvation caused a 12.5-fold increase in hnRNP $\mathrm{K}$ bound to regulatory element compared to refed mice. Binding of hnRNP K in the livers of refed mice was barely detectable and was similar to the amounts detected following immunoprecipitation with IgG (Fig. 4B). To test if the starvation-induced increase in hnRNP K binding was specific to G6PD, RNA corresponding to glyceraldehyde-3-phosphate dehydrogenase (GAPDH) was also measured. Expression of GAPDH is not regulated by starvation and refeeding [22, 32]. Starvation did not significantly alter the presence of GAPDH mRNA in hnRNP K immunoprecipitates and enrichment relatively to $\operatorname{IgG}$ was low in both dietary conditions (Fig. 4C). Our previous data has clearly demonstrated that decreased splicing of exon 12 is the primary mechanism by which starvation decreases G6PD mRNA abundance $[3,22,23]$. In this experiment, the increase in hnRNP $\mathrm{K}$ binding correlated with a $60 \%$ decrease in the abundance of G6PD mRNA in the same livers (Fig. 4D). In summary, hnRNP K inhibits the splicing of G6PD mRNA, it binds to the regulatory element in exon 12 of this RNA, and this binding is enhanced by starvation. Together these data are consistent with the hypothesis that hnRNP K is a starvation-induced splicing silencer.

\subsection{HnRNP K binds to C-rich motifs within exon 12 of G6PD mRNA}

We have previously demonstrated the SRSF3 also binds to exon 12 of the G6PD mRNA and in contrast to hnRNP K, its binding is decreased by starvation and increased by refeeding [24]. HnRNP K is known to form complexes with other 
proteins and therefore we asked if hnRNP K per se could bind to G6PD RNA and if its binding site co-localized with the sequences required for SRSF3 binding. The splicing regulatory element in exon 12 of the G6PD mRNA encompasses nt 43-72 of the 93 nt exon and contains two C-rich sequences, which are known to be hnRNP K binding motifs $[19,33]$. A third motif is located downstream of the splicing regulatory element; thus the entire region was used in RNA EMSAs to evaluate binding of hnRNP K to exon 12 (Fig. 5A). Incubation of a HEX-labelled probe representing nt 50 to 83 and recombinant hnRNP K protein resulted in two shifted bands (Fig. 5B, lane 1). The reason for 2 bands was not clear, thus a supershift was performed to determine which band represents the hnRNP K and RNA complex. The addition of hnRNP K specific antibody resulted in a supershift of both bands suggesting that they are protein:RNA complexes although this does not rigorously eliminate probe secondary structure or a peptide from hnRNP K degradation as a cause of the lower band (Fig. 5B, lane 2). Increasing concentrations of the WT specific competitor (Fig. 5A) were able to compete for binding of hnRNP K (Fig. 5C). In contrast, mutation of all three C-rich motifs within this RNA oligonucleotide abrogated binding to hnRNP K $(92 \%$ decrease in the shifted band with the WT competitor versus a 12\% decrease for the triple mutant at 100X; Fig. 5C). To further localize the sequences involved in binding, competitions were performed with oligonucleotides containing mutations of the $\mathrm{C}$-rich motif at nt 65-68 or the C-rich motif at nt 71-73. Mutants missing only a single C-rich motif were able to reduce binding of hnRNP $\mathrm{K}$ to the HEX-labelled probe by $52 \%$ and $40 \%$ at $100 \mathrm{X}$, respectively (Fig. 5D); however, when both of these C-rich motifs were mutated, the 
oligonucleotide failed to compete for hnRNP K binding (Fig. 5E). Thus the C-rich motif downstream of the regulatory element was unable to compensate for the loss of the C-rich motifs at nt 65-68 and 71-73, which is consistent with our functional data that defined the silencing element to the nt 43-72 region of exon 12 [3]. These results indicate that hnRNP $\mathrm{K}$ binds directly to the RNA and further the region between nt 65-73 co-localizes with the sequence to which SRSF3 binds.

\subsection{HnRNP K and SRSF3 compete for binding to the exon 12 regulatory element}

SRSF3 binds to nt 62-72 of exon 12, which contains the first C-rich motif that was necessary for maximal hnRNP K binding [24]. RNA EMSAs were used to test for competition between hnRNP K and SRSF3 for binding to the regulatory element. Addition of SRSF3 to the binding reaction failed to decrease the binding of $\mathrm{K}$ to the HEX-labelled probe (Fig. 6, lanes 1 and 2). In contrast, even small amounts of hnRNP K effectively competed with SRSF3 for binding (Fig. 6, lanes 3,4 and 5). This is despite the fact that SRSF3 was present in 28 and 7-fold molar excess over hnRNP K. Thus, hnRNP K and SRSF3 binding appears to be mutually exclusive and the ability of hnRNP K to block SRSF3 binding suggests a dominant effect of hnRNP K on regulating splicing of G6PD pre-mRNA.

\section{DISCUSSION}

The starved and fed states are regulatory challenges faced by all vertebrates. The need to switch between fuel storage and use occurs on a daily basis as the 
organism responds to limited periods of food consumption such as between meals or prolonged starvation during illness or lack of food availability. We have developed a body of evidence that demonstrates that the RNA splicing machinery is an intracellular target for regulation during starvation. The G6PD gene has provided a useful tool for these studies because starvation and refeeding result in large changes in the accumulation of G6PD mRNA and do so solely by regulating the rate of splicing of the G6PD transcript [34]. During starvation, decreased splicing of exon 12 results in the retention of the surrounding introns and degradation of the transcript. A cis-acting element in exon 12 is required for regulated splicing of G6PD pre-mRNA [3]. In this report, we demonstrate that hnRNP K is a starvation-induced splicing factor that binds to this cis-acting element and inhibits splicing of the G6PD pre-mRNA.

HnRNP K binds to the regulatory element via 2 C-rich motifs (Fig. 5). These C-rich binding sites are similar to other known binding sites that have been identified for hnRNP K by SELEX. Of note, a third C-rich motif just downstream of the nt 42-73 regulatory element did not bind hnRNP K effectively. Thus, hnRNP K binding does exhibit some selectivity. In contrast to hnRNP K, hnRNPs L and A2/B1 also bound to the regulatory element in RNA affinity assays [25] but failed to show regulation of G6PD expression or selectivity in further analysis. An interaction between these proteins and hnRNP K has been demonstrated and thus their appearance in the RNA affinity assay may only occur in vitro $[35,36]$. Alternatively, they may play a role enhancing the action of hnRNP K or in combination with other splicing regulators. Nonetheless, a sharp change in splicing regulation was not seen 
with hnRNP L deletion alone to the extent observed with hnRNP K. Highlighting the role for hnRNP K in G6PD expression, an interaction between hnRNP K and the RNA was observed in both intact cells and liver tissue (Fig. 4). The binding of hnRNP K to the regulatory element in exon 12 is enhanced following starvation, and this increase in binding coincides with decreased accumulation of G6PD mRNA. In addition to the direct interaction between hnRNP $\mathrm{K}$ and the RNA, loss of function and gain of function experiments further highlight the role of hnRNP K in silencing splicing of G6PD pre-mRNA. While, hnRNP K was relatively abundant in the refed livers, our data with overexpression of hnRNP K in HepG2 cells demonstrate that even small increases in the amount of this protein in the cells, can cause changes in the splicing of G6PD mRNA (Fig. 3). Our results demonstrate that hnRNP K plays an important role in regulating splicing in response to nutritional stimuli.

The fact that expression of hnRNP K protein is increased following periods of starvation provides additional evidence for a regulatory role linking splicing changes to dietary cues. To our knowledge, this is the first evidence that hnRNP K expression is regulated by dietary changes in the liver. Nutritional status may regulate hnRNP K via the hormones, insulin and glucagon, which change in abundance between the starved and refed states. In this regard, diabetes is associated with an increase in hnRNP K expression in proximal renal tubular cells and insulin reverses this effect [37]. The regulation of hnRNP K in liver may involve a similar effect as starvation and diabetes both involve decreased insulin action. Because hnRNP K has other cellular targets such as inhibition of the production of the pro-apoptotic Bcl- $\mathrm{x}_{\mathrm{S}}$ splice isoform [38], as well as, enhancing the transcriptional 
activity of p53 $[18,39,40]$, regulation of its activity by starvation may have multiple additional targets.

The changes observed in the expression of hnRNP K protein may only be partially responsible for the increase in hnRNP $\mathrm{K}$ binding to the G6PD regulatory element and the decrease in accumulation G6PD mRNA. HnRNP K is subject to various posttranslational modifications, including phosphorylation, sumoylation and methylation, which could play a role in regulating it actions [17-19, 21, 40-42]. Preliminary studies in primary rat hepatocytes did not show a change in either serine or tyrosine phosphorylation during insulin treatment (Cyphert and Salati, unpublished). We also tested for palmitoylation of hnRNP K, but none was observed (Cyphert and Salati, unpublished). An additional possibility is the recruitment of other splicing silencers. HnRNP L also bound to the regulatory element. While its absence from the cells did not enhance G6PD expression, its role may be complimented by other splicing regulatory factors, such as the hnRNP L-like protein [27]. Establishing these mechanisms are active areas for future research.

Strong evidence exists for a model whereby regulated splicing involves a competition between hnRNP K and SRSF3 for binding to the exon 12 regulatory element. Both proteins bind between nt 63 and 73 and the binding is regulated by starvation and refeeding (Fig. 5 and ref. [24]. In contrast with hnRNP K, SRSF3 binding in vivo is enhanced by refeeding and inhibited by starvation [24]. The binding of SRSF3 to the regulatory element in intact liver coincides with an increase in the splicing of the G6PD mRNA and the regulating splicing is dependent on the 
presence of exon $12[3,23]$. These results support the concept of mutually exclusive binding of these regulatory factors as a mechanism to control splicing of the exon. This hypothesis is also consistent with the observed competition between SRSF3 and splicing silencers in the regulation of the alternative splicing of the insulin receptor [43]. With respect to G6PD, hnRNP K appears to play a dominant role inhibiting splicing. HnRNP K competes against even molar excesses of SRSF3 for binding to the regulatory element (Fig. 6). Effective competition by SRSF3 may require phosphorylation in response to stimulatory signals. G6PD expression in liver is very low until stimulated to increase by insulin or a high carbohydrate diet $[22,44]$. Competition between hnRNP K and SRSF3 may regulate G6PD expression beyond the requirements for energy homeostasis. In this regard, G6PD expression is also elevated in liver tumors as compared to normal liver tissue [45]. HnRNP K amount is decreased in tumors as compared to normal liver [45]; in contrast, SRSF3 is increased in human tumors and rat hepatoma cells and it abundance is very low in normal liver and in rat hepatocytes (Jia, 2010 and Cyphert and Salati, unpublished).

In conclusion, hnRNP K joins SRSF3 as a nutrient regulated splicing factor. In addition, it establishes a role for hnRNP K for regulation of splicing via intron retention. Nutrient regulated splicing is likely occurring with other metabolic genes and the understanding of how these inhibitory and enhancing factors interact is essential for understanding how nutrients regulate metabolic processes.

Supplementary information is available online at 


\section{ACKNOWLEDGEMENTS}

We thank Dr. Peter Stoilov for helpful discussions and critically reading the manuscript. We thank Joseph Greschner for help developing the protocols for RNA EMSA. We than Douglas Poe for help developing the immunoprecipitation protocol for hnRNP K. This work was supported by the National Institutes of Health, National Institute for Diabetes and Digestive and Kidney Diseases [DK46897 to L.M.S.] and an Institutional Development Award (IDeA) from the National Institute of General Medical Sciences [2P20RR016477-13]. Funding for open access charge: National Institutes of Health [DK46897\}.

\section{REFERENCES}

[1] F.B. Hillgartner, L.M. Salati, A.G. Goodridge, Physiological and molecular mechanisms involved in nutritional regulation of fatty acid synthesis, Physiol Rev 75 (1995) 47-76.

[2] L.M. Salati, B. Amir-Ahmady, Dietary regulation of expression of glucose-6phosphate dehydrogenase, Annu Rev Nutr 21 (2001) 121-140.

[3] W. Szeszel-Fedorowicz, I. Talukdar, B.N. Griffith, C.M. Walsh, L.M. Salati, An exonic splicing silencer is involved in the regulated splicing of glucose 6phosphate dehydrogenase mRNA, J Biol Chem 281 (2006) 34146-34158. 
[4] D.L. Black, Mechanisms of alternative pre-messenger RNA splicing, Annu Rev Biochem 72 (2003) 291-336.

[5] H. Tilgner, D.G. Knowles, R. Johnson, C.A. Davis, S. Chakrabortty, S. Djebali, J. Curado, M. Snyder, T.R. Gingeras, R. Guigo, Deep sequencing of subcellular RNA fractions shows splicing to be predominantly co-transcriptional in the human genome but inefficient for lncRNAs, Genome Res 22 (2012) 16161625.

[6] M.J. Moore, P.A. Silver, Global analysis of mRNA splicing, RNA 14 (2008) 197203.

[7] B.J. Blencowe, S. Ahmad, L.J. Lee, Current-generation high-throughput sequencing: deepening insights into mammalian transcriptomes, Genes Dev 23 (2009) 1379-1386.

[8] B.J. Blencowe, Alternative splicing: new insights from global analyses, Cell 126 (2006) 37-47.

[9] Y.F. Chang, J.S. Imam, M.F. Wilkinson, The nonsense-mediated decay RNA surveillance pathway, Annu Rev Biochem 76 (2007) 51-74.

[10] A.M. Zahler, C.K. Damgaard, J. Kjems, M. Caputi, SC35 and heterogeneous nuclear ribonucleoprotein A/B proteins bind to a juxtaposed exonic splicing enhancer/exonic splicing silencer element to regulate HIV-1 tat exon 2 splicing, J Biol Chem 279 (2004) 10077-10084.

[11] C.R. Rothrock, A.E. House, K.W. Lynch, HnRNP L represses exon splicing via a regulated exonic splicing silencer, EMBO J 24 (2005) 2792-2802. 
[12] T. Kashima, N. Rao, C.J. David, J.L. Manley, hnRNP A1 functions with specificity in repression of SMN2 exon 7 splicing, Hum Mol Genet 16 (2007) 3149-3159.

[13] C.D. Chen, R. Kobayashi, D.M. Helfman, Binding of hnRNP H to an exonic splicing silencer is involved in the regulation of alternative splicing of the rat beta-tropomyosin gene, Genes Dev 13 (1999) 593-606.

[14] S. Kondo, N. Yamamoto, T. Murakami, M. Okumura, A. Mayeda, K. Imaizumi, Tra2 beta, SF2/ASF and SRp30c modulate the function of an exonic splicing enhancer in exon 10 of tau pre-mRNA, Genes Cells 9 (2004) 121-130.

[15] B.J. Blencowe, Exonic splicing enhancers: mechanism of action, diversity and role in human genetic diseases, Trends Biochem Sci 25 (2000) 106-110.

[16] P.J. Shepard, K.J. Hertel, The SR protein family, Genome Biol 10 (2009) 242.

[17] A. Ostareck-Lederer, D.H. Ostareck, C. Cans, G. Neubauer, K. Bomsztyk, G. Superti-Furga, M.W. Hentze, c-Src-mediated phosphorylation of hnRNP K drives translational activation of specifically silenced mRNAs, Mol Cell Biol 22 (2002) 4535-4543.

[18] F. Pelisch, B. Pozzi, G. Risso, M.J. Munoz, A. Srebrow, DNA damage-induced heterogeneous nuclear ribonucleoprotein K sumoylation regulates p53 transcriptional activation, J Biol Chem 287 (2012) 30789-30799.

[19] K. Bomsztyk, O. Denisenko, J. Ostrowski, hnRNP K: one protein multiple processes, Bioessays 26 (2004) 629-638.

[20] R. Martinez-Contreras, P. Cloutier, L. Shkreta, J.F. Fisette, T. Revil, B. Chabot, hnRNP proteins and splicing control, Adv Exp Med Biol 623 (2007) 123-147. 
[21] T. Li, E. Evdokimov, R.F. Shen, C.C. Chao, E. Tekle, T. Wang, E.R. Stadtman, D.C. Yang, P.B. Chock, Sumoylation of heterogeneous nuclear ribonucleoproteins, zinc finger proteins, and nuclear pore complex proteins: a proteomic analysis, Proc Natl Acad Sci U S A 101 (2004) 8551-8556.

[22] L.P. Stabile, D.L. Hodge, S.A. Klautky, L.M. Salati, Posttranscriptional regulation of glucose-6-phosphate dehydrogenase by dietary polyunsaturated fat, Arch Biochem Biophys 332 (1996) 269-279.

[23] H. Tao, W. Szeszel-Fedorowicz, B. Amir-Ahmady, M.A. Gibson, L.P. Stabile, L.M. Salati, Inhibition of the splicing of glucose-6-phosphate dehydrogenase precursor mRNA by polyunsaturated fatty acids, J Biol Chem 277 (2002) 31270-31278.

[24] C.M. Walsh, A.L. Suchanek, T.J. Cyphert, A.B. Kohan, W. Szeszel-Fedorowicz, L.M. Salati, Serine Arginine Splicing Factor 3 (SRSF3) is involved in enhanced splicing of glucose-6-phosphate dehydrogenase (G6PD) RNA in response to nutrients and hormones in liver, J Biol Chem 288 (2013) 2816-2828.

[25] B.N. Griffith, C.M. Walsh, W. Szeszel-Fedorowicz, A.T. Timperman, L.M. Salati, Identification of hnRNPs K, L and A2/B1 as candidate proteins involved in the nutritional regulation of mRNA splicing, Biochim Biophys Acta 1759 (2006) 552-561.

[26] L.M. Hellman, M.G. Fried, Electrophoretic mobility shift assay (EMSA) for detecting protein-nucleic acid interactions, Nat Protoc 2 (2007) 1849-1861.

[27] L.B. Motta-Mena, S.A. Smith, M.J. Mallory, J. Jackson, J. Wang, K.W. Lynch, A disease-associated polymorphism alters splicing of the human CD45 
phosphatase gene by disrupting combinatorial repression by heterogeneous nuclear ribonucleoproteins (hnRNPs), J Biol Chem 286 (2011) 20043-20053.

[28] D.M. Bhatt, A. Pandya-Jones, A.J. Tong, I. Barozzi, M.M. Lissner, G. Natoli, D.L. Black, S.T. Smale, Transcript dynamics of proinflammatory genes revealed by sequence analysis of subcellular RNA fractions, Cell 150 (2012) 279-290.

[29] L.A. Selth, C. Gilbert, J.Q. Svejstrup, RNA immunoprecipitation to determine RNA-protein associations in vivo, Cold Spring Harb Protoc 2009 (2009) pdb prot5234.

[30] J. Ule, K. Jensen, A. Mele, R.B. Darnell, CLIP: a method for identifying proteinRNA interaction sites in living cells, Methods 37 (2005) 376-386.

[31] H. Cui, F. Wu, Y. Sun, G. Fan, Q. Wang, Up-regulation and subcellular localization of hnRNP A2/B1 in the development of hepatocellular carcinoma, BMC Cancer 10 (2010) 356.

[32] D.L. Hodge, L.M. Salati, Nutritional regulation of the glucose-6-phosphate dehydrogenase gene is mediated by a nuclear posttranscriptional mechanism, Arch Biochem Biophys 348 (1997) 303-312.

[33] T. Thisted, D.L. Lyakhov, S.A. Liebhaber, Optimized RNA targets of two closely related triple $\mathrm{KH}$ domain proteins, heterogeneous nuclear ribonucleoprotein $\mathrm{K}$ and alphaCP-2KL, suggest Distinct modes of RNA recognition, J Biol Chem 276 (2001) 17484-17496.

[34] B. Amir-Ahmady, L.M. Salati, Regulation of the processing of glucose-6phosphate dehydrogenase mRNA by nutritional status, J Biol Chem 276 (2001) 10514-10523. 
[35] M. Mikula, A. Dzwonek, J. Karczmarski, T. Rubel, M. Dadlez, L.S. Wyrwicz, K. Bomsztyk, J. Ostrowski, Landscape of the hnRNP K protein-protein interactome, Proteomics 6 (2006) 2395-2406.

[36] M. Shnyreva, D.S. Schullery, H. Suzuki, Y. Higaki, K. Bomsztyk, Interaction of two multifunctional proteins. Heterogeneous nuclear ribonucleoprotein $\mathrm{K}$ and Y-box-binding protein, J Biol Chem 275 (2000) 15498-15503.

[37] C.C. Wei, S.L. Zhang, Y.W. Chen, D.F. Guo, J.R. Ingelfinger, K. Bomsztyk, J.S. Chan, Heterogeneous nuclear ribonucleoprotein K modulates angiotensinogen gene expression in kidney cells, J Biol Chem 281 (2006) 25344-25355.

[38] T. Revil, J. Pelletier, J. Toutant, A. Cloutier, B. Chabot, Heterogeneous nuclear ribonucleoprotein $\mathrm{K}$ represses the production of pro-apoptotic Bcl-xS splice isoform, J Biol Chem 284 (2009) 21458-21467.

[39] A. Moumen, P. Masterson, M.J. O'Connor, S.P. Jackson, hnRNP K: an HDM2 target and transcriptional coactivator of p53 in response to DNA damage, Cell 123 (2005) 1065-1078.

[40] Y. Chen, X. Zhou, N. Liu, C. Wang, L. Zhang, W. Mo, G. Hu, Arginine methylation of hnRNP K enhances p53 transcriptional activity, FEBS Lett 582 (2008) $1761-1765$.

[41] H. Habelhah, K. Shah, L. Huang, A. Ostareck-Lederer, A.L. Burlingame, K.M. Shokat, M.W. Hentze, Z. Ronai, ERK phosphorylation drives cytoplasmic accumulation of hnRNP-K and inhibition of mRNA translation, Nat Cell Biol 3 (2001) 325-330. 
[42] A. Ostareck-Lederer, D.H. Ostareck, K.P. Rucknagel, A. Schierhorn, B. Moritz, S. Huttelmaier, N. Flach, L. Handoko, E. Wahle, Asymmetric arginine dimethylation of heterogeneous nuclear ribonucleoprotein $\mathrm{K}$ by proteinarginine methyltransferase 1 inhibits its interaction with c-Src, J Biol Chem 281 (2006) 11115-11125.

[43] S. Sen, I. Talukdar, N.J. Webster, SRp20 and CUG-BP1 modulate insulin receptor exon 11 alternative splicing, Mol Cell Biol 29 (2009) 871-880.

[44] L.P. Stabile, S.A. Klautky, S.M. Minor, L.M. Salati, Polyunsaturated fatty acids inhibit the expression of the glucose-6-phosphate dehydrogenase gene in primary rat hepatocytes by a nuclear posttranscriptional mechanism, J Lipid Res 39 (1998) 1951-1963.

[45] R. Jia, C. Li, J.P. McCoy, C.X. Deng, Z.M. Zheng, SRp20 is a proto-oncogene critical for cell proliferation and tumor induction and maintenance, Int J Biol Sci 6 (2010) 806-826.

\section{FIGURES LEGENDS}

Figure 1. Starvation causes an increase in the amount of hnRNP K protein in mice livers. Mice were either starved for $18 \mathrm{~h}$ or starved for $18 \mathrm{~h}$ and then refed a high carbohydrate diet for $12 \mathrm{~h}$ and protein extracts were made from the mouse livers as described in the materials and methods. (A) A western blot shows the amount of hnRNP K in the livers of mice. Each lane represents an individual mouse liver. Quantification of the changes in the amount of hnRNP K protein is shown. The 
amount of hnRNP K protein was normalized to the amount of $\beta$-tubulin. The data are the mean $\pm \mathrm{SE}$ of $\mathrm{n}=3$ mice per group. (B) A western blot shows the amounts of hnRNP L and A2/B1 in the livers of mice. Each lane represents an individual mouse liver. These antibodies detect 2 bands for each of these proteins. The reason for the doublet is not apparent. Quantification of the changes in the amount of hnRNP L and A2/B1 protein is shown. The amount of hnRNP L and A2/B1 protein was normalized to the amount of $\beta$-tubulin. The data are the mean \pm SE of $n=3$ mice per group. (C) Nuclear extracts were prepared from mice that were starved or starved then refed and immunoblotted for hnRNP A2/B1. Each lane represents an individual mouse liver. Quantification of the changes in the amount of hnRNP A2/B1 protein was performed on the Typhoon imager and is shown. The data are the mean \pm SE of $\mathrm{n}=4$ mice per group. S, starved; $\mathrm{R}$, refed. The “*” symbol indicated a significant difference $(\mathrm{p}<0.05)$.

Figure 2. Depletion of hnRNP K by siRNA causes an increase in the splicing of G6PD mRNA. HepG2 cells stably expressing the G6PD reporter shown in (A) were transfected with 100nM siRNA against hnRNP K, hnRNP L, or a non-targeting (NT) control. After 48 hours, RNA and protein were isolated. The Exon 12(+) reporter contains mouse genomic DNA from exon 12 (nt 37-93), intron 12, and exon 13 including the entire 3'-untranslated region (3'-UTR) of the G6PD gene ligated to $\beta$ galactosidase ( $\beta$-gal) and transcription is driven by the CMV promoter. The open arrows indicate the location of the primers used to detect overall reporter 
expression. The closed arrows represent primers used to detect the splicing of the reporter. The Exon 12(-) vector also contains mouse genomic DNA ligated to $\beta$ galactosidase but contains only the last $8 \mathrm{nt}$ of exon 12 to preserve the 5 'splice site (5'SS) of intron 12. (B) A representative immunoblot of hnRNP K depletion in HepG2 cells is shown. (C) Expression of mRNA produced by the Exon 12(+) reporter in HepG2 cells that were transfected with the indicated siRNA was measured with the primers to the $\beta$-galactosidase sequence (open arrows). The data are normalized to the amount of GAPDH mRNA. The data are the mean \pm SE of $n=6$ independent siRNA knockdowns. (D) Following knockdowns with the indicated siRNA, splicing of the reporter RNA was with the primers indicated by black arrows. The products of a representative RT-PCR are shown. Samples were also amplified without prior treatment with reverse transcriptase (RT) to test for DNA contamination. The percentage of mRNA that was spliced is calculated as the intensity of the spliced band over the combined intensities of the bands for spliced and unspliced RNA. The data represent the mean $\pm \mathrm{SE}$ of $\mathrm{n}=6$ independent siRNA transfections. (E) Expression of the Exon 12(-) reporter in HepG2 cells that were transfected with the indicated siRNAs was measured by RT-qPCR and primers to the $\beta$-galactosidase portion of the reporter RNA. The amount of reporter mRNA is expressed relative to the amount of GAPDH mRNA. Each bar represents the mean $\pm S E n=3$ independent siRNA transfections. (F-H) Knockdown of hnRNP L and measurement of Exon 12(+) reporter expression and splicing were carried out as described for hnRNP L. Each bar represents the mean \pm SE $n=4$ independent siRNA transfections. The “*” symbol indicates a significant difference $(\mathrm{p}<0.05)$. 
Figure 3. Ectopic expression of hnRNP K decreases the splicing of G6PD mRNA. HepG2 cells that stably express either the Exon $12(+)$ reporter or Exon $12(-)$ were transfected with a construct containing Myc-FLAG-tagged hnRNP K. After 48 hours, RNA and protein were isolated from the cells and the effects of ectopically expressing hnRNP K (Myc-FLAG-hnRNP K) or the control (RFP) on reporter splicing and expression were measured. (A) A representative immunoblot of the ectopic expression of Myc-FLAG-hnRNP K is shown. Ectopically expressed hnRNP K was detected with FLAG-specific antibody. An hnRNP K specific antibody was used to detect both the endogenous (lower band) and ectopically expressed (upper band) hnRNP K proteins. (B) Expression of the Exon 12(+) reporter in HepG2 cells that were transfected with the indicated vectors was measured by RT-qPCR and primers to the $\beta$-galactosidase portion of the RNA (see Fig. 2A). The amount of reporter mRNA is expressed relative to the amount of GAPDH mRNA, which is not regulated by these treatments. Each bar is the mean $\pm \mathrm{SE}$ of $\mathrm{n}=3$ independent transfections. (C) Splicing of the Exon 12(+) reporter was measured by RT-PCR and the primers indicated in Fig. 2A followed by separation of the products on a $2 \%$ agarose gel. A representative gel is shown. Samples were also amplified without prior treatment with reverse transcriptase (RT) to test for DNA contamination. The percentage of mRNA that was spliced is calculated as the intensity of the spliced band over the combined intensities of the bands for spliced and unspliced RNA. The data are the mean $\pm \mathrm{SE}$ of $\mathrm{n}=3$ independent hnRNP K transfections. (D) Expression of the Exon 12(-) reporter in HepG2 cells that were transfected with the indicated vectors was 
measured by RT-qPCR and primers to the $\beta$-galactosidase portion of the RNA. The amount of reporter mRNA is expressed relative to the amount of GAPDH mRNA. Each bar is the mean $\pm \mathrm{SE}$ of $\mathrm{n}=3$ independent hnRNP K transfections. (E) HepG2 cells that stably express doxycycline-inducible FLAG-hnRNP K were treated with doxycycline (Dox) to increase the amount of hnRNP K protein. The arrow indicates the FLAG-tagged hnRNP K detected with the hnRNP K antibody. (F) The primers used for RT-qPCR are indicated on the gene diagram. Chromatin-associated RNA that represents newly transcribed RNA was isolated and the amount of endogenous G6PD mRNA was measured by RT-qPCR. The data are expressed as the amount of mRNA containing intron 11 (graph on left) or intron 12 (graph on right) relative to the amount of cyclophilin mRNA. The data are the mean $\pm S E$ of $n=3$ independent experiments. The "*” symbol indicates a significant difference $(p<0.05)$. The increase in hnRNP K expression by doxycycline is shown. (G) Following induction of hnRNP K expression with doxycycline (Dox), the HepG2 cells were transiently transfected with a reporter expressing the mouse G6PD cDNA as described in Materials and Methods. RNA was isolated $24 \mathrm{~h}$ later and mRNA produced by the reporter was measured by RT-pPCR and primers specific for the mouse mRNA. The data are expressed relative to the amount of GAPDH mRNA and are the mean \pm SE of $n=5$ independent transfections.

Figure 4. HnRNP K binds to exon 12 of the G6PD mRNA and in mouse liver; the binding is enhanced by starvation. (A) HepG2 cells expressing the Exon 12(+) reporter were crosslinked with formaldehyde and hnRNP K was 
immunoprecipitated from the lysates. G6PD mRNA bound to hnRNP K was measured by RT-qPCR and primers, which amplify the region of the reporter RNA from the end of $\beta$-galactosidase to the end of exon 12. Immunoprecipitation with IgG was used as a control for non-specific binding. Immunoprecipitation with hnRNP K or IgG followed by RT-qPCR of an upstream region of $\beta$-galactosidase (open arrows Fig 2A) was used as a control for non-specific pull-down of reporter RNA. The amount of RNA detected is expressed relative to input RNA in each sample. The abbreviation "ND" represents not detectable. (B) Mice were either starved for $18 \mathrm{~h}$ or starved for $18 \mathrm{~h}$ and then refed a high carbohydrate diet for $12 \mathrm{~h}$. Following the formaldehyde crosslinking of the livers, RNA bound to hnRNP K was precipitated using an antibody against hnRNP K, or IgG as a control. Equal amounts of protein from the crosslinked lysates were added to each immunoprecipitation. G6PD mRNA immunoprecipitated with hnRNP K or IgG was detected with RT-qPCR and primers nucleotides 18-89 of exon 12, which contains the regulatory element (nucleotides 43 to 72). The amount of detected RNA is expressed relative to the input RNA in each sample. The “*” symbol indicates a significant difference $(\mathrm{p}<0.05)$ between the IgG control and the hnRNP K RIP. The data are the mean \pm SE of $n=3$ mice per group. (C) GAPDH mRNA immunoprecipitated by the hnRNP K antibody was measured by RT-qPCR using primers to GAPDH (nt 2281-2348) in order to assess specificity of hnRNP K binding. Data are expressed as fold increase in enrichment relative to the amount of IgG enrichment. (D) Total RNA was isolated from a portion of liver used in the RIP analysis. G6PD mRNA was measured using RT-qPCR as previously 
described. The data are the mean $\pm \mathrm{SE}$ of $\mathrm{n}=3$ mice per group. The “*” symbol indicates a significant difference $(\mathrm{p}<0.05)$.

Figure 5. HnRNP K binds to C-rich sequences with in the regulatory element of G6PD mRNA. RNA EMSA assays were carried out using a fluorescently labelled probe, encompassing nt 50 to 83 of exon 12 and purified recombinant hnRNP K. (A) The sequence of the wild type (WT) labelled probe and the various competitor probes are shown. The boxes highlight the C-rich regions within exon 12 that have been mutated in the competitor oligonucleotides. (B) Purified hnRNP K protein was incubated with the WT labelled probe or the WT labelled probe plus an antibody specific for hnRNP K. A representative of two RNA EMSAs is shown. The asterisk represents a band of unknown origin that disappears upon supershift with hnRNP K antibody. (C) Competition for hnRNP K binding by the WT specific competitor, or the triple mutant competitor with the same results is shown. All competitor probes were added at 10X, 25X, 50X, 75X, and 100X molar excess. A representative of two RNA EMSAs is shown. (D) Competitors that contain mutations to a single C-rich motif (NT 65-68 or NT 71-73) were incubated with WT labelled probe and purified hnRNP K protein. (E) Competition for hnRNP K binding between the WT labelled probe and the double mutant competitor is shown.

Figure 6. 
Binding of hnRNP K and SRSF3 to the regulatory element is mutually exclusive. RNA EMSA assays were carried out using the fluorescently labelled probe, encompassing nt 50 to 83 of exon 12 (Fig. 5A). Purified recombinant hnRNP K protein and purified recombinant SRSF3 were incubated with the WT labelled probe with the amounts of protein indicated on the figure. A representative of two RNA EMSAs both with identical results is shown. The band corresponding to the protein:RNA complexes are indicated with arrows. The asterisk represents a band of unknown origin that disappears upon supershift with hnRNP K antibody. 


\section{Figure 1}

A
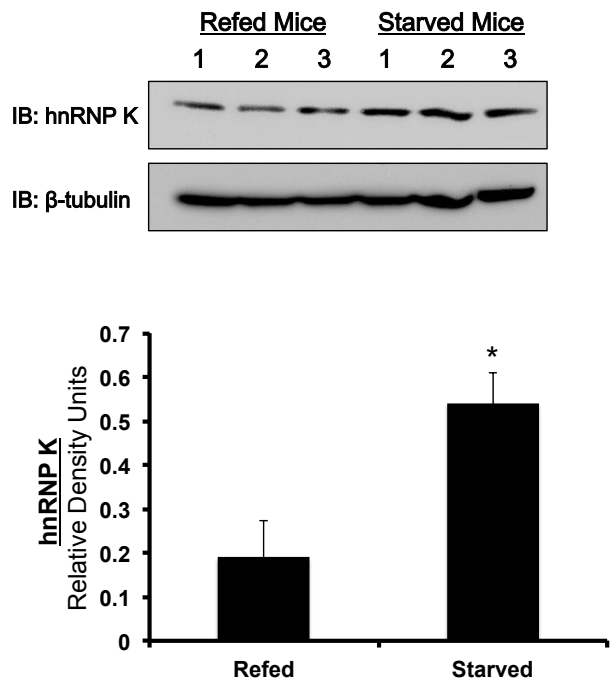

B

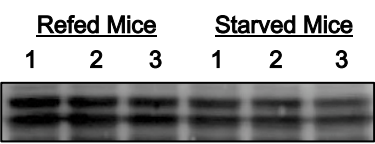

IB: hnRNP L

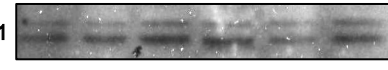

IB: hnRNP A2/B1

IB: $\beta$-tubulin
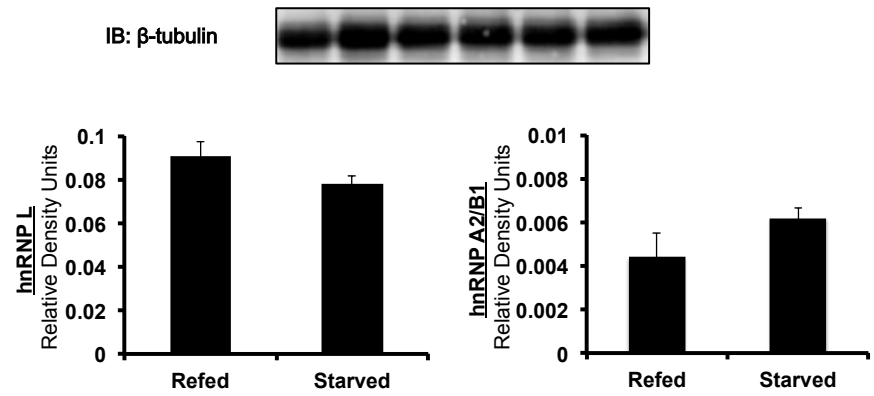

C $S R \quad S R S R \quad S R S R$ IB: hnRNP A2/B1 ?

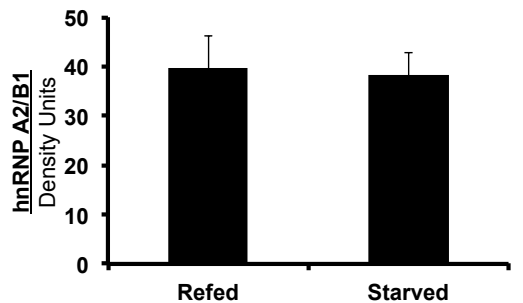


Figure 2
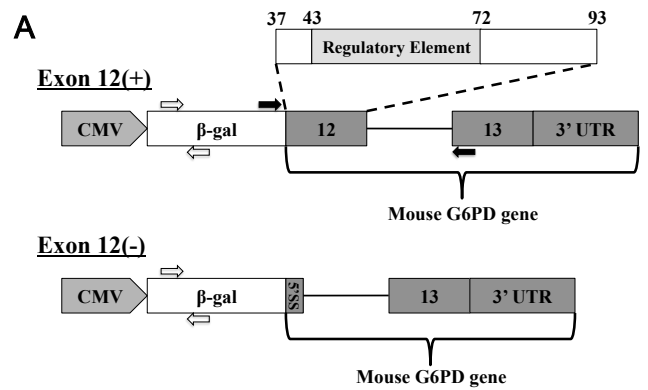

B

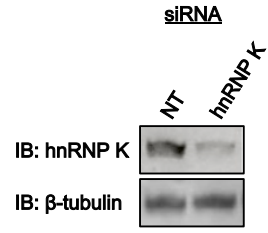

C

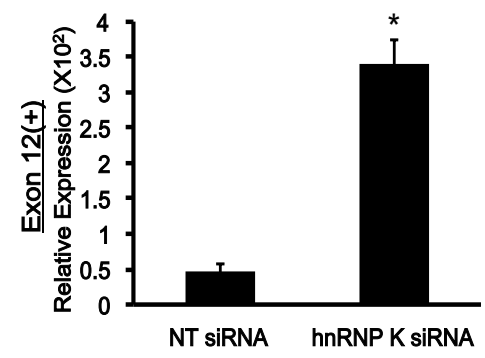

E

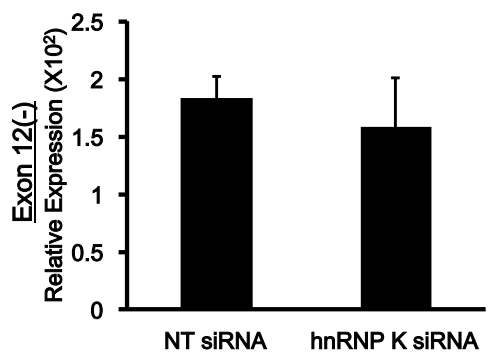

G

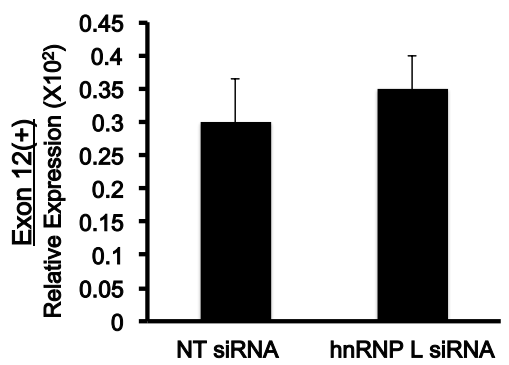

D

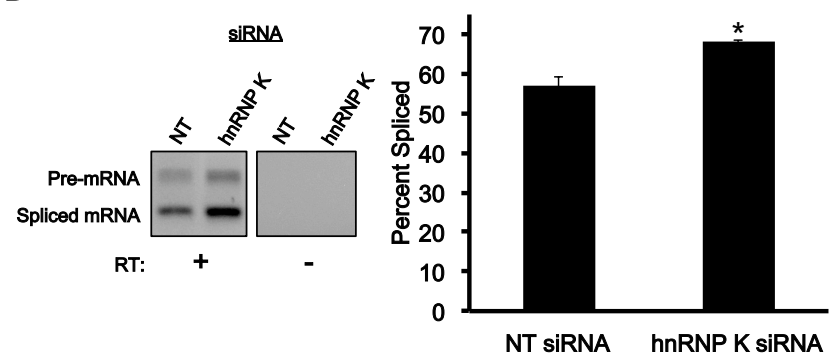

F

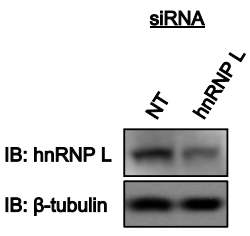

$\mathrm{H}$

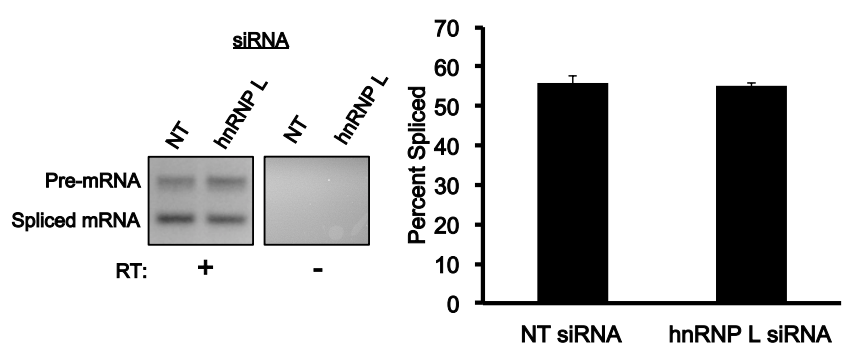

Figure 2 
Figure 3

A

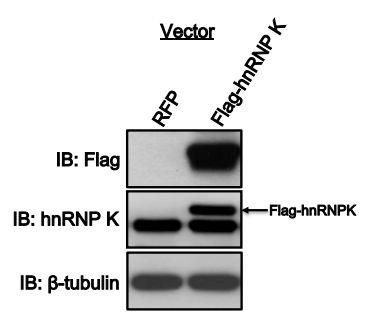

B

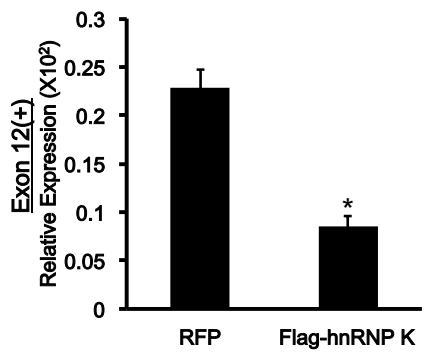

C

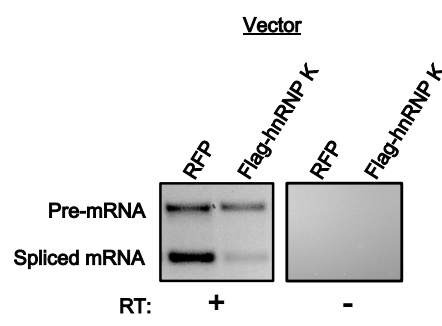

E

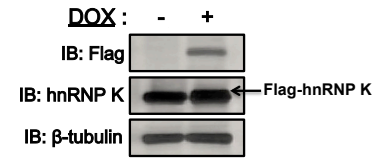

G

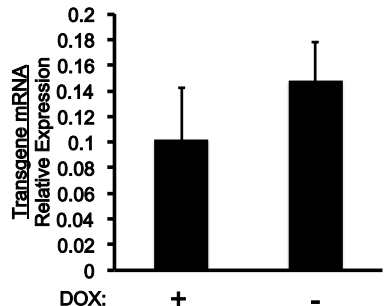

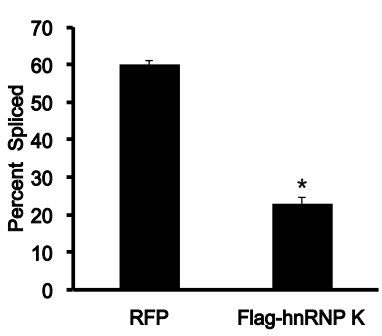

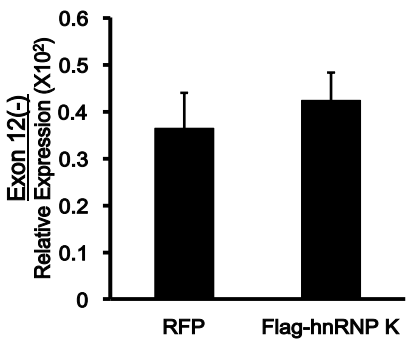

F
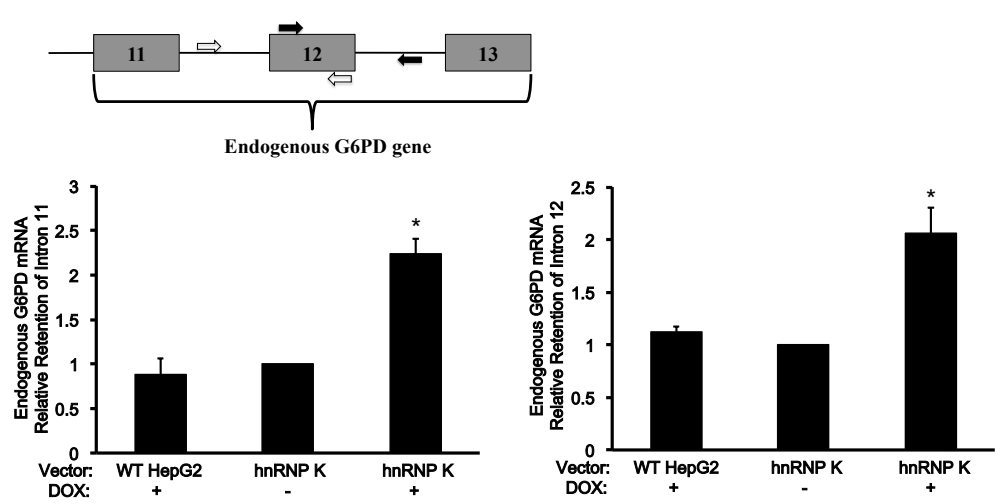


\section{Figure 4}

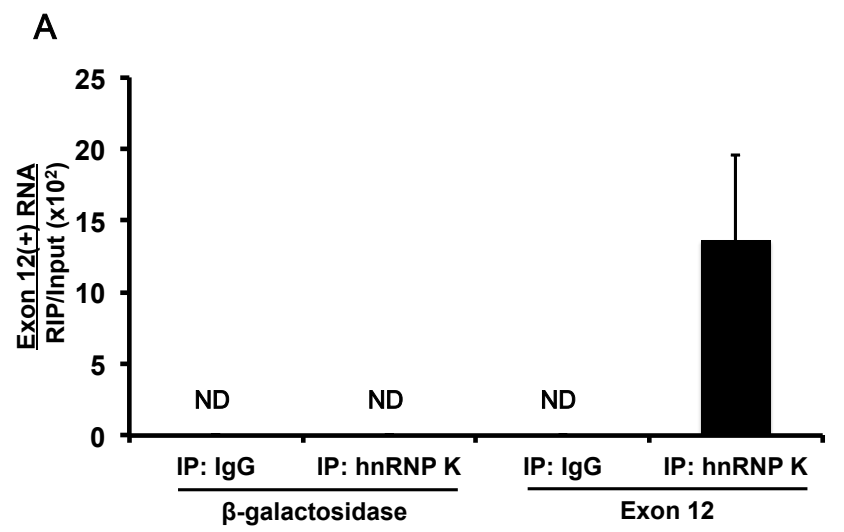

C

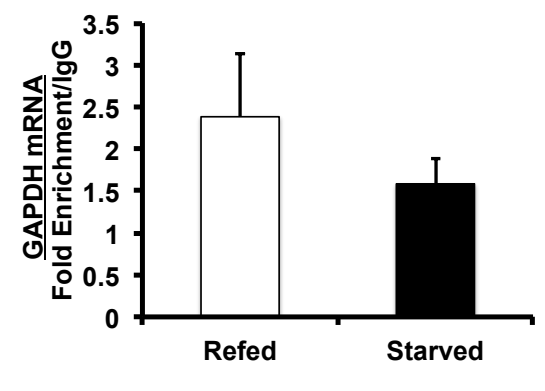

B

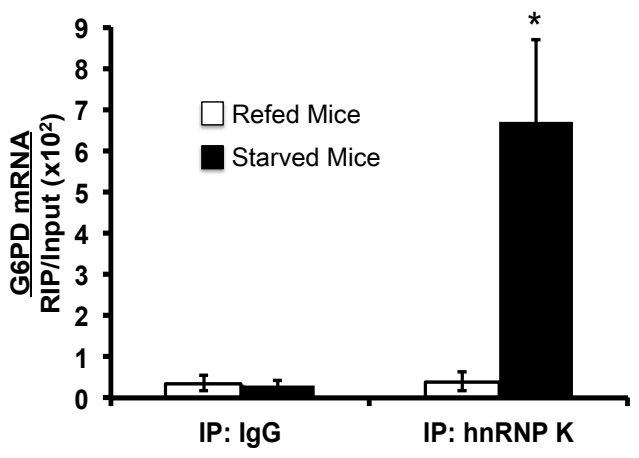

D

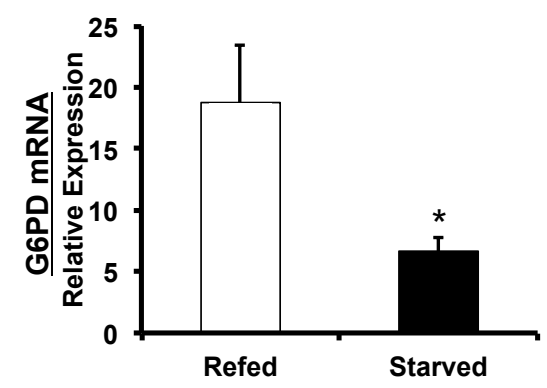




\section{Figure 5}

A

HEX

5'-AUUGAUCGAGAAAAGCCCCAGCCCAUCCCCUAUG-3'

5'-AUUGAUCGAGAAAG CUUCAGUUCAUCUUC AAUG-3'

5'-AUUgaUCGAGAaAaGUUUAG CCCAUCCCC IAUG-3'

5'-AUUgAUCGAGAAAAG CCCCAGUUUAYCCCC AUG-3'

5'-AUUGAUCGAGAAAAGUUUUAGUUAUCCCCUAUG-3'

B

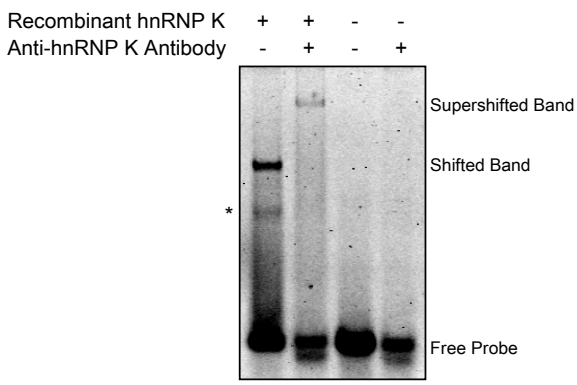

C

Recombinant hnRNP K +++++++++++ WT Specific Competitor -

Triple Mutant Competitor

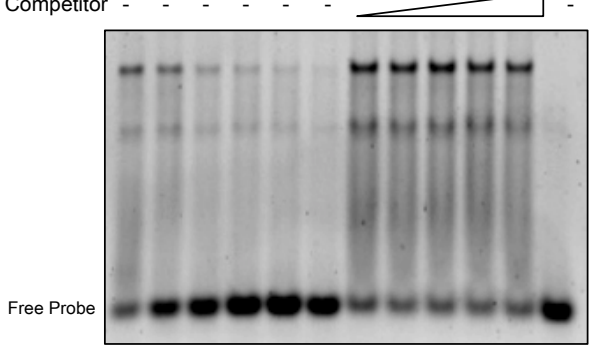

D
WT Labeled Probe

WT Specific Competitor

Triple Mutant Competitor

NT 65-68 Mutant Competitor

NT 71-73 Mutant Competitor

Double Mutant Competitor

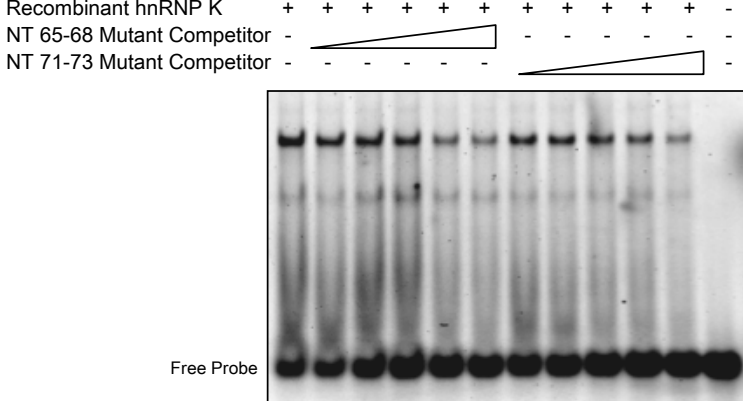

E

Recombinant hnRNPK ++++++ Double Mutant Competitor

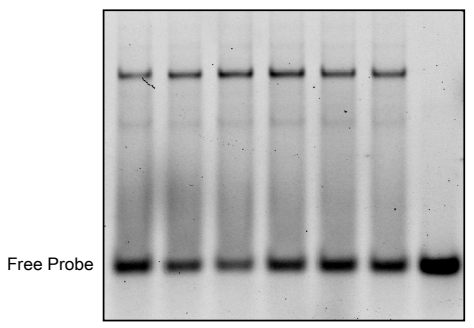


Figure 6

Recombinant hnRNP K (ng) $92 \quad 92 \quad 0 \quad 25 \quad 92$

Recombinant SRSF3 (ng) $\quad 0 \quad 500250250250$

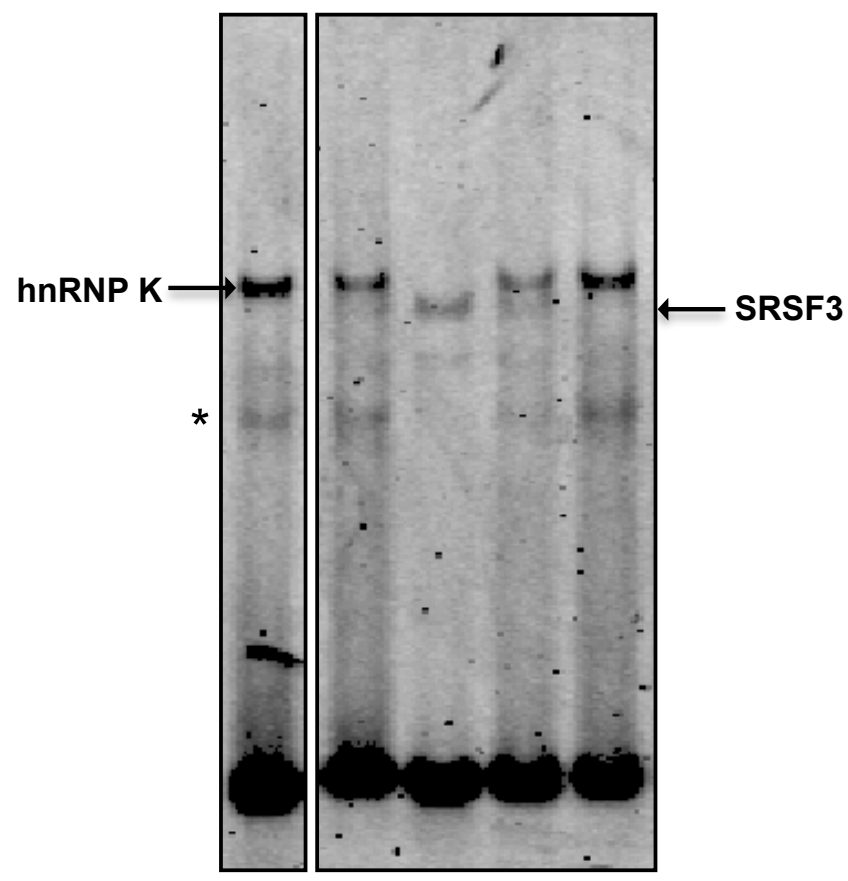




\section{Appendix}

\section{Appendix Experiment \#1}

The purpose of the experiment was to determine if the serine and/or tyrosine phosphorylation of hnRNP K changes due to nutrient signals.

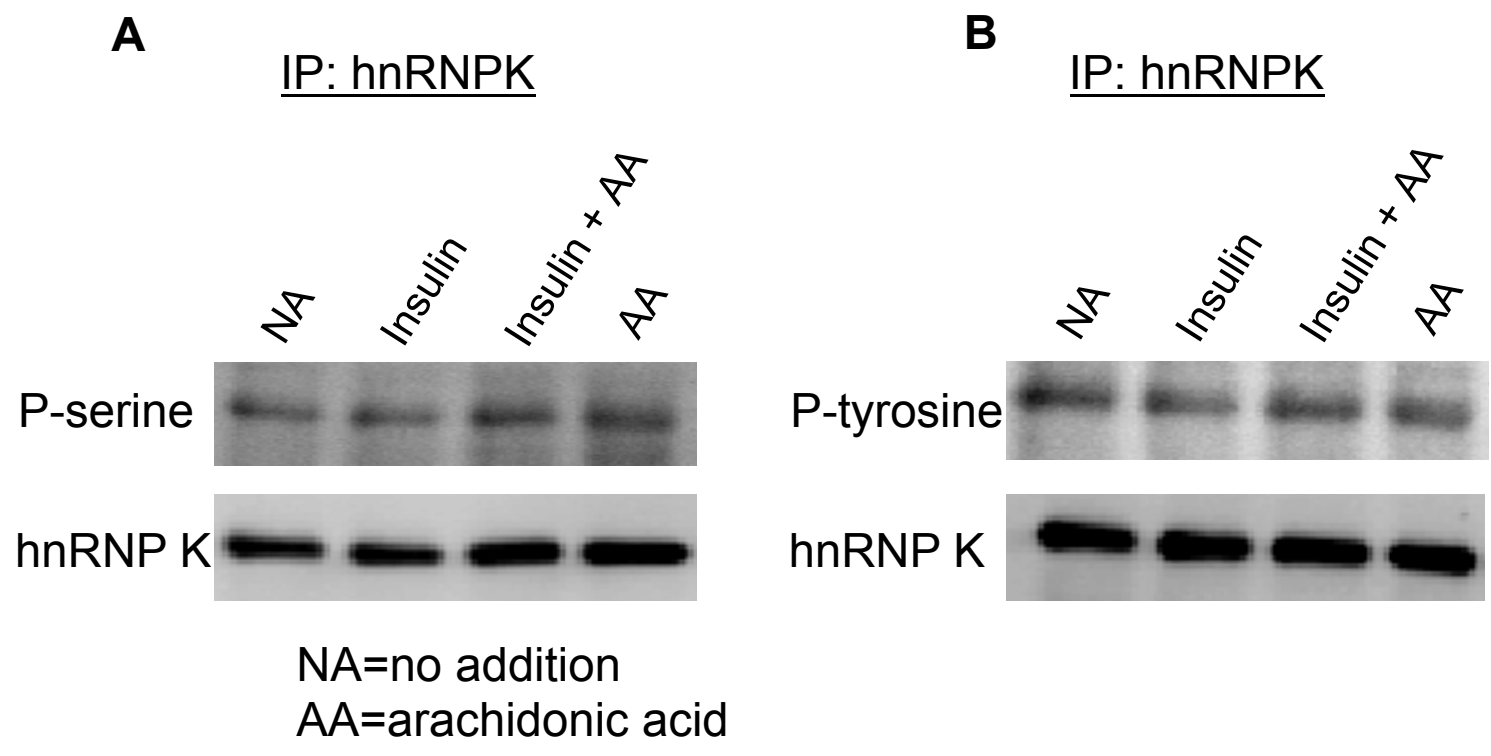

Figure 1. Phosphorylation of hnRNP K is not altered by nutrient signals after 2 hours of treatment. Primary rat hepatocytes were treated with insulin, insulin plus arachidonic acid, or arachidonic acid alone. The rat hepatocytes were pre-treated with arachidonic for 2 hours before the addition of insulin. After pre-treatment with arachidonic acid, the rat hepatocytes were treated for 2 hours with insulin. Whole cell lysates were made from the cell and hnRNP K was immunoprecipitated. Following the IP of hnRNP K, the protein that was pulled down was detected by western blotting for phospho-serine, phospho-tyrosine, and hnRNP K. (A) A western blot after the immunoprecipitation of hnRNP K is shown that was blotted for 
phosphorylation of serine residues within hnRNP K. (B) A western blot after the immunoprecipitation of hnRNP K is shown that was blotted for phosphorylation of tyrosine residues within hnRNP K. The treatments did not alter the phosphorylation of hnRNP K. This data represents one time point and does not completely rule out that these nutrient signals do not alter the phosphorylation of hnRNP K.

\section{Appendix Experiment \#2}

The purpose of the experiment was to test the effects of hnRNP M depletion of the Exon 12(+) reporter. HnRNP M binding to the regulatory element within exon12 of G6PD mRNA has not bee detected and hnRNP M depletion was a control to show that not every hnRNP would cause the splicing inhibition of G6PD mRNA.

siRNA

A

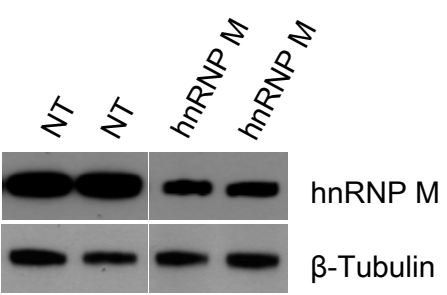

B

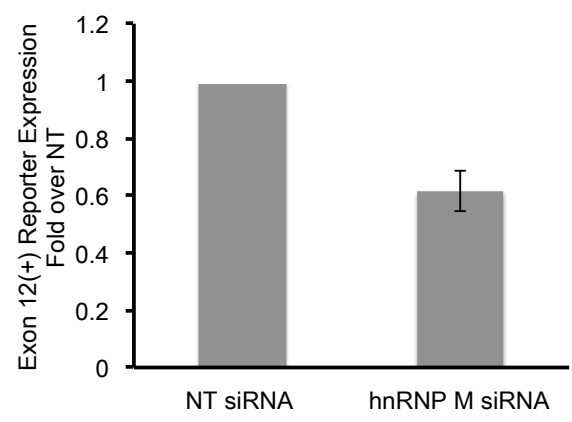

siRNA

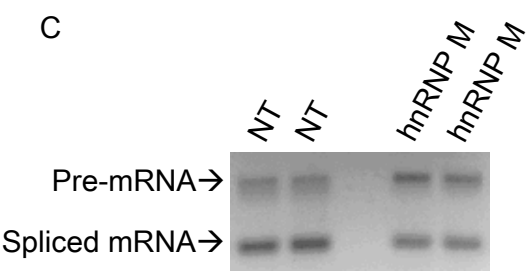

D

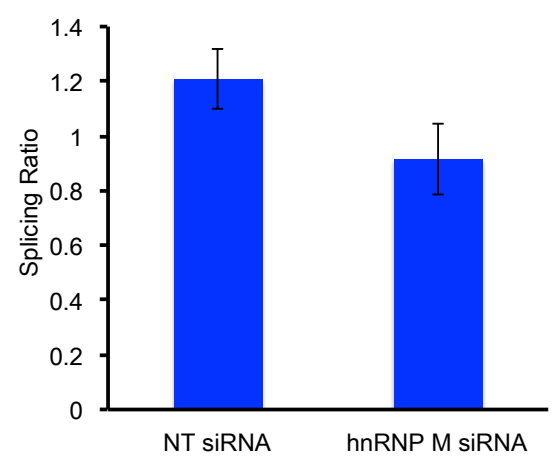


Figure 2. Depletion of hnRNP M by siRNA causes a slight but not significant decrease in the splicing of G6PD mRNA. HepG2 cells stably expressing Exon 12(+)were transfected with 75nM siRNA against hnRNP M or a non-targeting (NT) control. After 48 hours, RNA and protein were isolated. (A) A representative immunoblot of hnRNP M depletion in HepG2 cells is shown. (B) Expression of mRNA produced by the Exon $12(+)$ reporter in HepG2 cells that were transfected with the indicated siRNA was measured with the primers to the $\beta$-galactosidase sequence. The data are normalized to the amount of GAPDH mRNA. The data is expressed as fold change to the NT control. The data are the mean \pm SE of $n=5$ independent siRNA knockdowns. (C) Following knockdowns with the indicated siRNA, splicing of the reporter RNA was measured. The products of a representative RT-PCR are shown. (D) Quantification of changes in the splicing ratio is calculated as the intensity of the spliced band over intensity of the band of unspliced RNA. The data represent the mean $\pm \mathrm{SE}$ of $\mathrm{n}=5$ independent siRNA transfections.

The knockdown of hnRNP M has a trend toward the inhibition of splicing of the reporter mRNA and mRNA expression. The knockdown of hnRNP M has the opposite effect on reporter expression and splicing when compared to hnRNP K. It is possible that the effects of hnRNP M knockdown are indirect as the binding of hnRNP M to the regulatory element has not been detected. 